\title{
A STUDY OF THE AL-ZAWEA OIL REFINERY POWER SYSTEM IN LIBYA
}

\author{
By \\ AKRAM TAHER IBRAHIM GAWEDAR \\ Bachelor of Engineering in Electrical and Electronic \\ Engineering \\ University of $7^{\text {th }}$ of April \\ Al-Zawea, Libya \\ 2004 \\ Master of Science in Control Engineering \\ Coventry University \\ Coventry, United Kingdom \\ 2007
Submitted to the Faculty of the
Graduate College of the
Oklahoma State University
in partial fulfillment of
the requirements for
the Degree of
DOCTOR OF PHILOSOPHY
December, 2016




\section{A STUDY OF THE AL-ZAWEA OIL REFINERY}

\section{POWER SYSTEM IN LIBYA}

Dissertation Approved:

Dr. R. Ramakumar

Dissertation Adviser

Dr. Qi Cheng

Dr. Nishantha Ekneligoda

Dr. Sundar V. Madihally 


\section{ACKNOWLEDGEMENTS}

First and foremost, I would like to express my sincere gratitude and profound respect to my advisor Dr. R. Ramakumar for his constructive comments, guidance and continuous intellectual support, invaluable advice and constant encouragement of my endeavors throughout my study. He was very generous with his time and knowledge, and assisted me enthusiastically in each step to complete the thesis. I am also grateful to him for his important advice on my future career.

I am profoundly indebted to my academic committee members Dr. Qi Cheng, Dr. Nishantha Ekneligoda and Dr. Sundar V. Madihally for their help, suggestions and enlightening discussions towards my research.

I would like to acknowledge the financial support of the Government of my home country Libya and the Engineering Energy Laboratory and the PSO/Albrecht Naeter Professorship in the School of Electrical and Computer Engineering, Oklahoma State University.

I would also like to extend thanks to all my colleagues, lab mates and the Engineering Energy Lab coordinator Mrs. Nancy with all love and gratitude.

Last but not least, special thanks go to my whole family, especially my beloved parents, wife and children, who have been an important and indispensable source of motivation and inspiration. I love my family. This thesis is dedicated to them and to my home country Libya. 
Name: AKRAM TAHER IBRAHIM GAWEDAR

Date of Degree: DECEMBER, 2016

\section{Title of Study: A STUDY OF THE AL-ZAWEA OIL REFINERY POWER SYSTEM IN LIBYA}

\section{Major Field: ELECTRICAL ENGINEERING}

Abstract: Libya is an oil exporting country located in the middle of the North Africa. Exporting oil is the major income resource for the economics of the country. Al-Zawea refinery is one of the oil refineries in Libya. It is the largest refinery in the region. The refinery is located on the Mediterranean coast. Electricity is the main enabler in the refinery to produce and export oil. The refinery experienced power fluctuations in the last few years due to its own power plant instability and frequency variants. This research discusses the aspects of upgrading the existing power system of the refinery by converting it from a traditional system to a smart system (Smart Grid) to overcome the technical power problem. Smart grid technology is very much in the forefront in the energy and power industry. Billions of dollars have been invested so far for smart grid implementation. The effective utilization of smart grid technology to achieve bi-directional power flow, integration of renewable energy sources, and improving the quality and reliability of power supply require suitable communication systems and sensors. Intelligent system requires sensing and switching technology to communicate with the electric grid. Integrating renewable energy resources to the system is a main feature of Smart Grid implementation. A portion of the power supply of the system will be derived from Wind Energy to feed the electricity into the refinery electric grid and ensure sufficient power for operation. Although, renewable energy application in Libya was started in the middle of the seventies, it has still not found its way into industry sector. This study employs earthier a wind speed analysis in the site (AL-Zawea City) using Raleigh pdf to model the wind speed which is the initial step to integrate wind with the existing grid. System with 25 buses has been used for simulation studies and implementation suggestions. Possible impacts of renewable (wind) energy system integration and its performance with the Al-Zawea refinery electric grid will be studied by load flow analysis using Newton Raphson method and Matlab software with PowerWorld. 


\section{TABLE OF CONTENTS}

Chapter $\quad$ Page

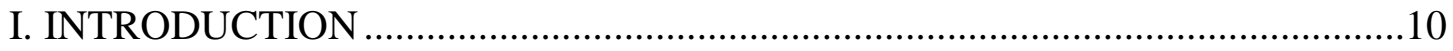

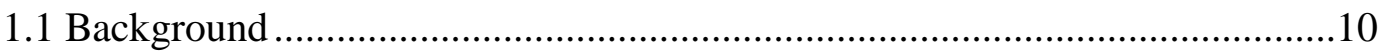

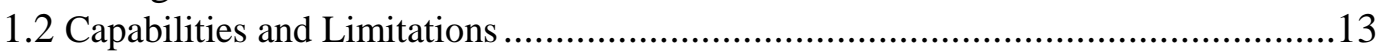

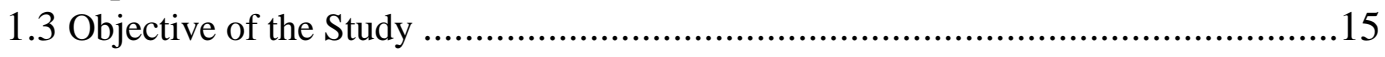

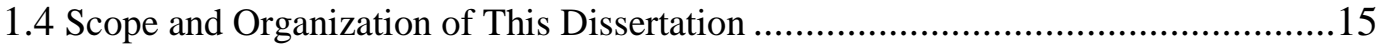

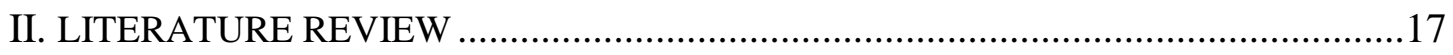

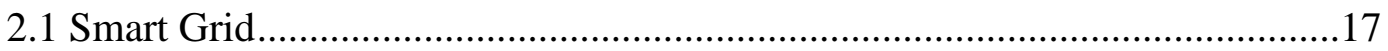

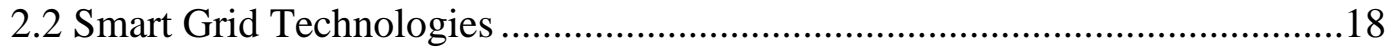

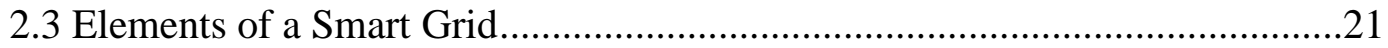

2.3.1 Energy Storage ........................................................................21

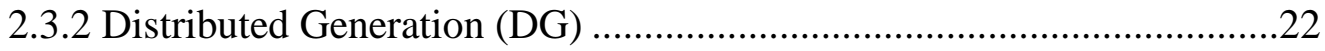

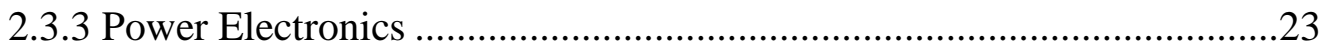

2.3.4 Communication System ............................................................23

2.3.5 Smart Sensors and Advanced Metering Infrastructure ..........................24

2.4 Challenges of the Smart Grid....................................................................24

2.5 Prospects of Smart Grid and its Applications ............................................25

2.5.1 Optimization of Active and Reactive Power Flow in the Smart Grid ....25

2.5.2 Self-healing and Fault Detection ........................................................25

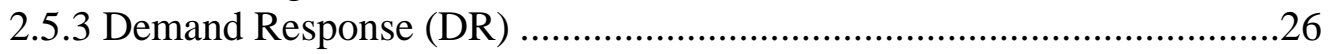



2.5.5 Power System Stability .............................................................26

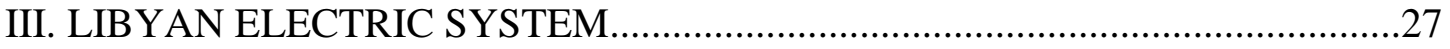

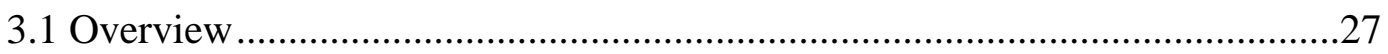

3.2 Renewable Energy Resources in Libya ...................................................29

IV. EXISITNG POWER SYSTEM AT THE AL-ZAWEA OIL REFINERY ............30



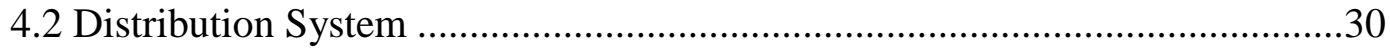

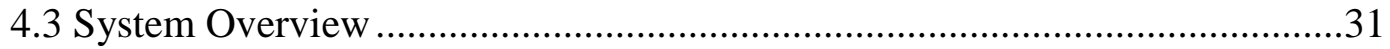

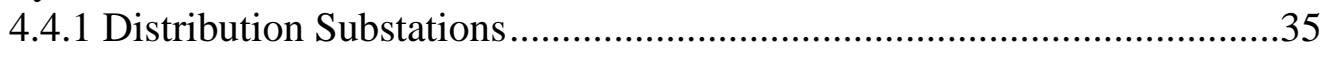

4.4.2 The Feeders of the Distribution System .............................................36 


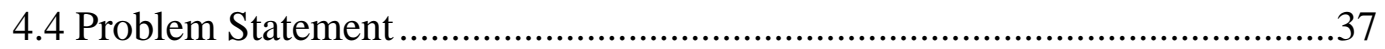

4.4.1 Gas Turbine Control System investigation .........................................37

4.4.2 Frequency Data and Power Factor Analysis .......................................37

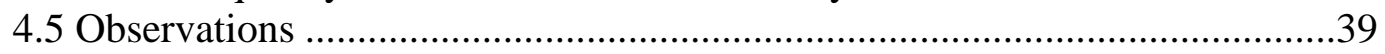

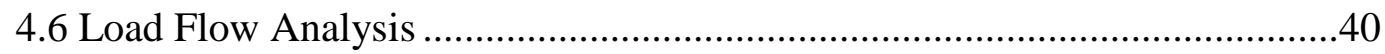

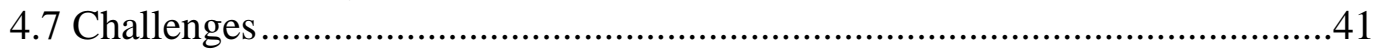

V. PROPOSED MODIFICATIONS FOR THE EXISTING REFINERY SYSTEM .42

5.1 Distributed Generations (DG) Overview .................................................42

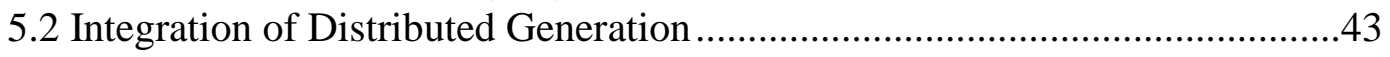

5.3 Wind Energy System as Distributed Generation .........................................44

5.3.1 Wind Energy Conversion System ..................................................46

5.3.2 Power Performance Curve of Wind Turbine ......................................48

5.4 Integration Wind Power Based DG into the Refinery .................................49

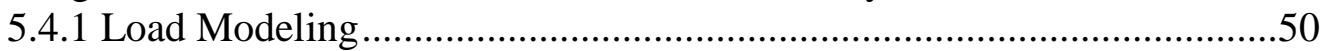

5.4.2 The Optimal Sizing of the Proposed (DG) ..........................................51

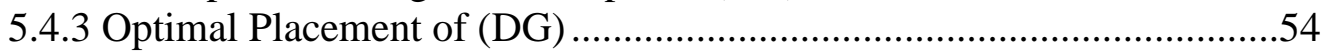

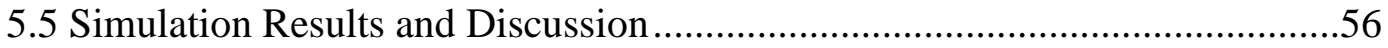

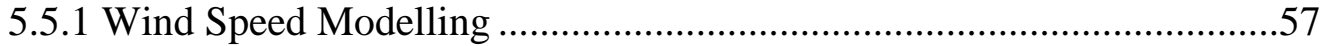

5.5.2 Optimal Placement of (DG) ......................................................60

5.5.3 The Steady State System Performance after DG Installation ................61

VI. CONCLUDING REMARKS AND FUTURE WORK ...................................68

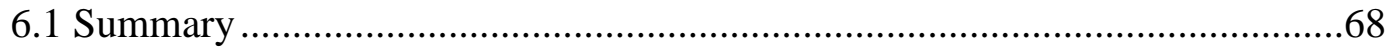

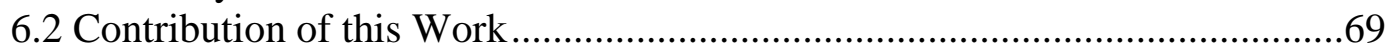

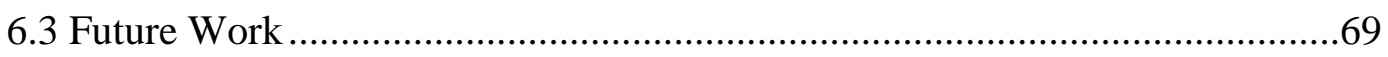

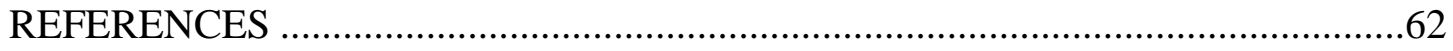

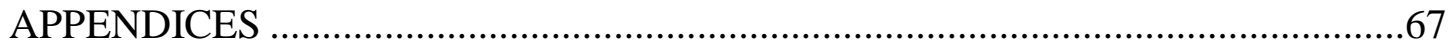




\section{LIST OF TABLES}

Table Page

TABLE 2.1 Comparison of traditional grid and smart grid....................................20

TABLE 4.1 The different variables associated to the types of the buses in the power flow analysis ........................................................................35

TABLE 4.2 Load data of critical loads of the current refinery distribution system ..40

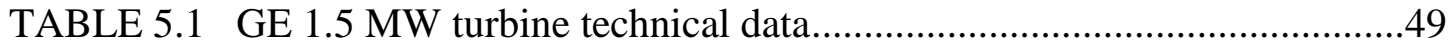

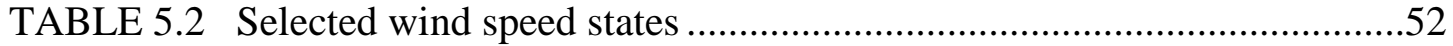

TABLE 5.3 Load Uncertainty Model ..................................................................5

TABLE 5.4 Wind speed and power probabilities for each state..............................59

TABLE 5.5 The voltage index values when DGs are installed at load buses ...........60 


\section{LIST OF FIGURES}

$\begin{array}{ll}\text { Figure } & \text { Page }\end{array}$



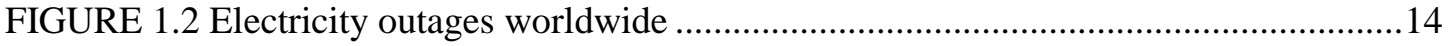

FIGURE 2.1 Smart Grid concept (Source: EPRI) …………………………………………...18

FIGURE 2.2 Rated power for some grid energy storage technologies....................................21

FIGURE 3.1 Locations of the electrical power plants (Source GECOL) …………………......28

FIGURE 4.1 One-Line diagram of the Al-Zawea refinery power system .................................31

FIGURE 4.2 Percentages of power supply …………………………………………........32

FIGURE 4.3 Single Line Diagram of the Distribution system in the Refinery

Power System...........................................................................................33

FIGURE 4.4 A segment of the current distribution system layout at Al-Zawea Refinery .......34

FIGURE 4.5 Types of the distribution system.................................................................36

FIGURE 4.6 The concept of the power stability based on frequency and load changing .......38

FIGURE 4.7 Frequency variation in normal operation..........................................................38

FIGURE 4.8 Frequency fluctuations plot ...........................................................................

FIGURE 5.1 One-line diagram of the Al-Zawea refinery power system with proposed

wind power system …………………………………………………….....4

FIGURE 5.2 Simple horizontal axis and vertical axis wind turbines .......................................46

FIGURE 5.3 Power curve of GE 1.5 MW wind turbine....................................................48

FIGURE 5.4 Flowchart for the proposed methodology .......................................................55

FIGURE 5.5 A segment of Al-Zawea refinery distribution system .................................56

FIGURE 5.6 Wind speed and its Weibull pdf with shape parameters $\beta=1,2$ and $3 \ldots \ldots \ldots \ldots . . .58$

FIGURE 5.7 Variation of voltage index when DG is installed at load buses ......................... 61

FIGURE 5.8 Modified Systems with DG …………………………………………….......61

FIGURE 5.9 p.u voltage at all busses with DG integrated in the system ...............................62

FIGURE 5.10 p.u voltage at all busses when DG is on and DG is off .................................64

FIGURE 5.11 p.u voltage at all busses when DG is on and DG is off ..................................64

FIGURE 5.12 p.u voltage at all busses when DG is on and DG is off ..................................65

FIGURE 5.13 p.u voltage at all busses when DG is on and DG is off ..................................65

FIGURE 5.14 p.u voltage at all busses when DG is on and DG is off ................................66

FIGURE 5.15 p.u voltage at all busses when DG is on and DG is off ..................................66

FIGURE 5.16 p.u voltage at all busses when DG is on and DG is off ................................67

FIGURE 5.17 p.u voltage at all busses when DG is on and DG is off ................................67

FIGURE 5.18 p.u voltage at all busses when DG is on and DG is off ................................68

FIGURE 5.19 p.u voltage at all busses when DG is on and DG is off .................................68 


\section{CHAPTER I}

\section{INTRODUCTION}

\subsection{Background}

It is well-known that Thomas Edison and Alexander Graham Bell were the key architects of the electric power and communication systems. Electric power is one of the most important technologies in the twentieth century. The electric utility was born 1882 when the first electric power station, Pearl Street Electric Station in New York City, went into operation. The electric utility industry grew very rapidly and generation stations, transmission and distribution networks have spread across the entire country [1]. Around the beginning of the 20th century, there were over 4,000 individual electric utilities in the US, each operating in isolation. Almost all of those used low-voltage connections from nearby generating power plants to the distribution lines serving their local customers. As the demand for electricity grew, particularly in the post-World War II era, electric utilities found it more efficient to interconnect their transmission systems. In this way, they could share the benefits of building larger and, often, jointlyowned generators to serve their combined electricity demand at the lowest possible cost, and to avoid building duplicate power plants. Interconnection also reduced the amount of extra capacity that each utility had to hold to assure reliable service. Recently or in fact in the last decade the digital revolution has increased the demand for higher quality of power and energy. There are more than 9,200 electric generating units with more than $1,000,000$ megawatts of generating capacity connected to more than 300,000 miles of transmission lines over the world [2]. The electric power grid of today has developed over a long time and many of its components have been operating beyond their 
useful life. Most of the transmission lines are 25 years old or older, $70 \%$ of the power transformer are more than 25 years old and $30 \%$ of the circuit breakers are more than 30 years old [3]. The pressure on energy resources and the environment has been increasing because of the exponential growth in global economy, population and energy demand. Today transmission and distribution lines are owned by individual utilities. Electrical systems have been expanded and interlinked. The systems now provide for the transport of electricity on the transmission lines where buyers and sellers may be geographically spread apart. For instance, while the growth in demand for primary energy in East Asia is around 5\% per year that for electricity is $7-8 \%$ per year. In China, power generation requirements are expected to almost double in 15 years, with much of this being met by nuclear. China intends a fivefold increase in nuclear power capacity by 2020 (from 2005 level) [3]. The world electricity consumption and its growth can be seen in Figure 1.1.

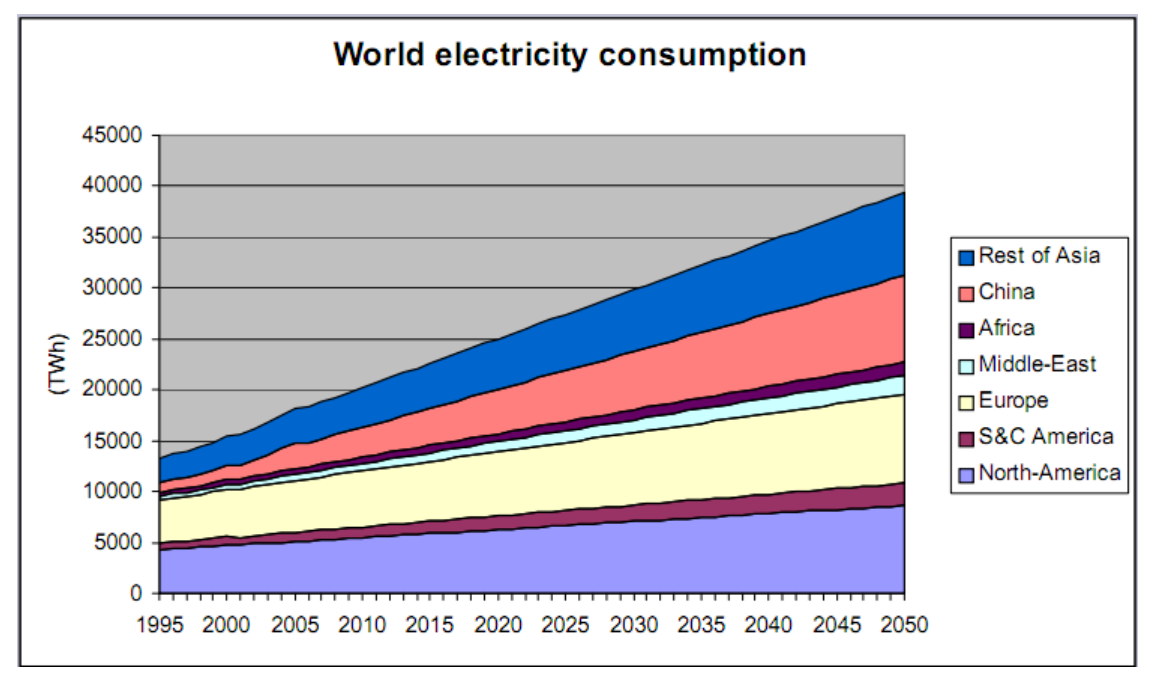

Figure1.1: World electricity consumption [4]

As seen in Figure 1.1, world electricity consumption is expected to double by 2050; plenty of GW of new power stations are needed to be in operation to fulfill the power demand. Based on environmental and climate change considerations, energy recourses for use in the future must include increasing fraction of clean energy components to reduce the emission of $\mathrm{CO}_{2}$ and other green house gases. Renewable 
energy utilization is on the rise and is being integrated into existing global electric grid. Research in solar-thermal systems, Wind Electric Conversion Systems, fuel cells, hydrogen storage, etc, has brought new challenges to the electric power industry in the last few decades. The current grid has been designed to serve linear loads supplied with sinusoidal voltages drawing sinusoidal currents. But, with the entry of power electronic devices, there has been a surge in the usage of technologies that employ these on a very large scale ranging from personal computers and various other digital devices to large variablespeed drives. This has made life simpler, efficient and more convenient in today's world. However, the disadvantage of this is that these devices are very sensitive to variations of the voltages and frequencies. By integrating these devices with the current grid along with introduction of information and communication technologies (ICT) the traditional grid can be upgraded to a smart grid.

The development of the Smart Grid is expected to provide a means to handle two-way power flows and the problem associated with intermittency of renewable energy sources. Also, shaving of the peak demand by even a small amount can save millions of dollars with the reduction in the number of required standby power plants which is very likely in a smart grid scenario [5]. All of these have created an exciting set of unprecedented challenges and opportunities to the current energy/power industry. They will have to deploy and utilize better ways for real-time monitoring and control of their existing facilities as well as ways for the consumers to do the same by expanded monitoring and control throughout their distribution grids all the way to the consumers' side of the meter. The use of advanced electronics, telecommunications, Internet, wireless sensor networks and information systems is imperative to achieve higher efficiency, improved power quality, and enhanced reliability, lower costs, safety and security [6]. Smart Grid consists of advanced sensors, actuators, communication infrastructure, Information Technology (IT) systems, advanced monitoring, control and decision making applications. Many objectives for deploying Smart Grid technologies are enumerated below:

- To improve system reliability and efficiency

- To reduce cost and maintenance time 
- To integrate renewable energy sources

- To monitor the system and locate faults

- To enhance security and safety in system operation

- To maintain and improve the quality of power delivery to meet the needs of digital loads.

Smart Grid relies on many advanced applications to deliver benefits to the customer, grid operators, and other societal stakeholders [7]. Smart grids have become high priority in the industry agenda in many countries around the world. Many definitions of smart grid exist, but still there is no universal concept agreed. According to the US department of energy smart grid is defined as " A smart grid uses digital technology to improve reliability, security, and efficiency (both economic and energy) of the electric system from large generation, through the delivery system to electricity consumers and growing number of distributed- generation and storage resources" [2]. On the other hand, the European Technology Platform defines the smart grid as "an electricity network that can intelligently integrate the action of all users connected to it- generators, consumers and those that do both in order to efficiently deliver sustainable, economic and secure electricity supplies" [8].

\subsection{Capabilities and Limitation}

In the near future, electricity demand is expected to continue to grow, as new technologies are introduced into the existing network. Electric power is expected to be the fastest growing source of energy supply throughout the world. As already mentioned, the existing power system is over the world old by now.

Several cascading failures during the past 40 years are spotlighted and illustrated in Figure 1.2. Need to understand the complex phenomena associated with power network systems and the development of emergency control restoration Figure 1.2. 


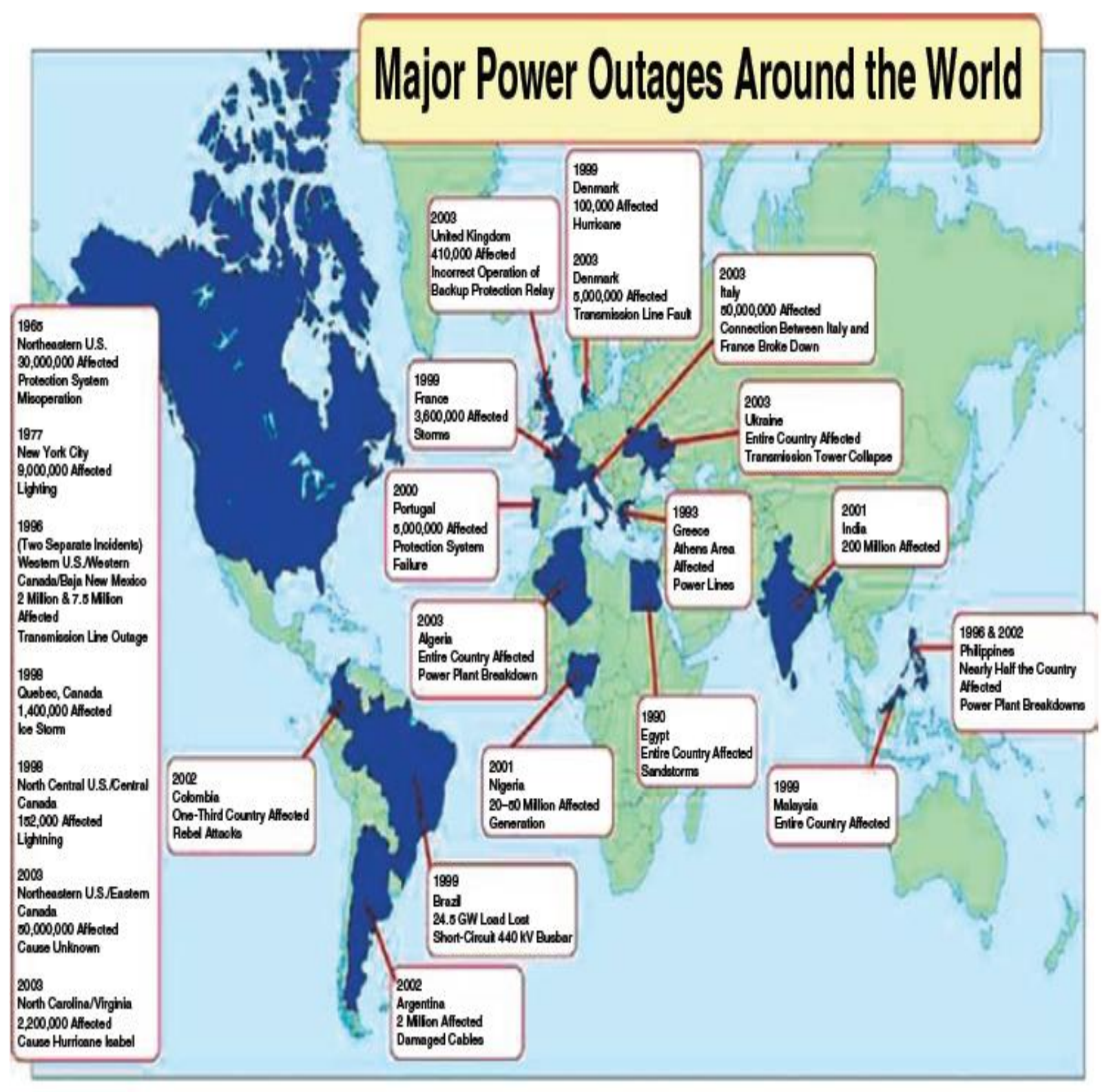

Figure 1.2: Electric outages worldwide. Source: EPRI PEAC Corporation

Overloading a line and mechanical failures can create power problems such as power fluctuations. To overcome the system instability, the frequency and phase of all power generation units must remain synchronous within narrow limits [9]. New technologies such as PMUs are being introduced to monitor these conditions. 


\subsection{Objective of the Study}

The concept of smart grid represents the merging of multiple technologies into a system that provides reliable and cost-effective energy. Smart grid enables operators to manage and monitor millions of devices and sensors. It has extensive communications capabilities that enable smart metering, as well as transformer monitoring and other data gathering devices. This dissertation discusses the main technology of Smart Grid implementation and distributed generation that can be used to improve the reliability of the existing power supply to Al-Zawea refinery's critical loads to improve its operation. Al-Zawea refinery electric network experienced some active power fluctuations when it is connected to the national grid. Fluctuations cause disturbances in the electrical network during the operation hours. In order to mitigate the fluctuations, smart grid technologies have been proposed to improve the performance of the existing power system. This study could be expanded to include economic aspects as well. The smart grid is a reinvention of how energy is transmitted, distributed, and measured. It is becoming the new standard for utilities and consumers.

\subsection{Scope and Organization of this Dissertation}

This dissertation is structured with the intention of guiding the reader systematically to the work performed in a form with good readability and overview.

\section{Chapter II: Literature Review}

This chapter presents a synopsis of smart grid, smart grid technologies with their advantages, the difference between traditional grid and smart grid, briefly explanation of smart grid applications and its technical challenges.

\section{Chapter III: Existing Power System in Libya}

This chapter briefly summarizes the historical evolution of the current power system in Libya. 


\section{Chapter IV: Existing Power System at Al-Zawea Oil Refinery}

This chapter summarizes the existing distribution system at Al-Zawea Refinery, operation scenarios, generation resources with load flow analysis and investigation of its power problem.

\section{Chapter V: Proposed Modifications for the Existing Al-Zawea Refinery Power System}

This chapter presents the simulation results of the proposed modified system for the Al-Zawea Refinery and with discussion of results. Distributed generation DGs options and their types with their capability and availability in Libya are discussed, system modelling and load flow analysis with and without distributed generation DGs using Matlab and PowerWorld software were employed. Different scenarios are studied using simulation results.

\section{Chapter VI: Concluding Remarks and Future Work}

This chapter summarizes the entire study and discusses scope for further work. 


\section{CHAPTER II}

\section{LITERATURE REVIEW}

\subsection{Smart Grid}

There has been no change in the basic structure of the electrical power grid for about 100 years. The components of the current electrical grids are operating beyond their useful life. The demand for electricity with higher quality has rapidly increased. According to the U.S Department of Energy report, the demand and consumption of electricity in the U.S have increased by $2.5 \%$ annually over the last 20 years [9]. These days' electric grid became very complex and ill-suited to the needs of the $21^{\text {st }}$ Century. Among the weaknesses of the current electric grid are lack of situational awareness and automated analysis [10]. These have led to electrical outages over past 40 years. Rapid increase in the population and electricity consumption has directed electrical engineers to the way electricity is generated, and the evolution of new technologies (information technology and power electronics) is beginning to impact power generation, transmission and utilization. Consequently, a new grid infrastructure is urgently needed to address those challenges.

A new concept next generation electric power system has emerged called Smart Grid, to realize those capabilities. Smart grids have become high priority in the industry agenda in many countries around the world. Many definitions of smart grid exist. According to the US department of energy, smart grid is defines as follows: " A smart grid uses digital technology to improve 
reliability, security, and efficiency (both economic and energy) of the electric system from large generation, through the delivery system to electricity consumers and growing number of distributed- generation and storage resources" [11]. On the other hand, the European Technology Platform defines the smart grid as "an electricity network that can intelligently integrate the action of all users connected to it- generators, consumers and those that do both in order to efficiently deliver sustainable, economic and secure electricity supplies" [12]. Smart grid refers to a two-way system that monitors and automatically optimizes the operation of the interconnected elements of a power system from generator through the high-voltage network and distribution system to the load [13].

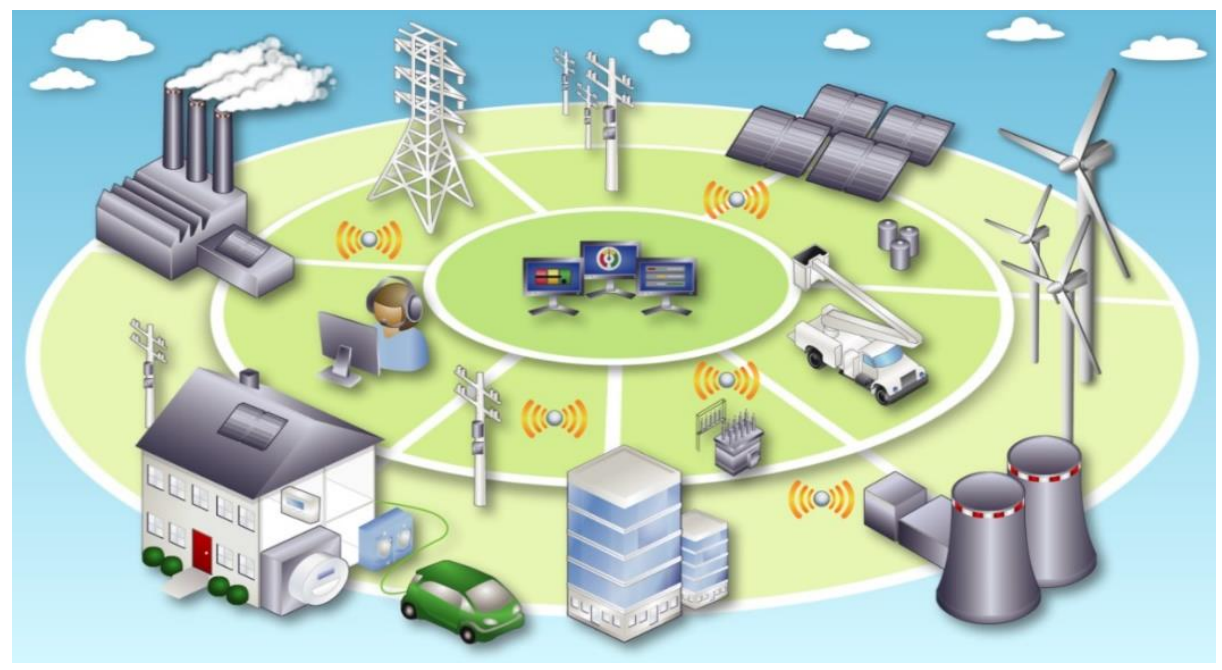

Figure 2.1: Smart Grid concept (Source: EPRI)

As illustrated in Figure 2.1, the smart grid can be defined as a system that employs digital information and control technologies to facilitate the deployment and integration of distributed and renewable resources, electricity storage, smart meters and automated system [14].

\subsection{Smart Grid Technologies}

Smart Grid adds new technologies to the current grid such as sensors, smart meters, communication system, control, monitoring and real time data analysis to increase the efficiency and maximize the 
reliability of the system with minimization of the electricity cost. By implementing smart grid technologies and deploying them along with distributed generation to the traditional power system the following potential benefits could be realized.

- Mitigate power fluctuations.

- Accommodate renewable energy resources.

- Self-healing.

- Increase reliability of operation.

- Reduce costs and improve efficiency.

- Minimize environmental impacts.

The smart grid enables operators to manage and monitor millions of devices and sensors. The smart grid has extensive communications infrastructure with capabilities to mitigate any power fluctuations that could cause system collapse [15]. Some of the alternate definitions of the smart grid are:

- Concourse of communication technology and information technology with electrical system.

- Smart grid is the integration of the electricity generation with users in intelligent way.

- Set of the new technologies, those allow distribution, transmission and generation to be replaced by smart system for services with exchange of system's data in real time.

- Smart grid is the system that allows renewable energy resources to be integrated to the traditional grid at any edge of the electrical network.

- Real time response between demand and power supply.

- Intelligent system that can detect and locate the failure of the electricity at the grid.

- Smart grid that may include distributed generation, battery storage system and demand management optimal operation [8]. 
Integration of new sensors at the distribution level with automation in the system will enhance and improve the data exchange in the system with higher quality to be processed.

Smart Grid refers to a two-way system that monitors and automatically optimizes the operation of the interconnected elements of the power system from the generator through the high-voltage network and distribution system, to the end use consumer and their thermostats, appliances and other household devices. Table 2.1 shows a comparison between the traditional or the current electric grid and the proposed smart grid.

\begin{tabular}{|c|c|}
\hline TRADITIONAL GRID & SMART GRID \\
\hline Electromechanical & Digital \\
\hline One way Communication & Two way Communication \\
\hline Failures and Blackouts & Adaptive and Islanding \\
\hline No energy Storage & Energy Storage \\
\hline Lack of real time monitoring & Extensive real time monitoring \\
\hline Slow Reaction time & Extremely quick reaction time \\
\hline Centralized Generation & Distributed Generation \\
\hline Manual Restoration & Self-healing \\
\hline Total control by Utility & Increased customer participation \\
\hline No renewable generation & Renewable included \\
\hline
\end{tabular}

Table 2.1: Comparison of traditional grid and smart grid

In the past, power quality denoted the ability of electric utilities to provide electric power without interruption. But now after the information technology revolution and other advanced power electronic equipment and digital devices with increasing density of sensitive equipment on the electric grid, there is increasing pressure on the regulators to lay strict rules regarding power quality issues [16]. Several technologies have to mature in order to realize smart grid. 


\subsection{Elements of a Smart Grid}

\subsubsection{Energy Storage}

With the increasing in electricity demand and integration of renewable energy, energy storage has become a major concern and main player to enhance the quality of power to the consumers. Energy storage devices enable the grid to achieve the following [17]:

- Possibility of renewable energy integration into the traditional power system.

- Compensate power demand when the distributed generation fails to supply required power to the loads.

- Organize and manage the amount of energy needed to be stored by the system during off peak time and supply it during peak time.

Energy can be stored in different forms such as kinetic, electromagnetic, thermal, potential, and electrochemical. There are many types of energy storage options such as flywheels (FES), pumped hydro (PHS), super conducting magnetic energy storage (SMES), hydrogen storage etc. [18-19]. Multiple existing technologies are compared in Figure 2.2. Load Acid batteries are still used due to their low cost. This technology can protect the electrical network from blackout condition and provide sufficient power to the system in the peak time and during emergencies.

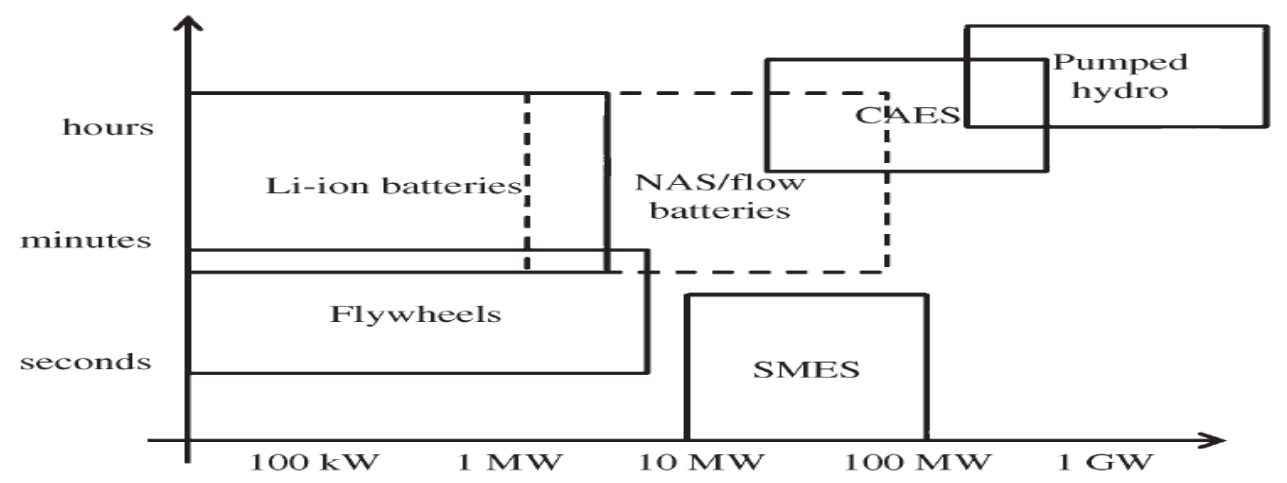

Figure 2.2: Rated power for some grid energy storage technologies [20]

Supplying energy storage in the grid provides the following advantages: 
1. Improve grid efficiency and reliability with higher power quality.

2. Offers ancillary services.

3. Reduce the frequency variation in the power interconnection areas with multiple power resources.

4. Improving load factor and increasing load diversity.

5. Regulates voltage profile of the power system by supplying reactive power.

\subsubsection{Distributed Generation (DG)}

Electrical utilities are seeking new technologies to improve power quality and system voltage. The revolution in power electronics and renewable energy generation is becoming attractive and beneficial for upgrading the conventional electrical grid with less environmental impact. DG refers to penetration of small rating electricity sources that are scattered throughout the electric grid to provide required power for the system loads. DG can be installed at or close to the load, DG ratings range from $5 \mathrm{~kW}$ up to $100 \mathrm{MW}$. These distributed generations could be conventional generators or renewable energy sources. Multiple benefits can be obtained by integrating distributed generations to the existing electrical grid as listed below [21]:

1. Significantly reduce system electricity outage.

2. Increase system reliability.

3. Reduce and eliminate power losses in the transmission lines since it's connected close to loads.

4. Result in higher power quality.

5. Decentralize electrical grid's management.

6. Reduced regional consequences of system failure. 


\subsubsection{Power Electronics}

Power electronics is a major component of smart grids because it connects the renewable energy sources to the grid by using inverters and converters. A power electronics converter is an interface between distributed generation and smart grid, since the renewable energy sources (Solar \& Wind) play a significant role as alternative source of power in the smart grid [20].

\subsubsection{Communication System}

Today, the electric network is moving forward towards intelligent, reliable, and fully automatic grid called the Smart Grid. The difference between the current electric grid and the smart power grid is that the current grid has one-way communication system while the smart grid has two-way communication system. A variety of energy ancillaries including distributed generation, real time monitoring, demand response and load management can be achieved by taking advantage of advanced information technologies. The typical requirements for communications networks in the Smart Grid can be summarized as follows [22] [23]:

- Availability: Self-healing ability in the existing system to overcome power failures.

- Reliability: The grid must have the ability to provide reliable communication to match the reliability of the power grid itself.

- Security. The grid must guarantee the privacy of the system's data handled by the communication system.

Two-way communication system in the Smart Grid allows smart appliances; smart meters for control of loads and sources by means of digital information flow through the two-way smart communication infrastructure. 


\subsubsection{Smart Sensors and Advanced Metering Infrastructure}

In traditional electrical grid substations all the sensors and meters need to be upgraded to the new technologies for high accuracy by using a global positioning system (GPS) signal. In the future the remote terminal unit (RTU)p function will be replaced by phasor measurement unit (PMU). Additionally, the traditional electromechanical current transformer (CT) and potential transformer (PT) will be replaced by electronic or optical sensors with high accuracy of measurement [24]. Many benefits will be realized by using smart sensors and advanced metering as summarized below:

- Real time load monitoring.

- Failure detection and islanding.

- Load profile summarizing.

- Real time pricing.

- Monitor the sensitive equipment.

The concept of smart meters and advanced metering in the smart grid provides customers the ability to automatically manage their electricity usage, minimizing power cost and improve the power quality.

\subsection{Challenges of the Smart Grid}

Smart grid technologies give a chance to upgrade and develop the entire power grid, but they still are facing a number of technical challenges to be implemented on the existing power grid. They are briefly enumerated below:

- Complicated system.

- Handling a huge Advanced metering infrastructure data.

- Real time data analysis.

- Integration of distributed generation and protection. 
- Expenses of energy storage technology.

\subsection{Prospects for Smart Grid and its Application}

Smart Grid integrates several new technologies with existing grid by means of sensors, communication system, advanced actuators, information technology and distributed generation.

The objectives of implementing smart grid are as follows [25]:

1. Create a smart energy infrastructure that provides environmental benefits, low system costs, and reliable service.

2. Enable integration of renewables, distributed generation, and energy storage.

3. Improve capacity, utilization, and performance of existing system and adding new transmission lines to improve voltage profile.

4. Improve reliability of the overall electricity system.

5. Empower employers by enabling distributed renewables, electric vehicles

\subsubsection{Optimization of Active and Reactive Power Flow in the Smart Grid}

Electricity flow from the generation system to the consumers through the distribution system is at medium voltage (typically $10 \mathrm{kV}$ to $35 \mathrm{kV}$ ) where the voltage is stepped down for suitable end use consumption, switchable capacitor banks with energy storage devices and integration of distributed energy resources are used to optimize reactive and active power for high power quality [25].

\subsubsection{Self-healing and Fault Detection}

Self-healing refers to the capability of the grid to address the sustained shortage of the power on the customer's side, determine the location of the fault on the feeders, take quick action by sending the command to switch and isolate the section of the feeder where the fault is located, and then restore power to repower the system again [26]. 


\subsubsection{Demand Response (DR)}

Generally, demand response refers to a system that gives the utilities and consumers on both sides the ability to reduce energy consumption during peak hours; demand response forecast real time prices in order to reduce the energy consumption level of individual customers [27] [25].

\subsubsection{Integration of Renewable Energy}

Smart Grid enables the system to integrate renewable energy resources (Wind \& Solar) installed close to loads. Moreover, the size and the number of transmission lines that need to be used to transmit power will be reduced. Penetration of renewable energy will decrease $\mathrm{CO} 2$ emission for clean environment and green energy.

\subsubsection{Power System Stability}

Often in interconnection power areas, the grid struggles from the redundancy and fluctuations due to frequency variation or because of undesirable events, which lead the system to complete blackout, Smart Grid with the new technologies, has the ability to stabilize the system and operate at a stable equilibrium with acceptable grid voltages and system frequency. Most of blackouts over the last decades have been caused by the failure to preserve one or more forms of power system stability [28]. 


\section{CHAPTER III}

\section{LIBYAN ELECTRIC SYSTEM}

\subsection{Overview}

Libya is situated in the northern part of Africa between Tunisia and Egypt on the southern coast of the Mediterranean Sea with about $1900 \mathrm{~km}$ of coastline. Libya has a population of about 6 million and more than $70 \%$ of the total population live in the coast side. It occupies nearly $1,759,540$ square kilometers of are [29].

Recently, consumption of electricity has been rapidly increasing in Libya. Information from the administration office of the GECOL (General Electricity Company of Libya) indicated that electricity consumption in Libya has jumped from 13.4 BkWh in 2003 to $22.17 \mathrm{Bkwh}$ in 2007 [30]. This is an increase in the energy consumption of $60 \%$ over four years.

Most of Libya's existing power stations are being converted from oil to natural gas. Libya currently has an installed electrical generation capacity of about $6.51 \mathrm{GW}$. And new power plants are being built to run on natural gas. Libya is also considering potential wind and solar projects. The peak load on the electric power system in Libya is continuously increasing with a relatively high growth rate of about 8 to $10 \%$ per year. Libya has the longest transmission system in the region at $220 \mathrm{kV}$ level. The internal interconnection of the Libyan transmission system was achieved in 1993 by creating a high voltage $220 \mathrm{kV}$ Libyan national grid [31]. 
The electrical grid of Libya is interconnected with Egypt's electric grid at $220 \mathrm{kV}$ level since May 1998 and interconnected with Tunisia's electric grid in 2009, also at $220 \mathrm{kV}$ level. The Transmission System is completely interconnected and designed to ensure both reliability and security. The total energy demand has increased with growth of $60 \%$. The oil sector has the highest share with $61 \%$ of total consumption.

The electric energy sector has been developed during the last decade in Libya. The peak load has increased from 1595 MW in 1990 to 3875 MW in 2005 while the total installed capacity has increased from $3352 \mathrm{MW}$ in 1990 to $5121 \mathrm{MW}$ in 2005, and the generated electric energy from $9851 \mathrm{GWh}$ in 1990 to $22500 \mathrm{GWh}$ in 2005 . The contribution of steam power plants is at $65 \%$. Natural gas represents $32 \%$ of the fuel supply for electric power plants and 33\% heavy oil fuel and $35 \%$ light oil. The national electric network is accessible to $99 \%$ of the population. Most of electric network is concentrated on the coast, where most of the inhabitants live. Figure 3.1 shows the locations of the electrical power plants in Libya [32].

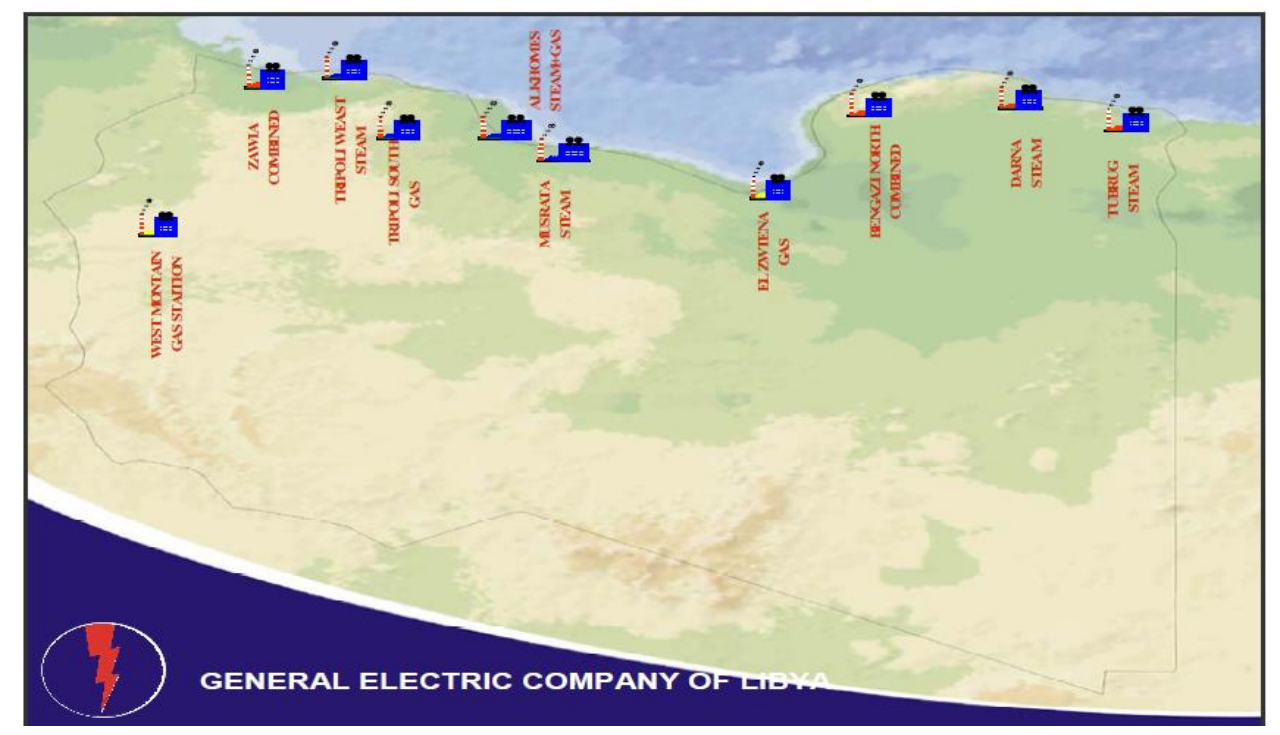

Figure 3.1: Locations of the electrical power plants (Source GECOL) 


\subsection{Renewable Energy Resources in Libya}

Libya has $1900 \mathrm{~km}$ of coastline with $90 \%$ of 1,759,540 square kilometers of desert; Libya is one of the richest countries in the region in wind and solar recourses. The daily average of solar radiation on a horizontal plane is $7.1 \mathrm{kWh} / \mathrm{m}^{2}$ in the coastal region, and $8.1 \mathrm{kWh} / \mathrm{m}^{2}$ in the southern region, with a daylight duration of more than 3500 hours per year. Wind potential is also very high in many regions and sites in Libya and can contribute to the energy scenario to increase the efficiency and reliability of the current power system [33] [34]. Renewable energy became a very promising research area in last few decades due to its advantages of being able to be integrated with the existing power system in Libya. Integration of Renewable Energy is facing some challenges since wind and solar are non-controllable and partial unpredictability, both depending on the location.

Since the Al-Zawea oil refinery is connected to the Libyan national electric grid, a study of renewable energy penetration into Al-Zawea refinery existing power system is considered in this dissertation. One of the smart grid technologies requirements to be implemented in the existing power system is investigating the impact of the penetration of renewable energy system (Wind Turbine) with reference to voltage profile improvement and system reliability. 


\section{CHAPTER IV}

\section{EXISITNG POWER SYSTEM AT THE AL-ZAWEA OIL REFINERY}

\subsection{Overview of Al-Zawea Refinery}

Al-Zawea refinery is located at about 40 kilometers ( $25 \mathrm{mi}$ ) west of the capital city (Tripoli) Libya. It is the largest refinery in the region. The refinery was opened in 1974 and it currently produces an estimated 120,000 barrels and (19,000 m3) of oil products per day (bpd). Research Programs goal is to study power flow and provides suggestions to upgrade the existing power system of the refinery at Al-Zawea.

\subsection{Distributed System}

Distribution system of the electric grid is the most involved and needs to be reliable for power distribution [35]. And it is the last stage of electric power delivery to the loads. Distribution system connects the transmission lines between high and medium voltage to the low voltage with the use of transformers [36]. As in general in any power system, the electrical system at Al-Zawea refinery can be broken down into three main parts namely, the distribution substation, distribution primary, distribution secondary. Voltage levels are reduced at the refinery in the main substation for distribution to the other substations to feed the various loads. The refinery's electrical network is connected to the General Electricity Company of Libya as a secondary power supply with $2 \mathrm{MW}$ of capacity. In addition, the refinery has its own power plants consisting of three steam turbines and one gas turbine using natural gas with a combined capacity of $11 \mathrm{MW}$ under normal operation. Technical analysis have been done by meeting with Al-Zawea refinery engineers to investigate the refinery power system and to address its issues. 


\subsection{System Overview}

The refinery has an on-refinery power plant, with rating of $11 \mathrm{MW}$ and it is connected to the Libyan national grid by two $31.5 \mathrm{kV}$ feeders. The electrical distribution network of the refinery is connected to the national grid by a $6.6 \mathrm{kV}$ bus-bar system, as represented in Figure 4.1 with the following sources.

- Three steam turbines $6.6 \mathrm{kV}, 6 \mathrm{MVA}$ each.

- One gas turbine generator $6.6 \mathrm{kV}, 21 \mathrm{MVA}$.

- Two incoming $6.6 \mathrm{kV}$ cable feeders stepped down from $31 \mathrm{kV}$ to $6.6 \mathrm{kV}$ with capacity of 1 MVA each.

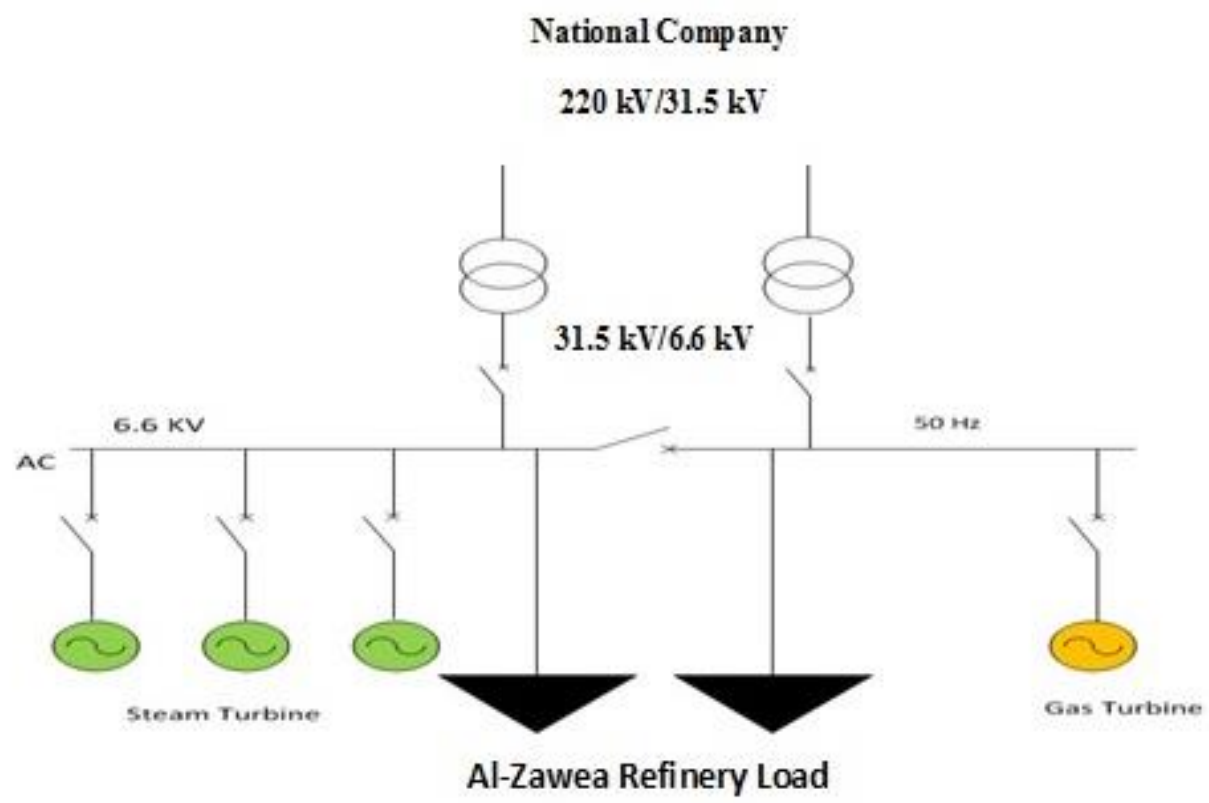

Figure.4.1: One-Line diagram of the Al-Zawea refinery power system

The total load demand of the refinery is around $11 \mathrm{MW}$ to $12 \mathrm{MW}$ supplied by.

1. Two steam turbines with $2.5 \mathrm{MW} \sim 3 \mathrm{MW}$ power output (the third in standby).

2. The $6.6 \mathrm{kV}$ incoming cable feeders. 
3. The gas turbine generator with a $5 \mathrm{MW} \sim 6 \mathrm{MW}$ output.

Al-Zawea refinery power resources are represented by percentages in Figure 4.2:

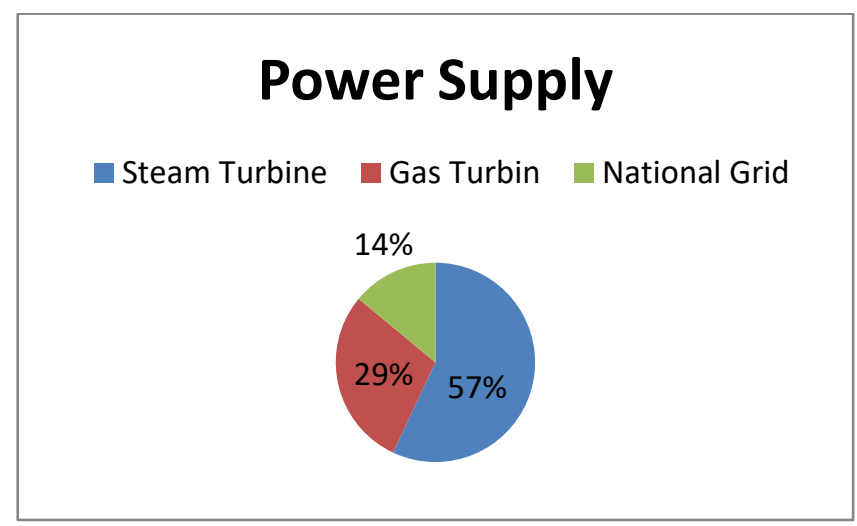

Figure 4.2: Percentages of power supply

The $6.6 \mathrm{kV}$ incoming cables are protected by the following devices:

1. Overcurrent relay.

2. Minimum voltage relay.

3. Active reverse power relay.

These incoming feeders are crucial since they connect the refinery network to the Libyan national grid.

The first requirement of power supply to the refinery is maximum availability; furthermore, it has to be considered that:

$>$ Generating capability is much higher than typical load (approximately $30 \mathrm{MW}$ possible generation, versus 12 to $15 \mathrm{MW}$ loads).

$>$ Gas turbine has proven to be not much reliable (2 or more trips/year).

$>$ Steam turbines are old and show low availability factor (less than 50\%).

$>$ Import power from grid is costly. 
There is an agreement not to export to electricity National Grid.

In order to fulfill these requirements, power supply is consequently based on:

- Put in operation gas turbine at low power (30\% of nominal or less), so that a reserve is available in case of islanding.

- Put in operation two steam turbines, keeping one in backup.

- Put in operation one of the two feeders from National Grid, in order to have a backup in case of Gas Turbine Trip.

- Keep energy imports low (to reduce costs), less than $1 \mathrm{MW}$ usually.

- Limit reverse power

The observed problem is not under complete dominion of Al-Zawea refinery.

- It is initiated by external frequency fluctuation in the National Grid.

- The National Grid itself is connected to other countries, remaining exposed to contingencies.

Figure 4.3 shows a single line diagram of the current distribution system at the Al-Zawea refinery power system.

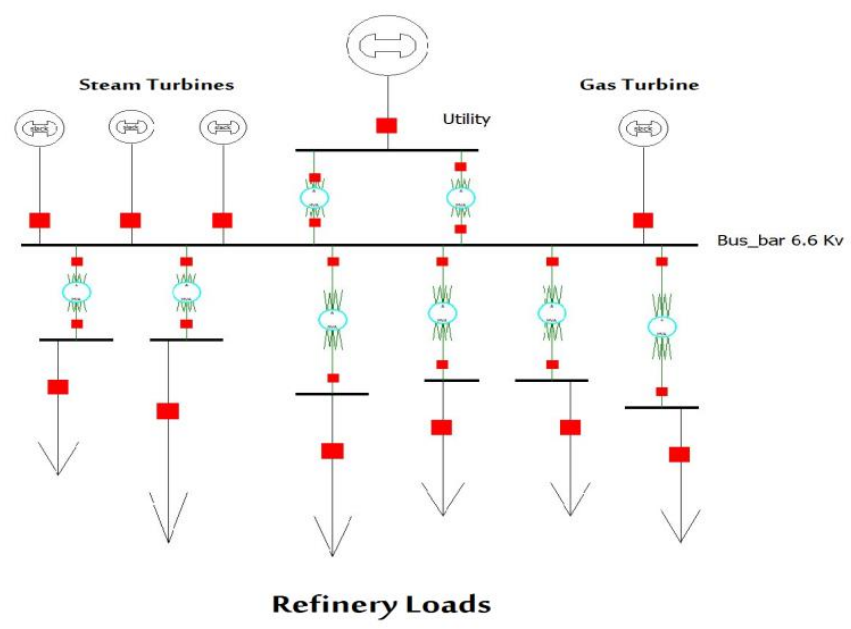

Figure 4.3: Single Line Diagram of the Distribution system in the Refinery Power System 
This system feeds five different areas in the refinery of which one of them is considered as critical due to the sensitive equipment and the research work being conducted to this area. These critical loads are very sensitive to frequency variations, power fluctuations and power outage. The protection systems used to protect the equipment from failure in the refinery distribution system are fuses manufactured by CESI.

Figure 4.4 shows one of the five areas of the current distribution system where critical loads at the Al-Zawea refinery are located.

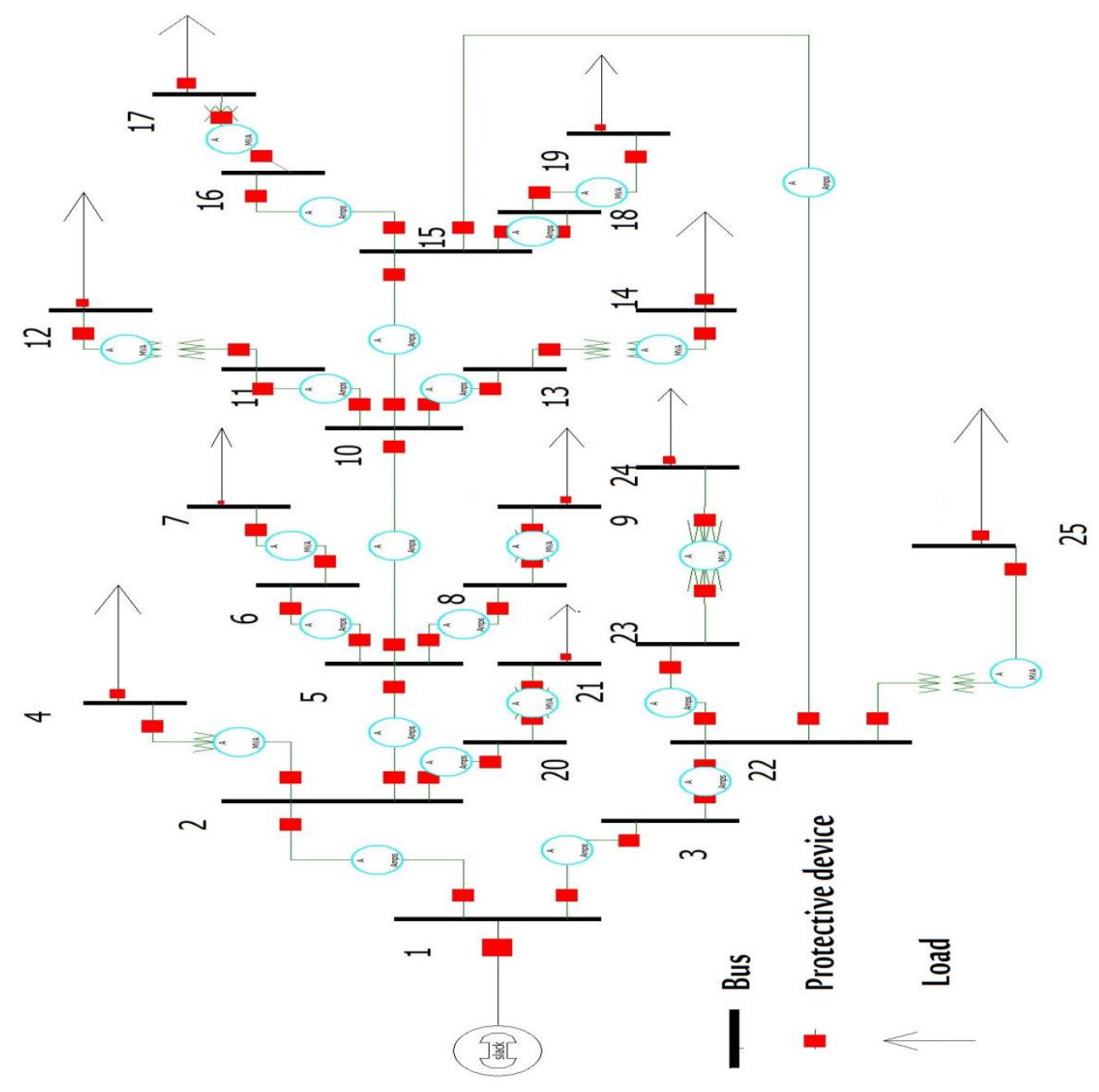

Figure.4.4: A segment of the current distribution system layout at Al-Zawea Refinery. 
The number of the distribution lines at the Al-Zawea refinery is very large and all the distribution across the refinery is done using underground cables. There are different types of buses, understanding the types of the buses is very helpful in this research study as illustrated in Table 4.1. The buses are represented as nodes. Every type of bus is designed based on its operation constrains. As known there are two major types of buses in the distribution system they are generator buses, which are connecting the generators to the grid and load buses that are connecting the load to the grid. Load buses named PQ buses, $\mathrm{P}$ is a real power $\mathrm{Q}$ is a reactive power specified based on power consumption. Both reactive and real power are specified for every load bus. The known and unknown variables of the various buses used in load flow studies are summarizes by

\section{Table 4.1.}

Table. 4.1: The different variables associated to the types of the buses in the power flow analysis

\begin{tabular}{|c|c|c|}
\hline Bus Type & Known Variables & Unknown Variables \\
\hline Load bus & $\begin{array}{c}\text { Real power }(\mathbf{P}) \\
\text { Reactive Power }(\mathbf{Q})\end{array}$ & $\begin{array}{c}\text { Voltage Magnitude (V) } \\
\text { Voltage Angle }(\boldsymbol{\theta})\end{array}$ \\
\hline Generator Bus & $\begin{array}{c}\text { Real Power }(\mathbf{P}) \\
\text { Voltage Magnitude }(\mathbf{V})\end{array}$ & $\begin{array}{c}\text { Reactive Power(Q) } \\
\text { Voltage Angle }(\boldsymbol{\theta})\end{array}$ \\
\hline Slack Bus & $\begin{array}{c}\text { Voltage Magnitude }(\mathbf{V}) \\
\text { Voltage Angle }(\mathbf{\theta})\end{array}$ & $\begin{array}{c}\text { Real Power }(\mathbf{P}) \\
\text { Reactive Power }(\mathbf{Q})\end{array}$ \\
\hline
\end{tabular}

As shown in Figure 4.4, there are 10 load buses namely; Bus 4, Bus 7, Bus 9, Bus 12, Bus 14, Bus 17, Bus 19, Bus 21, Bus 24, Bus 25.

\subsubsection{Distribution Substation}

Based on literature review and studies done in this research, the distribution substations were found to be somewhat standard. The distribution substation typically includes:

1. Circuit breaker.

2. Disconnecting switches. 


\section{Shunt reactors.}

4. Station buses and insulators.

5. Current limiting reactors.

6. Current transformer.

7. Coupling capacitors.

8. Series capacitors.

9. Grounding system.

10. Station batteries.

11. Power transformers.

12. Others.

There are eleven distribution substations in the refinery and they feed the entire distribution system at the refinery at different rates.

\subsubsection{The Feeders of the Distribution System}

Distribution feeders in the refinery are either loop or radial. The majority of the feeders in the refinery are designed to be a radial for economic reasons where they are less costly comparing to the others. Figure 4.5 shows the types of distribution system.
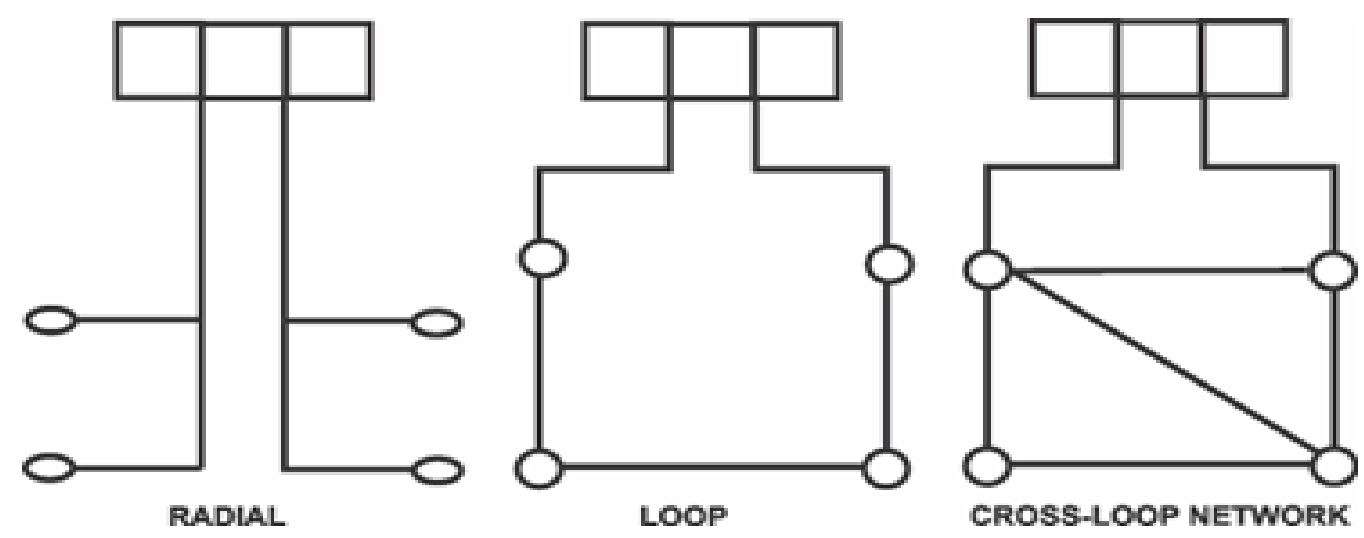

Figure 4.5: Types of the distribution system [37] 
As shown in the Figure 4.4 the radial system exactly matches the current distribution system of the refinery. The feedback loop in the current system is connected from Bus 17 to Bus 26.

\subsection{Problem Statement}

Al-Zawea Oil Refinery electric network experienced some active power fluctuations when connected to the national grid. Fluctuations cause disturbances to the electrical network leading to system collapse. In order to investigate the origin of these phenomena and to identify their most probable cause, an onsite survey and power flow analysis were required.

\subsubsection{Gas Turbine Control System Investigation}

The control system of the gas turbine is not reliable because of its governor reaction versus frequency. The frequency variation between the national grid and local grid causes severe power fluctuation problem, needing rapid reaction from the operator to follow the grid frequency to avoid any fluctuations. This requires fast operator actions (in less than 30 second), implies possible gas turbine trip, implies possible feeder trip by the reverse power relay. The operational problem can be identified as follows:

1. Grid events initiate frequency fluctuations.

2. Gas turbine reacts trying to keep speed at reference to maintain system stability which is not possible sometimes as in the peak time.

3. The operator tries to limit gas turbine reaction, adjusting speed/load reference.

\subsubsection{Frequency Data and Power Factor Analysis}

Apart from the electricity supplied to the refinery from the National Grid, a series of interconnected power stations, substations and other infrastructure exist in the refineries. There is a specific demand (typically of the order $2 \mathrm{MW}$ ) imported from the National Grid, and the rest of the power demand is supplied by the various interconnected generators in the refinery as explained in previous sections. Grid stability is a technical requirement for a proper operation of an interconnected power 
system and it is a prerequisite for a stable power system to guarantees secure supply at a frequency of $50 \mathrm{~Hz}$ to avoid any power fluctuations. The concept of the relation between frequency and load versus the system stability is illustrated in Figure 4.6.

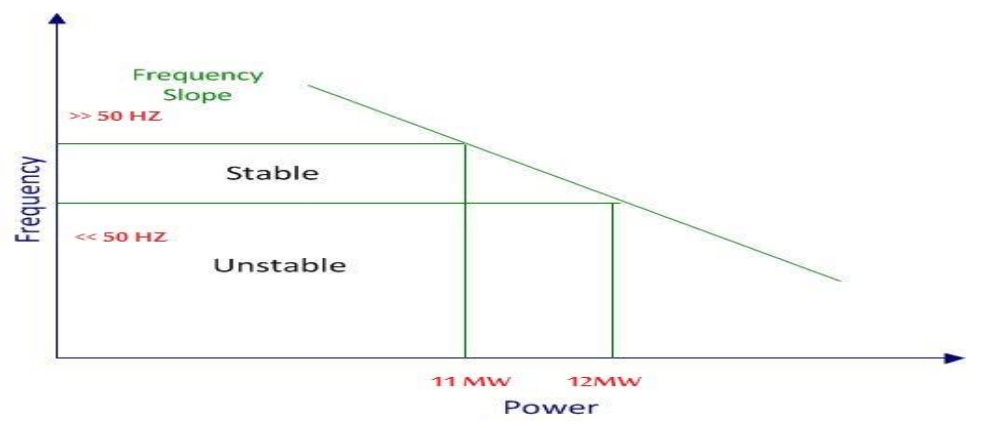

Figure 4.6: The concept of the power stability based on frequency variation and power generation

Frequency data has been collected from the refinery's SCADA system for period of time (three months). The data put under study and analysis to clarify the causes of the fluctuation:

- When?

- Where?

- Why?

The grid frequency during normal operation is depicted in Figure 4.7.

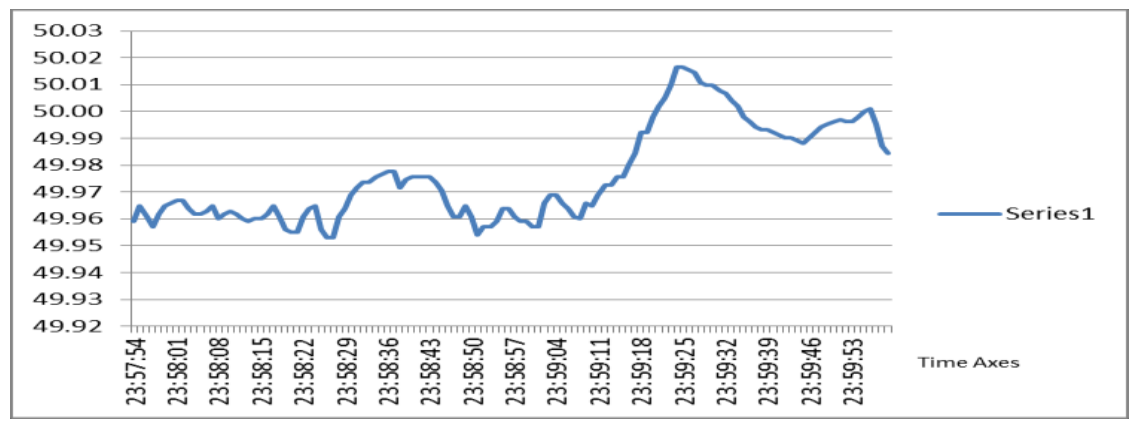

Figure 4.7: Frequency variations in normal operation

The refinery's grid experiences deviation in system frequency and scheduled power exchanges to other areas with undesirable effects. 
This typically happens at the peak time at early morning 6:7 am, and at around midnight as shown

Figure 4.8. The fluctuations are observed on the feeder which connects the refinery to national grid. Fluctuations cause disturbances to the electrical network and often cause system collapse.

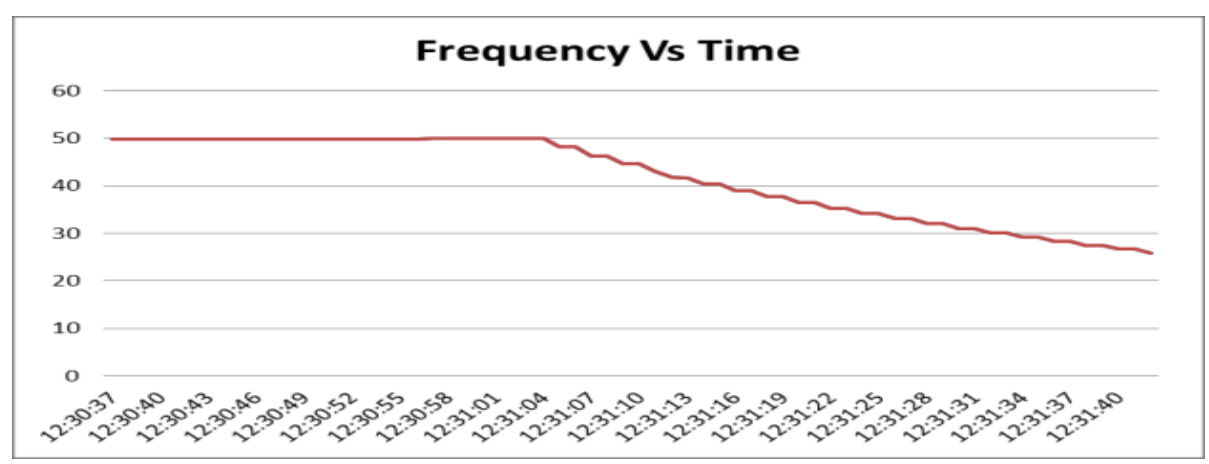

Figure 4.8 Frequency fluctuation plot

\subsection{Observation}

Steam Turbine: Steam turbine is more reliable for frequency deviation. The governor of the turbine does not get fast effect of frequency changing which mean the redundancy of the grid is not caused by steam turbine.

Gas Turbine: The gas turbines are usually equipped with relatively complicated control logic, which includes several different loops, such as governor, temperature controller, acceleration controller, etc. [38]. The power output of the gas turbine is related to the governor and frequency. The governor is usually known as the main control loop in the gas turbine control algorithm during its normal operation and any frequency deviation out of acceptable range will affect the stability of the grid [39]. So, the fluctuation happened because of the gas turbine.

Power flow analyses need to be done on the system. PowerWorld and Matlab will be employed for this analysis. Load flow model was developed for the current distribution system at AL-Zawea refinery for one segment with maximum load of $4 \mathrm{MW}$. Load data, grid frequency and voltages 
with distribution line parameters are under consideration as known values. Frequency variation under changing load conditions or outages can be calculated.

\subsection{Load Flow Analysis}

Load flow analysis is one of the most important part in the power engineering. System needs to be evaluated whether stable or non-stable and its performance under normal operation or during time of faults Load flow analysis for the critical loads of the current distributed system at AL-Zawea refinery is performed. The entire system comprises of 25 Buses and load data, 10 buses are represented as a load buses with different demands, distribution line parameters and bus voltages are used as input data to conduct the study. Load data in Table 4.2 are used in the study. A Load flow analysis can provide the following information:

1. Active and reactive power losses.

2. Phase angle at each line.

3. Voltages at each line.

4. Power factor.

5. Total power losses.

\begin{tabular}{|c|c|c|}
\hline Bus NO & Real Power (MW) & $\begin{array}{c}\text { Reactive Power } \\
\text { (MVar) }\end{array}$ \\
\hline 4 & 0.5 & 0.1 \\
7 & 0.27 & 0.05 \\
9 & 0.15 & 0.03 \\
12 & 0.7 & 0.14 \\
14 & 0.6 & 0.121 \\
17 & 0.3 & 0.06 \\
19 & 0.13 & 0.02 \\
21 & 0.45 & 0.09 \\
24 & 0.36 & 0.07 \\
25 & 0.45 & 0.08 \\
\hline
\end{tabular}

Table.4.2: Load data of critical loads of the current Refinery distribution system 


\subsection{Challenges}

The refinery consumes from 11 12 MW with sensitive loads consisting of sensitive equipment. The main objective is to keep the system on power $24 / 7$ every single second. The refinery does have a local power plant with capability to generate $9 \mathrm{MW}$ of electricity using natural gas. However, Al-Zawea refinery imports electricity form the National Grid for the rest of the power demand. One of the steam turbine refinery units acts as a system buffer and back up supply in emergency case. Switches and fuses are being used as protection devices to avoid any outages due to redundancy. A frequency variation in the tie line leads to disturbance of power at all buses and loads. The loads connected to buses $4,7,9,12,14,17,19,21,24$ and 25 are critical loads. These loads consist of many sensitive equipment.

There have been recorded major blackouts at the refinery in the past few years. The system needs to be upgraded since it is plagued with various challenges that need to be addressed. They are:

- Frequency variation.

- Load growth.

- System centralization.

- Distribution automation.

- Central control system. 


\section{CHAPTER V}

\section{PROPOSED MODIFICATIONS FOR THE EXISTING AL-ZAWEA REFINERY POWER SYSTEM}

\subsection{Distributed Generation (DG) Overview}

Electrical utilities are seeking new technologies to improve power quality, reliability and voltage profile with revolution in power electronics, renewable energy generation is becoming attractive. This can be a benefit to upgrading the conventional electrical grid with less environmental impact. Distributed renewable generation promises a clean environment and sufficient power to the load.

Distributed generation (DG) is power generation scattered throughout the power system to feed the load demand, or employed at an isolated site not connected to the power grid. Distributed generation can be installed at or close to the load. Distributed generation typically has capacities ranging from $5 \mathrm{~kW}$ to $100 \mathrm{MW}$ [40]. Recently, distributed generation has started to play a larger role in power distribution systems. Distributed generation reduces the amount of energy lost in transmitting electricity because the electricity is generated very near where it is used. Proper implementation of distributed generation in the system needs advanced sensors with integrated wireless communication system to measure and transmit the required data for real time analysis and control. 


\subsection{Integration of Distributed Generation}

The integration of distributed generation into the grid requires a good knowledge of the operation and control for the different types of power plants and analysis to evaluate the system performance with the new distributed generation. The selection criteria of the types of generators needed for distributed generation depends on their application [41]. Distributed Generation (DG) aims to generate part of power demand on a small scale closer to the load and interchange the power with the grid. Distributed generation also called decentralized generation or embedded generation or dispersed generation. It is defined as small electric power sources that can be connected to a distribution system at any bus-bar close to the load or to the customer at the meter [42].Recently, several distributed generation technologies are under study and research for development. They are photovoltaic system (PV), micro turbines, gas turbines, diesel engines and wind energy conversion system (WECS). At present wind energy has become the most economically competitive among all renewable energy technologies [43].

Integration of distributed generation into existing power system at Al-Zawea refinery can result in several benefits. These benefits include:

1. Reduced environmental impact.

2. Avoid system blackout.

3. Power loss reduction.

4. Increase overall system efficiency.

5. Overcome power fluctuations.

Wind distributed generation technology is proposed to be integrated with AL-Zawea refinery power system at Al-Zawea refinery. 


\subsection{Wind Energy Systems as Distributed Generation}

Although renewable energy application in Libya was started in the middle of the seventies, it has still not found its way into industry sector. This study considers the possible impacts of renewable (wind) energy system integration with the Al-Zawea refinery electric grid to satisfy the refinery load demand.

Recently, renewable energy technologies have accelerated around the globe. Increasing the proportion of electricity generated from renewable sources is one of the viable ways to reduce the reliance on fossil fuels and reduce greenhouse gas emissions for clean environment [44]. Currently, conventional generation plays a pivotal role in maintaining the power balance between generation and demand. Entry of renewable generation will require a major upgrade of the existing utility system leading to its transformation as a "Smart" grid. Smart grids have become high priority items on the industry agenda in many countries around the world. The concept of "Smart grid" is to allow utility to move electricity around the system as efficiently and economically as possible. This study discusses the main features of smart grid which is distributed generation integration to improve system reliability and efficiency. The source of distributed generation considered here is the renewable wind energy. Libya is one of the richest countries in the region in wind and solar recourses. The daily average of solar radiation on a horizontal plane is $7.1 \mathrm{kWh} / \mathrm{m}^{2}$ in the coastal region, and $8.1 \mathrm{kWh} / \mathrm{m}^{2}$ in the southern region, with daylight duration of more than 3500 hours per year. Wind potential is also very high in many regions and sites in Libya and can contribute to the energy scenario to increase the efficiency and reliability of the current power system [45] [46]. Renewable energy became a very promising research area in the last few decades due to its advantages of being able to be integrated with the existing power system: in Libya. Since the AlZawea refinery is connected to the Libyan national electrical grid, a study of renewable energy penetration into Al-Zawea refinery is considered in this study. The objective of this study is to investigate the impact of the penetration of distributed renewable generation (Wind Turbines) on 
the Al-Zawea refinery power system with reference to voltage profile improvement and system reliability. Wind power is one of the cleanest and most abundant forms of renewable energy and it has the smallest footprint of all.

The Impact of wind power integration on the system depends on the size of the network and the penetration level. Changing wind conditions will affect the power output generated by wind turbines. However, it is technically possible to integrate fairly large amounts (up to 50\%) of wind capacity in power systems. Wind energy resources are available in many regions in Libya in reasonable quantities; preliminary studies indicate that it can be economically exploited [47]. AlZawea is a city in northwestern Libya, situated on the Libyan coastline of the Mediterranean Sea about $45 \mathrm{~km}$ west of Tripoli [48]. The electrical load of Al-Zawea refinery is about 11 12 MW. Since wind potential is plentiful in many areas around the refinery, wind DG is proposed as a solution to balance the net load uncertainty. The term net load is defined as system demand minus system generation. A single line diagram of the Al-Zawea power system with Wind DG is illustrated in Figure 5.1.

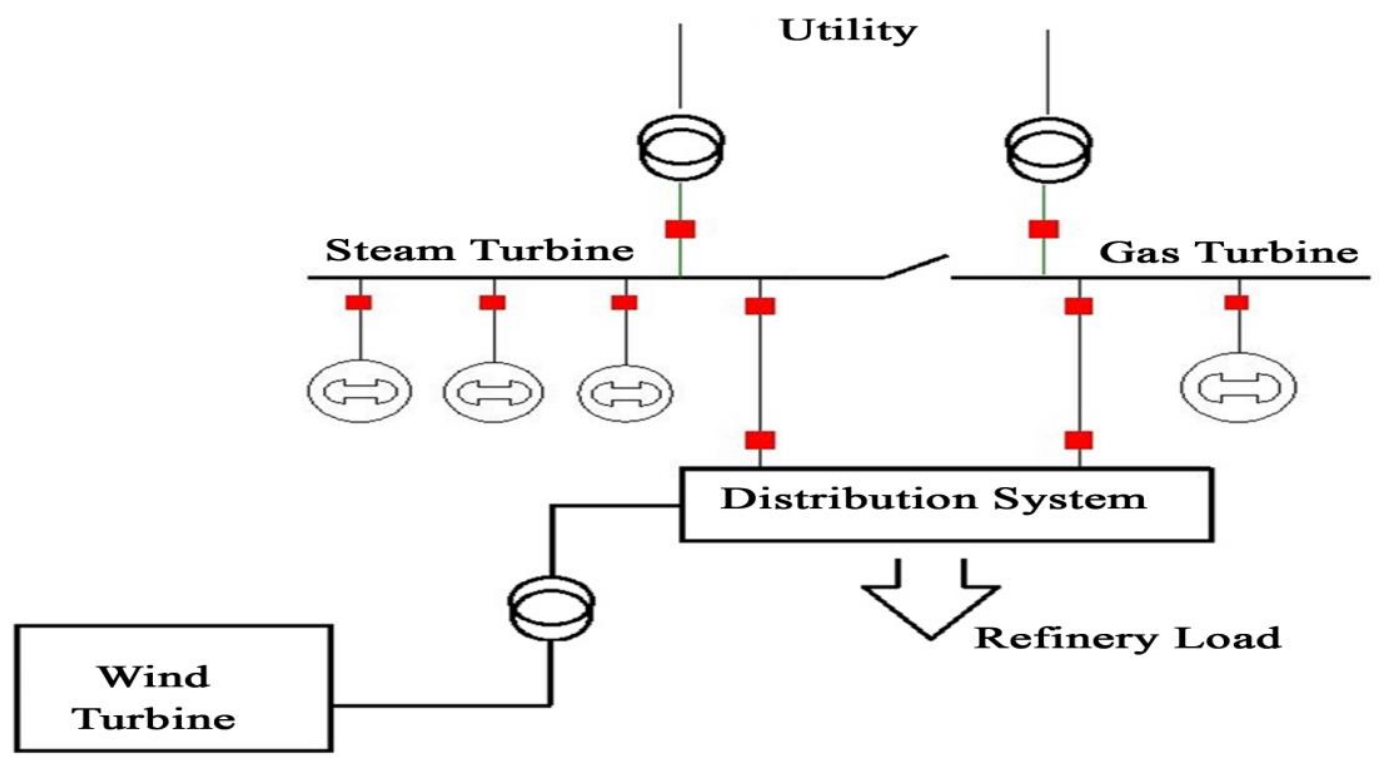

Figure 5.1: One-line diagram of the Al-Zawea refinery power system with proposed wind power system 


\subsubsection{Wind Energy Conversion System}

A wind turbine works by converting the kinetic energy in the wind first into rotational energy and then to electrical energy that can be supplied via the grid for consumption. Although the design of wind turbines varies based on their application, the main components have the same functions. The wind speed and the swept area of the turbine mainly control the electrical output of each wind turbine. A typical wind turbine consists of:

- A tower to situate the generator.

- A nacelle (protecting the wind turbine from damage).

- A gearbox (matching the speed between the rotor and the generator in the turbine).

- A rotor (transferring the kinetic energy from the wind into rotational shaft energy).

- A generator (converting the mechanical energy to electrical energy)

- A tail vane system (maintaining the turbine pointed into the wind direction).

The power generated by the turbine is injected into the grid through a transformer. The connection between the wind turbine and the grid is possible at different levels of voltage [49]. Power electronics also can be used for enhanced power extraction and variable speed operation of the wind turbine. There are two types of wind turbines: vertical axis and horizontal axis. They are designed and built in different sizes and shapes [50]. Figure 5.2 shows the configuration of typical horizontal axis and vertical axis wind turbines [51].

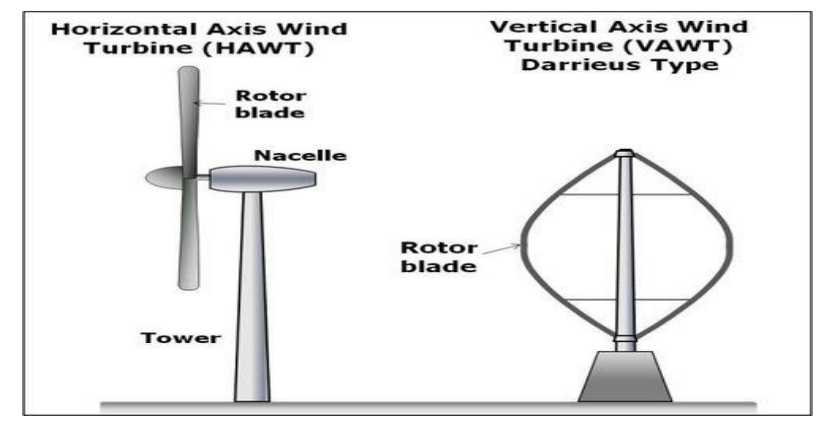

Figure 5.2: Simple horizontal axis and vertical axis wind turbines [51] 
The amount of power generated by the turbine and transformed to the grid depends on the density of the air, the wind speed and the rotor swept area [52] [53]. This is shown by the following relationship in Equation (5.1) [54].

$$
P_{\text {wind }}=\frac{1}{2} \rho_{\text {air }} v_{\text {wind }}^{3}
$$

where:

$$
\begin{aligned}
& P_{\text {wind }}=\text { the specific wind power }\left[\mathrm{w} / \mathrm{m}^{2}\right] \\
& V_{\text {wind }}=\text { the average wind speed }[\mathrm{w} / \mathrm{s}] \\
& \rho_{\text {air }}=1.225 \text { (the density of dry air at sea level at } 15^{\circ} \mathrm{C}\left(\mathrm{kg} / \mathrm{m}^{3}\right) \text { ) }
\end{aligned}
$$

We must consider the aerodynamics and the efficiency of the combination between the generator and the rotor. Therefore, the output power of the wind turbine can be calculated using equation (5.2).

$$
\text { Wind Turbine Power Output (Watt) }=\frac{1}{2} \rho A C_{p} V^{3} \eta_{g} \eta_{b}
$$

where:

$C_{p}=$ Coefficient of performance $(0.59$ (Betz Limit) is the maximum theoretically possible, 0.35 for ideal design).

$$
\begin{aligned}
& A=\text { rotor swept area }\left[\mathrm{m}^{2}\right] . \\
& \eta_{g}=\text { generator efficiency. } \\
& \eta_{b}=\text { Gearbox and bearing efficiency. }
\end{aligned}
$$

Generated power from the wind turbine depends on many factors besides wind condition. As seen in equation (5.2) the power output from a wind turbine changes based on wind speed, air density and the size of the rotor blades. Other parameters influence the power production from the turbine in indirect way such as atmospheric pressure, temperature and humidity. 


\subsubsection{Power Performance Curve of Wind Turbine}

The relationship between wind speed and power output of a turbine is represented by a graph called power curve. It varies from turbine to turbine based on their design and size. In this study, we consider GE 1.5 MW wind turbine since it is one of the popular types used around the world. The power curve of the GE 1.5 MW wind turbine is shown in Figure 5.3

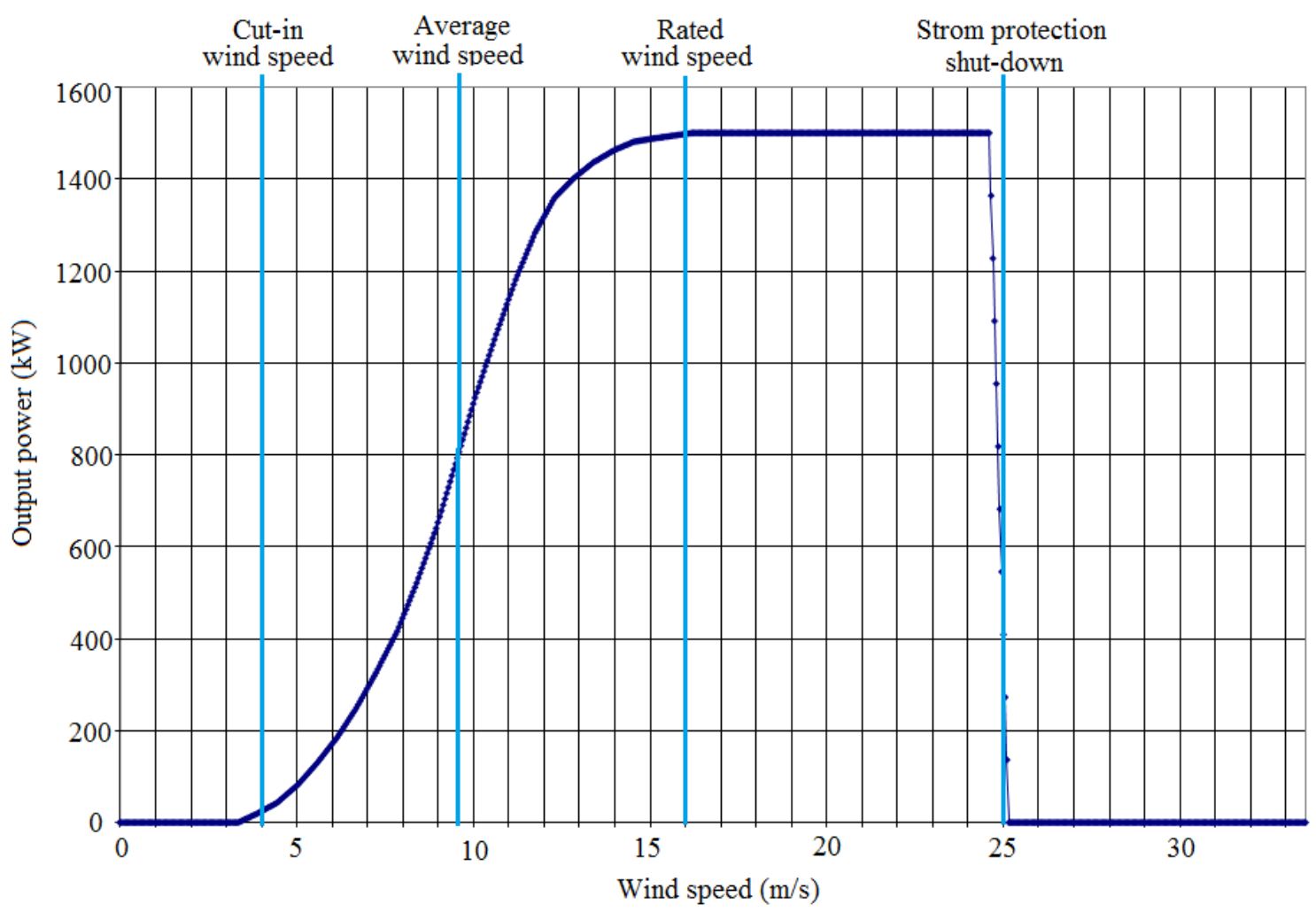

Figure 5.3: Power curve of GE 1.5 MW wind turbine [16]

As indicated in the power curve in Figure 5.3, if the wind is below the cut-in speed no power is generated. Whenever the wind starts to go above the cut-in speed, the turbine starts to generate power and the amount of power produced changes based on wind speed variation. When the wind speed reaches to the rated wind speed of the wind turbine, the turbine will produce the rated power and then the output power remains constant as wind speed increases above the rated speed. The technical data of the GE 1.5 MW wind turbine is shown in Table 5.1 [55]. 
Table 5.1: GE 1.5 MW turbine technical data

\begin{tabular}{|c|c|}
\hline Rated capacity & $1.5 \mathrm{MW}$ \\
\hline Cut-in Wind Speed & $3.5 \mathrm{~m} / \mathrm{s}$ \\
\hline Cut-out Wind Speed & $25 \mathrm{~m} / \mathrm{s}$ \\
\hline Rated Wind Speed & $14 \mathrm{~m} / \mathrm{s}$ \\
\hline
\end{tabular}

One of the main consideration of any electrical power system is its rated power. If the system has a generator, the rated power is dictated by the rated output of the generator. Before installing wind turbine units their "Capacity factor" should be evaluated to see whether they can meet power demand. The capacity factor $(\mathrm{CF})$ is defined as:

$$
C F=\frac{\text { Actual annual energy delivered }}{\text { Prated } X 8760}
$$

Or, another way to express it is

$$
C F=\frac{\text { Actual annual energy delivered } / 8760 h}{\text { Prated }}=\frac{\text { Average power }}{\text { Rated } \text { power }}
$$

Capacity factor of wind turbines is typically gain as a percentage. If the capacity factor of an unit at a site is $35 \%$, with GE $1.5 \mathrm{MW}$ units, the annual average power generated by the turbine is $(0.35 X 1.5)=0.525 \mathrm{MW}$. Typically, capacity factors of wind turbine vary between $30 \sim 35 \%$ [56].

\subsection{Integrating Wind Power Based DG into the Refinery Power System}

If the electricity demand exceeds the cumulative power generated by the generators in the system, the units will respond by decreasing their rotational speed, as explained in Chapter IV due to power imbalance. The stability of the system frequency in Al-Zawea power system is a good measure of balance. The primary grid frequency also varies during peak times due to load imbalance. This affects the steady state operation of the grid and causes gas turbines to trip, followed by voltage collapse (system blackout). Integrating wind based DGs units with the existing distribution system 
can achieve the balance of loads in the refinery. Optimal allocation and optimum sizing of wind turbine based DG is studied considering load uncertainty and wind variability.

\subsubsection{Load Modelling}

Probabilistic load flow that accounts for load variability (uncertainty) is employed in this study. The load uncertainty is modeled as follows:

1. The maximum load is placed at every load bus once.

2. As a result, there will be loading scenarios equal to the number of load buses.

3. For simplicity, the maximum load is assumed based on the desired loading conditions and the mean and standard deviation of the load are calculated.

The data given in Table $\mathbf{4 . 2}$ have been used for load uncertainty study by placing the maximum load at each load bus in all busses, thus generating ten load scenarios. Probability density function of the load uncertainty conditions is determined by using (5.5).

$$
p r_{n}=\frac{1}{\sigma \sqrt{2 \pi}} e^{\frac{(x-\mu)^{2}}{2 \sigma^{2}}}
$$

where $\mu, \sigma^{2}$ and $X$ are the calculated mean, variance and power demand of assumed loads respectively.

\subsubsection{The Sizing of the Proposed DG units}

The probability distribution function (pdf) of wind speed is the key information that is needed to estimate and model the power output of wind energy units to determine the capacity factor and sizing the wind turbine based distributed generation DG [57]. A very good model often used to model the behavior of wind speed is the Rayleigh probability density function (pdf) which is a special case of Weibull distribution with a shape factor $\beta=2$. 
Weibull distribution function has been widely used, accepted and recommended to model wind speeds [58] [59]. The Weibull density function has two parameters - dimensionless shape parameters $(\beta)$ and a scale parameter $(\alpha)$ having units of wind speed $(\mathrm{m} / \mathrm{s})$. The two parameters describe the wind speed at a location [60] [61]. The probability density function is given by Equation (5.6):

$$
f(v)=\left(\frac{\beta}{\alpha}\right)\left(\frac{v}{\alpha}\right)^{\beta-1} \exp \left(-\left(\frac{v}{\alpha}\right)^{\beta}\right)
$$

where $f(v)$ is the probability density function for the random variable wind speed $(v), \beta$ is a dimensionless Weibull shape parameter and $\alpha$ is a scale parameter of wind speed $(\mathrm{m} / \mathrm{s})$.

There are several approaches to estimate Weibull parameters to fit wind speed data [50] [60] [61]. For a given set of data, several numerical methods can be employed to determine the Weibull parameters. The most common methods are listed below:

- $\quad$ Graphical method (GM);

- $\quad$ Empirical Method;

- $\quad$ Modified Maximum Likelihood Method;

- $\quad$ Energy Pattern Factor Method;

- $\quad$ Moment method (MM);

- $\quad$ Maximum likelihood;

In this study Rayleigh probability density function (pdf) is used to model the behavior of wind speed by using equation (5.7). Rayleigh is a special case of Weibull pdf with a shape index $\beta$ is equal to 2 .

$$
f(v)=\frac{2 v}{\alpha^{2}} e^{\left[-\left(\frac{v}{\alpha}\right)^{2}\right]}
$$

Where the scale parameter $\alpha$ can be calculated using (5.8) and (5.9) 


$$
\begin{gathered}
v_{m}=\int_{0}^{\infty} v f(v) d v=\frac{\sqrt{\pi}}{2} \alpha \\
\alpha \approx 1.128 v_{m}
\end{gathered}
$$

In order to evaluate wind turbines based distributed generation into the existing power system with the uncertainties wind speed, the continuous probability distribution function of the given wind speed is divided into states (segments) each with certain speed limits. Small number the states affects the accuracy, whereas choosing a large number of states increases. In this study, the speed range of each state is taken to be $1 \mathrm{~m} / \mathrm{s}$ as shown in Table 5.2.

Table 5.2: selected wind speed states

\begin{tabular}{|c|c|}
\hline Wind Speed state $(\mathrm{w})$ & Wind speed Limits, $\mathrm{m} / \mathrm{s}$ \\
\hline & \\
1 & $0-1$ \\
2 & $1-2$ \\
$\cdot$ & $\cdot$ \\
$\cdot$ & $\cdot$ \\
State $n$ & $\cdot$ \\
& \\
& \\
\hline
\end{tabular}

The average wind speed at the site can be calculated by using equation (5.10) [59].

$$
v_{\text {avg }}=\sum\left[v_{i} \cdot\left(\text { Fraction of hours @ } v_{i}\right]\right.
$$

where $v_{i}$ wind speed

The probability of each state $P\left(G_{w}\right)$ is calculated by using (5.11) [60].

$$
P\left(G_{w}\right)=\int_{w i}^{w j} \frac{\pi v}{2 \bar{v}^{2}} e^{\left[-\frac{\pi}{4}\left(\frac{v}{\bar{v}}\right)^{2}\right]}
$$

where $w j$ and $w i$ are the state speed limit. 
The output power of the candidate wind turbine corresponding to each state is calculated. Technical information data of the candidate wind turbine and its power curve properties are used for the calculation by using equation (5.12) [60] [61].

$$
P_{\text {output }}(v)=\left\{\begin{array}{lc}
0, & 0 \leq v_{a w} \leq v_{c i} \\
p_{\text {rated }} \times \frac{\left(v_{a w}-v_{c i}\right)}{\left(v_{r}-v_{c i}\right)}, & v_{c i} \leq v_{a w} \leq v_{r} \\
p_{\text {rated }}, & v_{r} \leq v_{a w} \leq v_{c o} \\
0, & v_{c o} \leq v_{a w}
\end{array}\right.
$$

where $v_{c i}, v_{r}$ and $v_{c o}$ are the cut-in speed, rated speed and cut-off speed of the wind turbine, respectively.

The annual average power and capacity factor $(\mathrm{CF})$ of the candidate wind turbine based distributed generation are calculated using equations (5.13) and (5.14) [60].

$$
\begin{aligned}
& P_{\text {ave }}=\sum_{w} P_{\text {output }} X P\left(G_{w}\right) \\
& C F=\frac{\text { Actual energy delivered } / 8760 \mathrm{~h} / \mathrm{yr}}{\text { Prated }}=\frac{\text { Pave }}{\text { Rated power }}
\end{aligned}
$$

Sizing of the integrated wind DG is calculated by using equation (5.15).

estimated average output power of the DG unit $=$ CF.rated power of the unit

\subsubsection{Optimal Placement of (DG)}

A proper allocation of DGs units into the existing distribution system plays a crucial role in the improvement of system performance. The voltage stability index has been employed in this study to tests the voltage sensitivity to load variation (uncertainty) and determine the optimal placement of wind turbine based distributed generation. 
The voltage index presented in Ref [63] [64] has been adopted in this study and is used to determine the optimal allocation of the wind turbine based distributed generation by using equations (5.16) (5.17) [65] [66].

$$
\begin{gathered}
V_{n}=\frac{V_{\text {candidate Bus,with } D G \text { on }}}{V_{\text {candidate Bus,with } D G \text { off }}} \\
V_{\text {index }}=\frac{\sum_{n=1}^{N} V_{n} p r_{n}}{10}
\end{gathered}
$$

where

$p r_{n}$ is the probability density function that has been calculated by using equation (5.5)

The optimum location of the wind turbine based distributed generation in the existing distribution system is determined based on obtained voltage index. The voltage index with highest voltage amplitude is the optimum location and is chosen bus to integrate the wind based DG into the system network.

The impact of the DG integration into the system can be evaluated based on the following three possible scenarios

- $V_{\text {index }}<1$, DG units will make the voltage profile worse.

- $\quad V_{\text {index }}=1$, DG units will have no impact on the voltage profile.

- $V_{\text {index }}>1$, DG units will improve the voltage profile worse. 
The methodology of the proposed system with DG is illustrated by the flowchart shown in Figure

\section{4 .}



Figure 5.4: Flowchart for the proposed methodology 


\subsection{Simulation Results and Discussion}

For simulation purpose, load uncertainty and wind variability model data are used in this study. Optimum size of wind DG is obtained and integrated into the existing distribution system at AlZawea refinery. The system under study is shown in Figure 5.5. It is a typical distribution system with a peak load of 4 MVA. The main substation at bus 1 is represented as a generator with capacity of 4 MW to supply electricity to the critical loads.

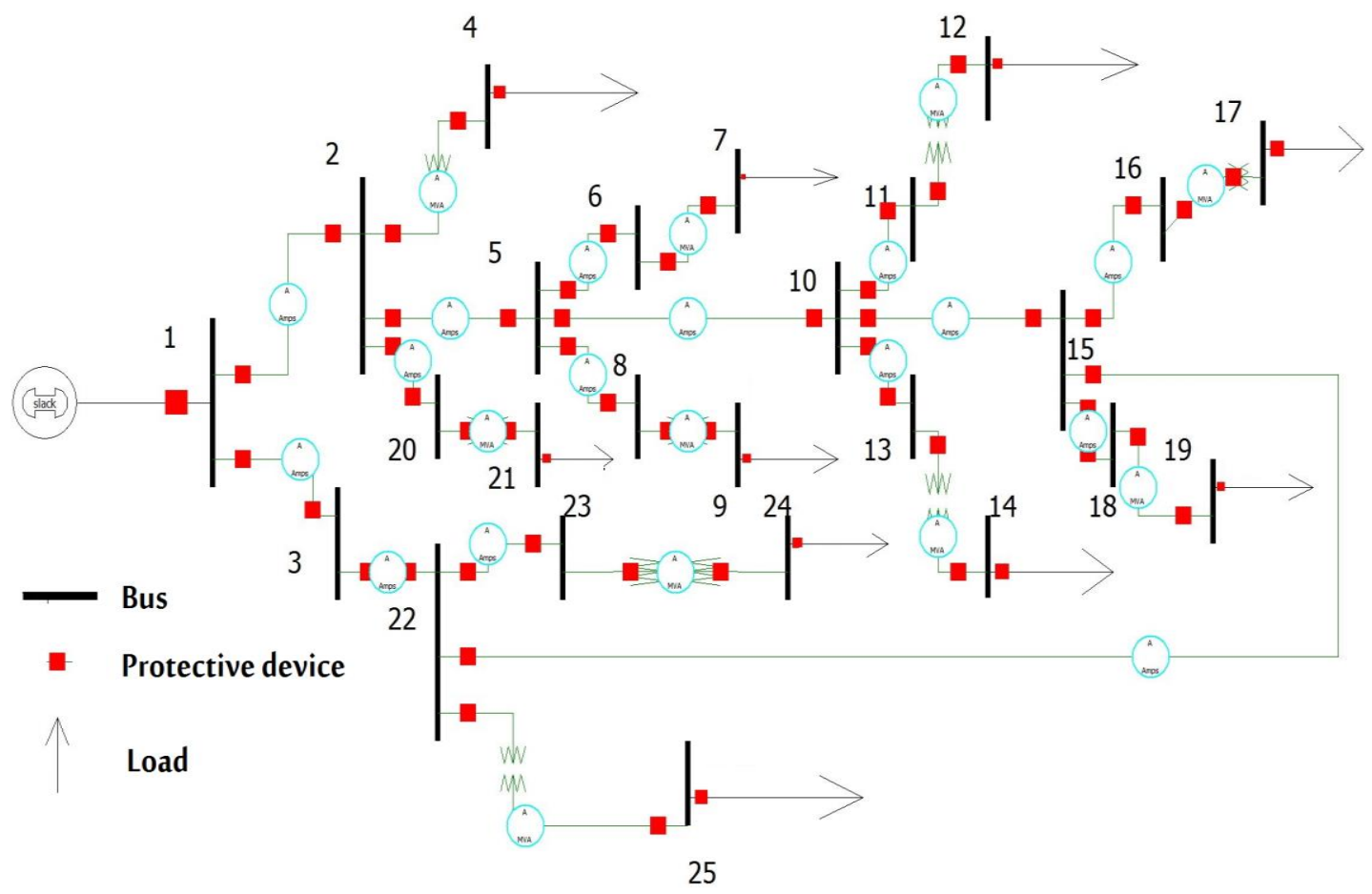

Figure 5.5: A segment of Al-Zawea refinery distribution system

Therefore, bus 1 is considered as a slack bus with a constant voltage of 1.05 per unit. Bus 4, 7, $9,12,14,17,19,21,24$ and 25 are load busses. The system has a total active power load of $4 \mathrm{MW}$ and total reactive power 1.314 MVAR. Integration of wind based DG into the existing distributed system is considered in this study. 
In order to obtain the voltage index, a probabilistic load flow that accounts for load uncertainty is

considered. The load uncertainty is modeled by placing the maximum loading conditions of 0.7

MW and 0.14 MVAR successively at every load bus as shown in Table $\mathbf{5 . 3}$ below.

Table 5.3 Load uncertainty model

\begin{tabular}{|c|c|c|c|c|c|c|c|c|c|c|}
\hline Bus & Bus4 & Bus7 & Bus9 & Bus12 & Bus14 & Bus17 & Bus19 & Bus21 & Bus24 & Bus25 \\
\hline 4 & $\begin{array}{l}0.7 \mathrm{MW} \\
0.14 \mathrm{MVar}\end{array}$ & $\begin{array}{l}0.27 \mathrm{MW} \\
0.05 \mathrm{MVar}\end{array}$ & $\begin{array}{l}0.15 \mathrm{MW} \\
0.03 \mathrm{MVar}\end{array}$ & $\begin{array}{l}0.5 \mathrm{MW} \\
0.1 \mathrm{MVar}\end{array}$ & $\begin{array}{l}0.6 \mathrm{MW} \\
0.12 \mathrm{MVar}\end{array}$ & $\begin{array}{l}0.3 \mathrm{MW} \\
0.06 \mathrm{MVar}\end{array}$ & $\begin{array}{l}0.13 \mathrm{MW} \\
0.02 \mathrm{MVar}\end{array}$ & $\begin{array}{l}\text { 0.45 MW } \\
\text { 0.09MVar }\end{array}$ & $\begin{array}{l}0.36 \mathrm{MW} \\
0.07 \mathrm{MVar}\end{array}$ & $\begin{array}{l}0.45 \mathrm{MW} \\
0.08 \mathrm{MVar}\end{array}$ \\
\hline 7 & $\begin{array}{l}0.45 \mathrm{MW} \\
0.08 \mathrm{MVar}\end{array}$ & $\begin{array}{l}0.7 \mathrm{MW} \\
0.14 \mathrm{MVar}\end{array}$ & $\begin{array}{l}0.27 \mathrm{MW} \\
0.05 \mathrm{MVar}\end{array}$ & $\begin{array}{l}0.15 \mathrm{MW} \\
0.03 \mathrm{MVar}\end{array}$ & $\begin{array}{l}0.5 \mathrm{MW} \\
0.1 \mathrm{MVar}\end{array}$ & $\begin{array}{l}0.6 \mathrm{MW} \\
0.12 \mathrm{MVar}\end{array}$ & $\begin{array}{l}0.3 \mathrm{MW} \\
0.06 \mathrm{MVar}\end{array}$ & $\begin{array}{l}0.13 \mathrm{MW} \\
0.02 \mathrm{MVar}\end{array}$ & $\begin{array}{l}0.45 \mathrm{MW} \\
0.09 \mathrm{MVar}\end{array}$ & $\begin{array}{l}0.36 \mathrm{MW} \\
0.07 \mathrm{MVar}\end{array}$ \\
\hline 9 & $\begin{array}{l}\text { 0.36MW } \\
\text { 0.07MVar }\end{array}$ & $\begin{array}{l}\text { 0.45 MW } \\
0.08 \mathrm{MVar}\end{array}$ & $\begin{array}{l}0.7 \mathrm{MW} \\
0.14 \mathrm{MVar}\end{array}$ & $\begin{array}{l}0.27 \mathrm{MW} \\
0.05 \mathrm{MVar}\end{array}$ & $\begin{array}{l}0.15 \mathrm{MW} \\
0.03 \mathrm{MVar}\end{array}$ & $\begin{array}{l}0.5 \mathrm{MW} \\
0.1 \mathrm{MVar}\end{array}$ & $\begin{array}{l}0.6 \mathrm{MW} \\
0.12 \mathrm{MVar}\end{array}$ & $\begin{array}{l}0.3 \mathrm{MW} \\
0.06 \mathrm{MVar}\end{array}$ & $\begin{array}{l}0.13 \mathrm{MW} \\
0.02 \mathrm{MVar}\end{array}$ & $\begin{array}{l}0.45 \mathrm{MW} \\
0.09 \mathrm{MVar}\end{array}$ \\
\hline 12 & $\begin{array}{l}0.45 \mathrm{MW} \\
0.09 \mathrm{MVar}\end{array}$ & $\begin{array}{l}0.36 \mathrm{MW} \\
0.07 \mathrm{MVar}\end{array}$ & $\begin{array}{l}0.45 \mathrm{MW} \\
0.08 \mathrm{MVar}\end{array}$ & $\begin{array}{l}0.7 \mathrm{MW} \\
0.14 \mathrm{MVar}\end{array}$ & $\begin{array}{l}0.27 \mathrm{MW} \\
0.05 \mathrm{MVar}\end{array}$ & $\begin{array}{l}0.15 \mathrm{MW} \\
0.03 \mathrm{MVar}\end{array}$ & $\begin{array}{l}0.5 \mathrm{MW} \\
0.1 \mathrm{MVar}\end{array}$ & $\begin{array}{l}0.6 \mathrm{MW} \\
0.12 \mathrm{MVar}\end{array}$ & $\begin{array}{l}0.3 \mathrm{MW} \\
0.06 \mathrm{MVar}\end{array}$ & $\begin{array}{l}0.13 \mathrm{MW} \\
0.02 \mathrm{MVar}\end{array}$ \\
\hline 14 & $\begin{array}{l}0.13 \mathrm{MW} \\
0.02 \mathrm{MVar}\end{array}$ & $\begin{array}{l}0.45 \mathrm{MW} \\
0.09 \mathrm{MVar}\end{array}$ & $\begin{array}{l}0.36 \mathrm{MW} \\
0.07 \mathrm{MVar}\end{array}$ & $\begin{array}{l}0.45 \mathrm{MW} \\
0.08 \mathrm{MVar}\end{array}$ & $\begin{array}{l}0.7 \mathrm{MW} \\
0.14 \mathrm{MVar}\end{array}$ & $\begin{array}{l}0.27 \mathrm{MW} \\
0.05 \mathrm{MVar}\end{array}$ & $\begin{array}{l}0.15 \mathrm{MW} \\
0.03 \mathrm{MVar}\end{array}$ & $\begin{array}{l}0.5 \mathrm{MW} \\
0.1 \mathrm{MVar}\end{array}$ & $\begin{array}{l}0.6 \mathrm{MW} \\
0.12 \mathrm{MVar}\end{array}$ & $\begin{array}{l}0.3 \mathrm{MW} \\
0.06 \mathrm{MVar}\end{array}$ \\
\hline 17 & $\begin{array}{l}0.3 \mathrm{MW} \\
0.06 \mathrm{MVar}\end{array}$ & $\begin{array}{l}0.13 \mathrm{MW} \\
0.02 \mathrm{MVar}\end{array}$ & $\begin{array}{l}0.45 \mathrm{MW} \\
0.09 \mathrm{MVar}\end{array}$ & $\begin{array}{l}0.36 \mathrm{MW} \\
0.07 \mathrm{MVar}\end{array}$ & $\begin{array}{l}0.45 \mathrm{MW} \\
0.08 \mathrm{MVar}\end{array}$ & $\begin{array}{l}0.7 \mathrm{MW} \\
0.14 \mathrm{MVar}\end{array}$ & $\begin{array}{l}0.27 \mathrm{MW} \\
0.05 \mathrm{MVar}\end{array}$ & $\begin{array}{l}0.15 \mathrm{MW} \\
0.03 \mathrm{MVar}\end{array}$ & $\begin{array}{l}0.5 \mathrm{MW} \\
0.1 \mathrm{MVar}\end{array}$ & $\begin{array}{l}0.6 \mathrm{MW} \\
0.12 \mathrm{MVar}\end{array}$ \\
\hline 19 & $\begin{array}{l}0.6 \mathrm{MW} \\
0.12 \mathrm{MVar}\end{array}$ & $\begin{array}{l}0.3 \mathrm{MW} \\
0.06 \mathrm{MVar}\end{array}$ & $\begin{array}{l}0.13 \mathrm{MW} \\
0.02 \mathrm{MVar}\end{array}$ & $\begin{array}{l}0.45 \mathrm{MW} \\
\text { 0.09MVar }\end{array}$ & $\begin{array}{l}\text { 0.36MW } \\
\text { 0.07MVar }\end{array}$ & $\begin{array}{l}0.45 \mathrm{MW} \\
0.08 \mathrm{MVar}\end{array}$ & $\begin{array}{l}0.7 \mathrm{MW} \\
0.14 \mathrm{MVar}\end{array}$ & $\begin{array}{l}\text { 0.27MW } \\
0.05 \mathrm{MVar}\end{array}$ & $\begin{array}{l}0.15 \mathrm{MW} \\
0.03 \mathrm{MVar}\end{array}$ & $\begin{array}{l}0.5 \mathrm{MW} \\
0.1 \mathrm{MVar}\end{array}$ \\
\hline 21 & $\begin{array}{l}0.5 \mathrm{MW} \\
0.1 \mathrm{MVar}\end{array}$ & $\begin{array}{l}0.6 \mathrm{MW} \\
0.12 \mathrm{MVar}\end{array}$ & $\begin{array}{l}0.3 \mathrm{MW} \\
0.06 \mathrm{MVar}\end{array}$ & $\begin{array}{l}0.13 \mathrm{MW} \\
0.02 \mathrm{MVar}\end{array}$ & $\begin{array}{l}0.45 \mathrm{MW} \\
0.09 \mathrm{MVar}\end{array}$ & $\begin{array}{l}0.36 \mathrm{MW} \\
0.07 \mathrm{MVar}\end{array}$ & $\begin{array}{l}0.45 \mathrm{MW} \\
0.08 \mathrm{MVar}\end{array}$ & $\begin{array}{l}0.7 \mathrm{MW} \\
0.14 \mathrm{MVar}\end{array}$ & $\begin{array}{l}0.27 \mathrm{MW} \\
0.05 \mathrm{MVar}\end{array}$ & $\begin{array}{l}0.15 \mathrm{MW} \\
0.03 \mathrm{MVar}\end{array}$ \\
\hline 24 & $\begin{array}{l}0.15 \mathrm{MW} \\
0.03 \mathrm{MVar}\end{array}$ & $\begin{array}{l}0.5 \mathrm{MW} \\
0.1 \mathrm{MVar}\end{array}$ & $\begin{array}{l}0.6 \mathrm{MW} \\
0.12 \mathrm{MVar}\end{array}$ & $\begin{array}{l}0.3 \mathrm{MW} \\
0.06 \mathrm{MVar}\end{array}$ & $\begin{array}{l}0.13 \mathrm{MW} \\
0.02 \mathrm{MVar}\end{array}$ & $\begin{array}{l}0.45 \mathrm{MW} \\
0.09 \mathrm{MVar}\end{array}$ & $\begin{array}{l}0.36 \mathrm{MW} \\
0.07 \mathrm{MVar}\end{array}$ & $\begin{array}{l}0.45 \mathrm{MW} \\
0.08 \mathrm{MVar}\end{array}$ & $\begin{array}{l}0.7 \mathrm{MW} \\
0.14 \mathrm{MVar}\end{array}$ & $\begin{array}{l}0.27 \mathrm{MW} \\
0.05 \mathrm{MVar}\end{array}$ \\
\hline 25 & $\begin{array}{l}0.27 \mathrm{MW} \\
0.05 \mathrm{MVar}\end{array}$ & $\begin{array}{l}0.15 \mathrm{MW} \\
0.03 \mathrm{MVar}\end{array}$ & $\begin{array}{l}0.5 \mathrm{MW} \\
0.1 \mathrm{MVar}\end{array}$ & $\begin{array}{l}0.6 \mathrm{MW} \\
0.12 \mathrm{MVar}\end{array}$ & $\begin{array}{l}0.3 \mathrm{MW} \\
0.06 \mathrm{MVar}\end{array}$ & $\begin{array}{l}0.13 \mathrm{MW} \\
0.02 \mathrm{MVar}\end{array}$ & $\begin{array}{l}0.45 \mathrm{MW} \\
0.09 \mathrm{MVar}\end{array}$ & $\begin{array}{l}0.36 \mathrm{MW} \\
0.07 \mathrm{MVar}\end{array}$ & $\begin{array}{l}0.45 \mathrm{MW} \\
0.08 \mathrm{MVar}\end{array}$ & $\begin{array}{l}0.7 \mathrm{MW} \\
0.14 \mathrm{MVar}\end{array}$ \\
\hline
\end{tabular}

The DG integration is demonstrated as follows.

\subsubsection{Wind Speed Modeling}

Since the wind speed is highly variable data over one year is desirable to describe wind energy potential of the site. The hourly wind speed data have been measured and modelled by using Weibull pdf considering a shape ( $\beta$ ) parameter with values of 1,2 and 3 and found that, Weibull fit well the wind speed data when $\beta$ is equal to 2. The plots in the Figure 5.6 illustrate Weibull pdfs and the histogram of the hourly wind speed data.

For the sake of simplicity, only one type of wind turbines is assumed available. GE 1.5 MW wind turbine is chosen for this study and its data are given as follows:

- Cut-in wind peed $3.5 \mathrm{~m} / \mathrm{s}$

- Cut-out wind speed $25 \mathrm{~m} / \mathrm{s}$

- Rated wind speed 14 m/s 

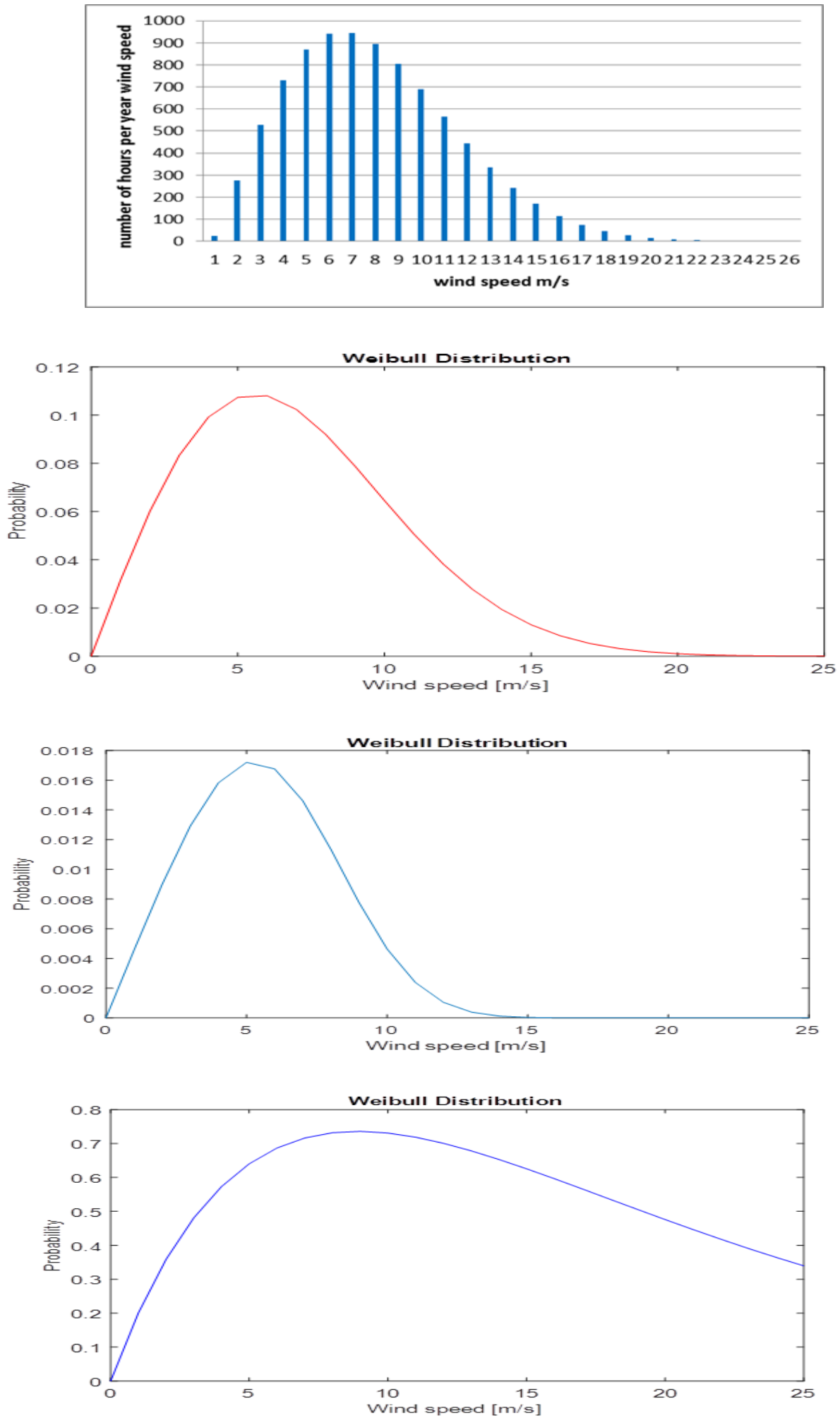

Figure 5.6 Wind speed data and its Weibull pdf with shape parameters $\beta=1,2$ and 3 
In order to calculate the capacity factor, the probabilistic description of the wind output power model is generated by using candidate wind turbine technical data. The capacity factor is calculated by using (5.12), (5.13) and (5.14), and found to be $0.32 \%$. Wind speed and wind power probabilities are shown in Table 5.4.

Table 5.4: Wind speed and power probabilities for each state

\begin{tabular}{|c|c|c|c|}
\hline Wind Speed Limit & Hours/Year & Probability & $P\left(G_{w}\right)$ \\
\hline $0-4$ & 1804 & 0.205936 & 0 \\
\hline $4-5$ & 579 & 0.066096 & 0.1045 \\
\hline $5-6$ & 984 & 0.112329 & 0.1089 \\
\hline $6-7$ & 908 & 0.103653 & 0.1063 \\
\hline $7-8$ & 983 & 0.112215 & 0.0982 \\
\hline $8-9$ & 799 & 0.09121 & 0.0863 \\
\hline $9-10$ & 677 & 0.077283 & 0.0724 \\
\hline $10-11$ & 439 & 0.050114 & 0.0582 \\
\hline $11-12$ & 395 & 0.045091 & 0.0449 \\
\hline $12-13$ & 286 & 0.032648 & 0.0333 \\
\hline $13-14$ & 219 & 0.025 & 0.0238 \\
\hline $14-25$ & 687 & 0.078425 & 0 \\
\hline
\end{tabular}

The capacity factor indicated that, capacity of $3 \mathrm{MW}$ based wind DG is needed to be integrated into the existing distribution at the refinery to ensure the sufficient load demand. The number of the required wind units are determined by using equation (5.15), and found to be two units with the capacity of $1.5 \mathrm{MW}$ each. 


\subsubsection{Optimal Placement of (DG)}

In order to investigate the optimal placement of DG, voltage index is calculated at every bus considering load uncertainty conditions. The best location of DG will give a highest voltage index.

The voltage index parameters are obtained by using (5.16) (5.17) and presented in the Table 5.5.

The variation of voltage index with respect to DG location is shown in Figure 5.7. The voltage index has been calculated for optimal allocation of DG.

Table 5.5: the voltage index values when DGs are installed at load buses

\begin{tabular}{|c|c|c|c|c|c|c|c|c|c|c|c|}
\hline Bus nu & $\mathrm{V}_{1}$ & $\mathrm{~V}_{2}$ & $\mathrm{~V}_{3}$ & $\mathrm{~V}_{4}$ & $\mathrm{~V}_{5}$ & $\mathrm{~V}_{6}$ & $\mathrm{~V}_{7}$ & $\mathrm{~V}_{8}$ & $\mathrm{~V}_{9}$ & $\mathrm{~V}_{10}$ & $\mathrm{~V}_{\text {index }}$ \\
\hline 4 & 0.9573 & 0.9428 & 0.9697 & 0.9846 & 0.9881 & 0.9775 & 0.9748 & 0.9789 & 0.9844 & 0.9743 & 1.5265 \\
\hline 7 & 0.9712 & 0.9835 & 0.9845 & 0.9864 & 0.9883 & 0.9870 & 0.9849 & 0.9884 & 0.9898 & 0.9849 & 1.5136 \\
\hline 9 & 0.8818 & 0.8765 & 0.9131 & 0.9198 & 0.9313 & 0.9371 & 0.9192 & 0.9480 & 0.9527 & 0.9197 & 1.5818 \\
\hline 12 & 0.8726 & 0.8658 & 0.8877 & 0.9346 & 0.9493 & 0.9029 & 0.8970 & 0.9063 & 0.9259 & 0.8972 & 1.6300 \\
\hline 14 & 0.7582 & 0.7498 & 0.7776 & 0.8297 & 0.9523 & 0.7980 & 0.7909 & 0.8041 & 0.8326 & 0.7917 & 1.6665 \\
\hline 17 & 0.8303 & 0.8236 & 0.8612 & 0.8767 & 0.8923 & 0.9174 & 0.8683 & 0.9014 & 0.9126 & 0.8688 & 1.6266 \\
\hline 19 & 0.8243 & 0.8172 & 0.8519 & 0.8761 & 0.8987 & 0.8777 & 0.9299 & 0.8902 & 0.9117 & 0.8661 & 1.6134 \\
\hline 21 & 0.7988 & 0.7915 & 0.8337 & 0.8471 & 0.8645 & 0.8642 & 0.8422 & 0.9068 & 0.9095 & 0.8517 & 1.6705 \\
\hline 24 & 0.7055 & 0.6961 & 0.7410 & 0.7701 & 0.7961 & 0.7739 & 0.7583 & 0.8056 & 0.9237 & 0.8185 & 1.7240 \\
\hline 25 & 0.6166 & 0.6054 & 0.6585 & 0.6920 & 0.7214 & 0.6964 & 0.6785 & 0.7322 & 0.8622 & 0.9136 & 1.6284 \\
\hline
\end{tabular}


It is clear that in the case of DG installed in the bus 24 , it gives the highest voltage index value.

This is indicating that bus 24 is the optimum location to install DG.

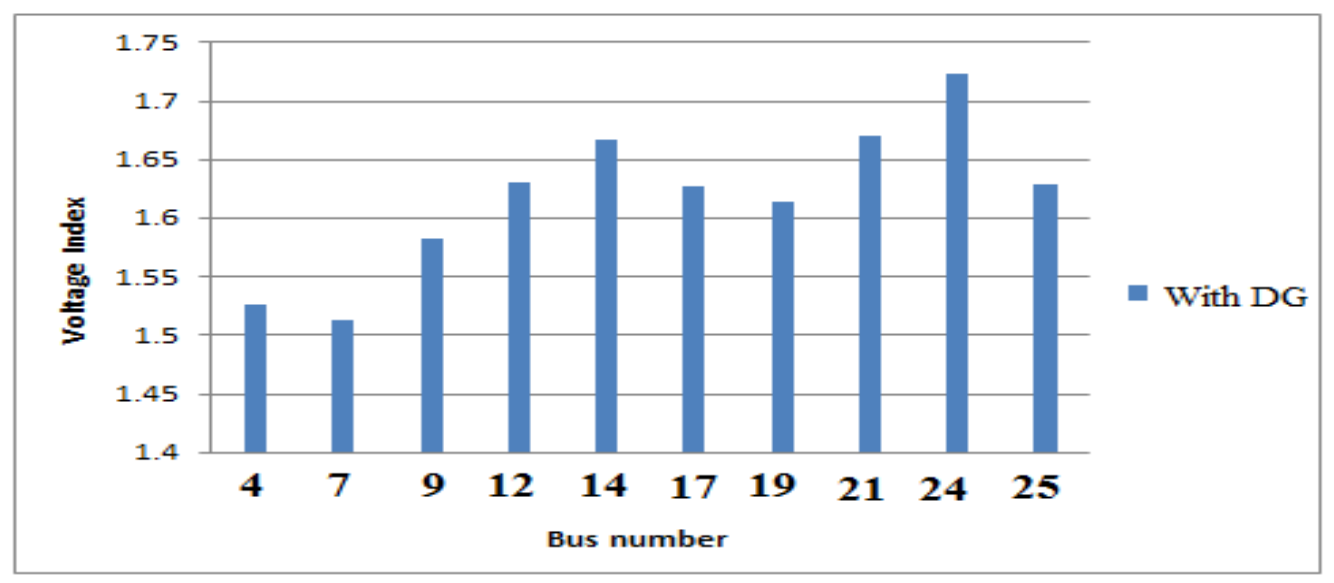

Figure 5.7: variation of voltage index when DG are installed at load buses

\subsubsection{The Steady State System Performance after DG Installation}

A modified system with DG units installed on bus 24 considering the optimum location with DG sizing of $3 \mathrm{MW}$ and a new transmission lines is simulated.

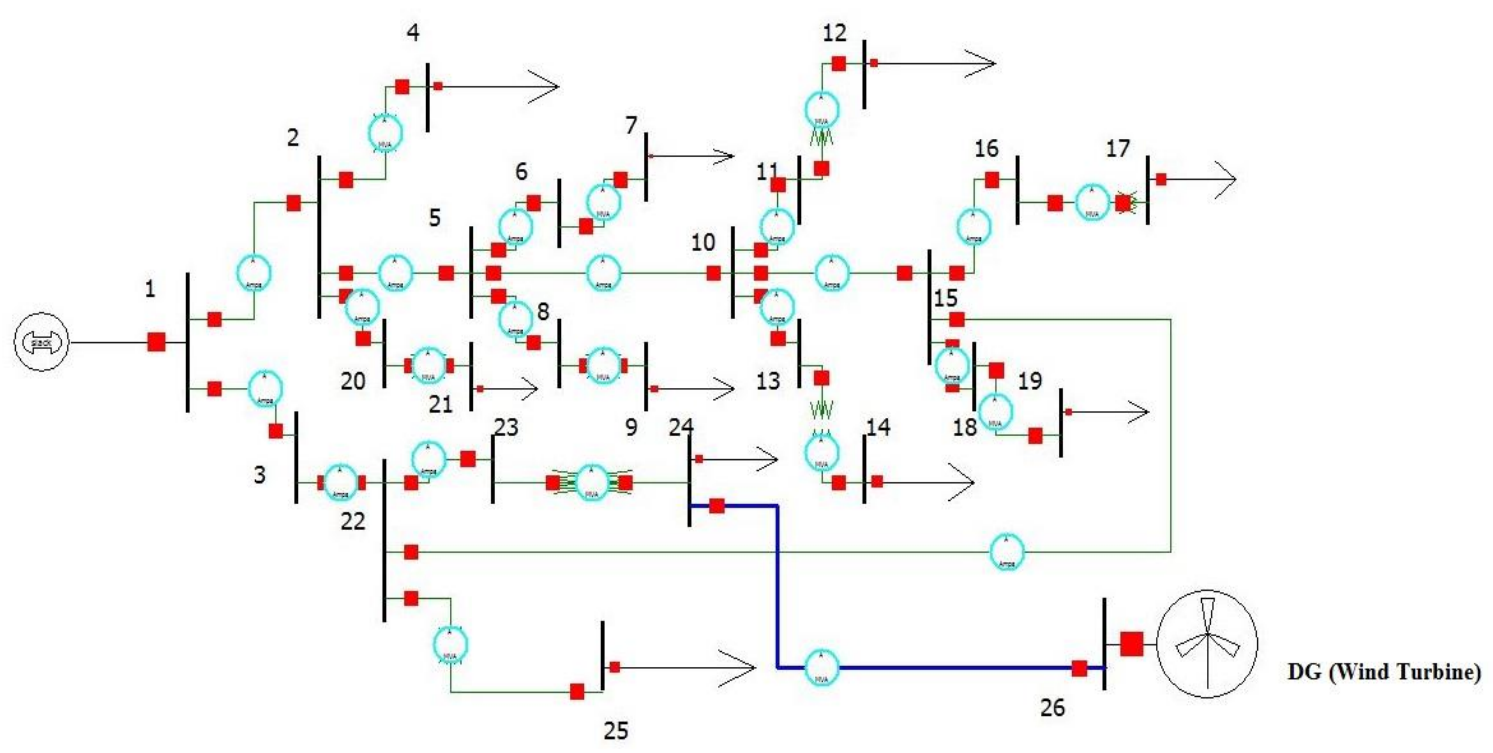

Figure 5.8: Modified Systems with DG 
PowerWorld and Matlab have been used for simulation purpose as shown in Figure 5.8.Load flow analysis has applied by using Newton Raphson method considering uncertainty load conditions. The load flow results obtained after the simulation in the extreme cases (load imbalance) are illustrated in the plots of the Figure 5.9. Moreover, they are listed in the Appendices. The results prove the efficiency of the methodology that proposed in this study. Also the system becomes stable if the DG is installed at the location defend in this study
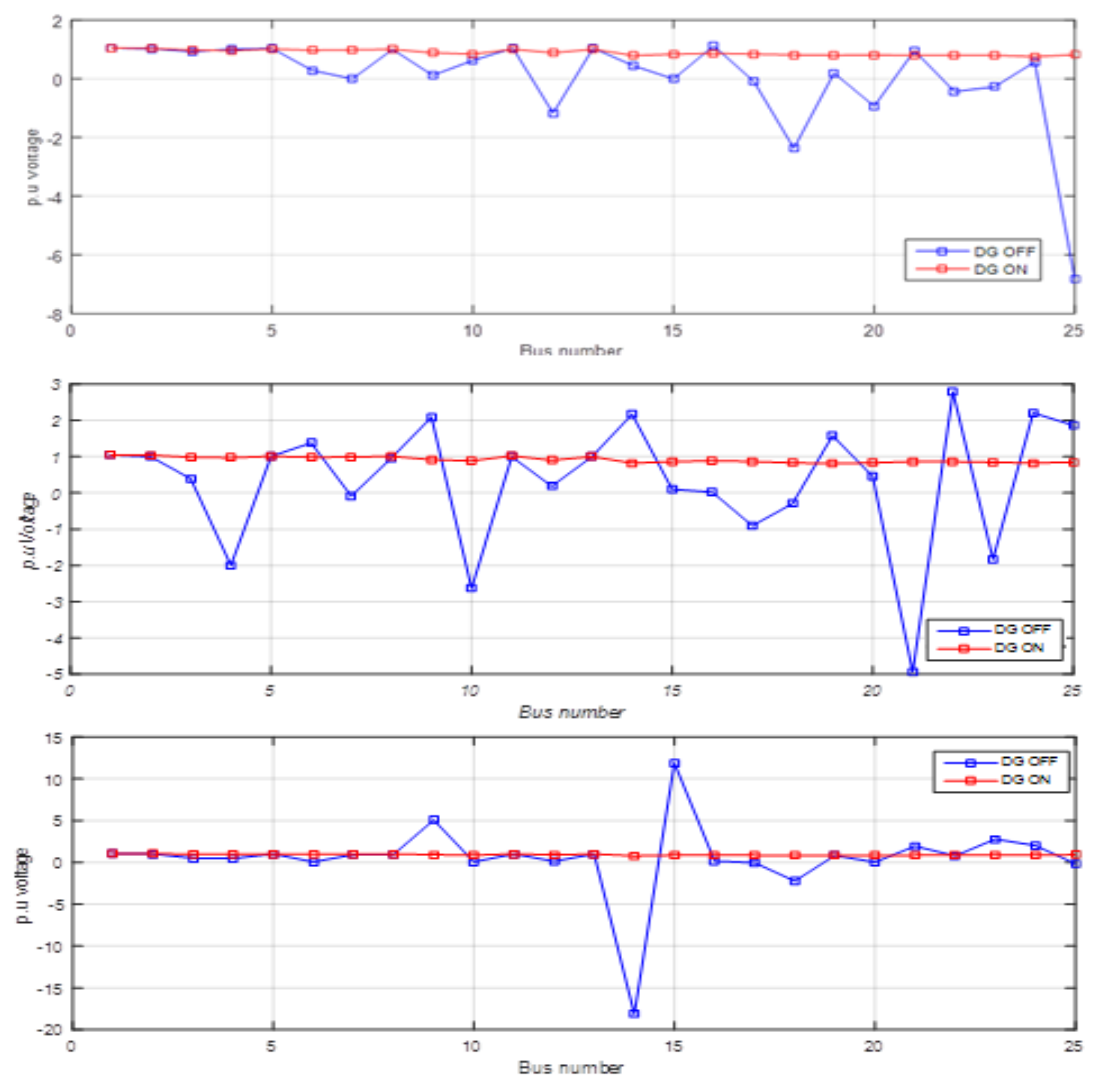

Figure 5.9: p.u voltage at all buses with DG integrated in the system

The variation of the voltages for uncertainty load scenarios $1,2 \ldots 10$ are clearly shown in the plots of Figures: (5.10), (5.11) ... (5.20). It can be seen that, the voltage levels at all load buses has increased, these buses are saving critical loads; such situations could prove far worse especially during peak load conditions. In such scenarios, power is effectively re-routed (DG ON) without causing an outage of the critical loads and at the same time, improving the voltage profile at all 
buses. It is worth mentioning that wind based DG has improved the voltage profile and mitigated the voltage collapse possibility.

\section{Scenario 1}

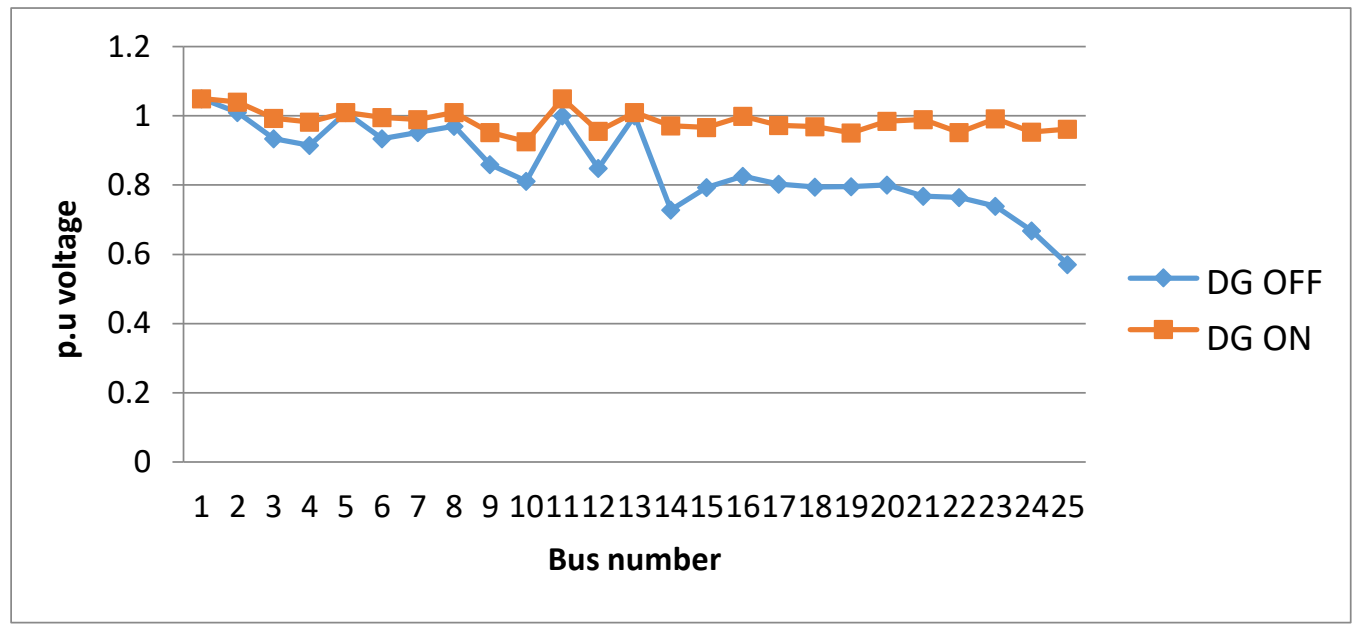

Figure 5.10: p.u. voltage at all buses when DG is $\mathrm{ON}$ and $\mathrm{DG}$ is off

\section{Scenario 2}

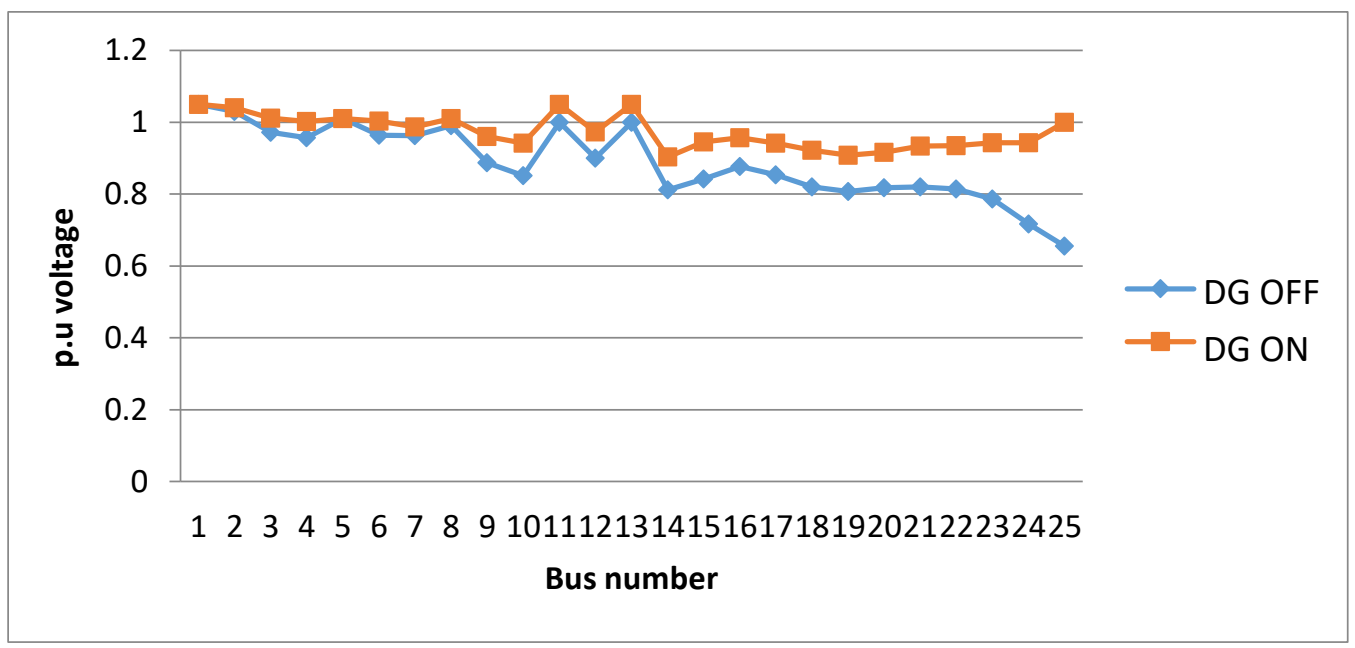

Figure 5.11: p.u. voltage at all buses when DG is ON and DG is off 


\section{Scenario 3}

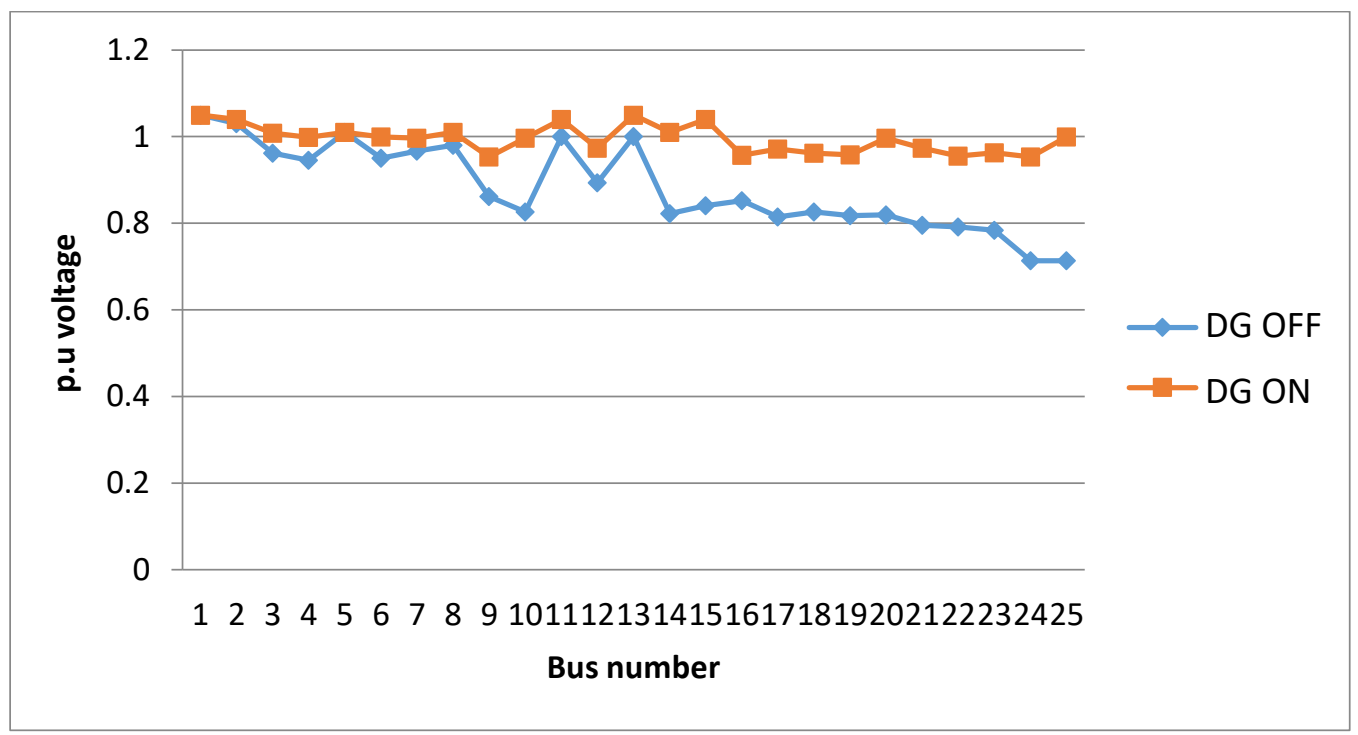

Figure 5.12: p.u. voltage at all buses when DG is ON and DG is off

\section{Scenario 4}

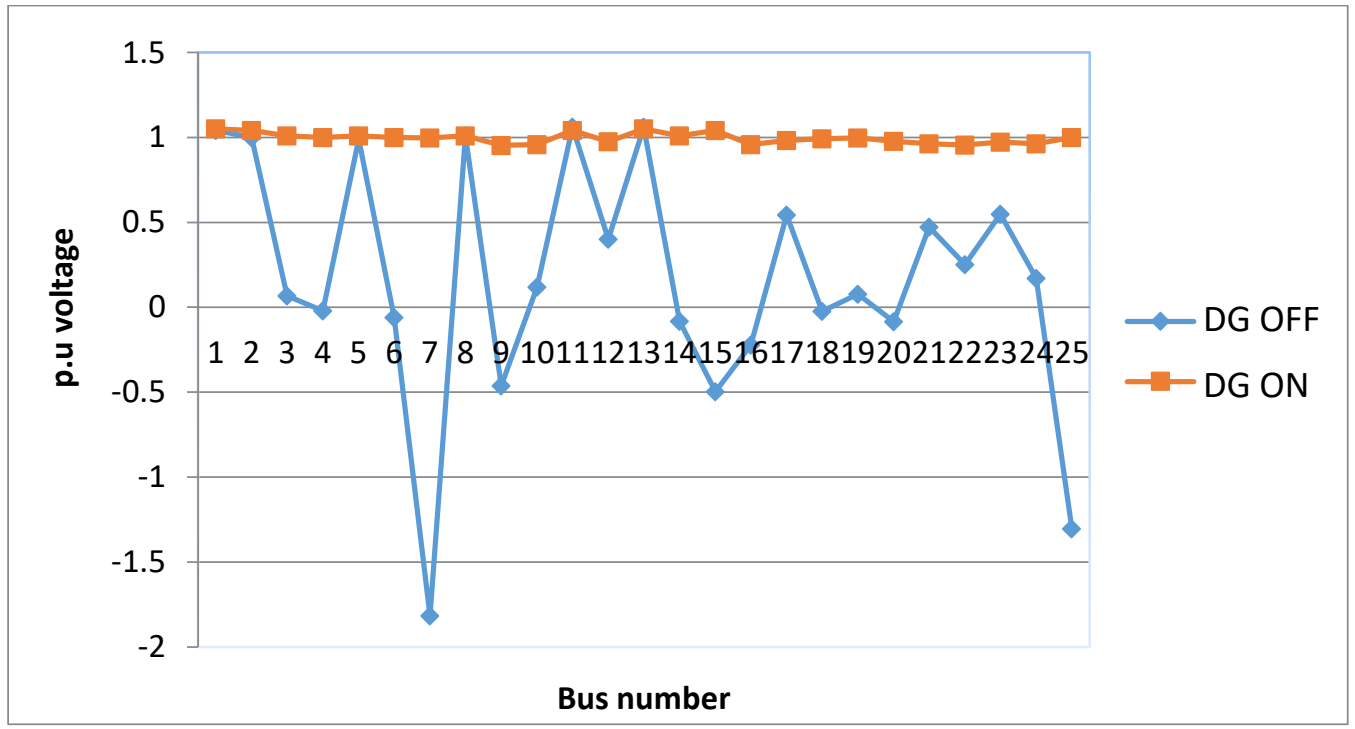

Figure 5.13: p.u. voltage at all buses when $D G$ is $O N$ and $D G$ is off 


\section{Scenario 5}

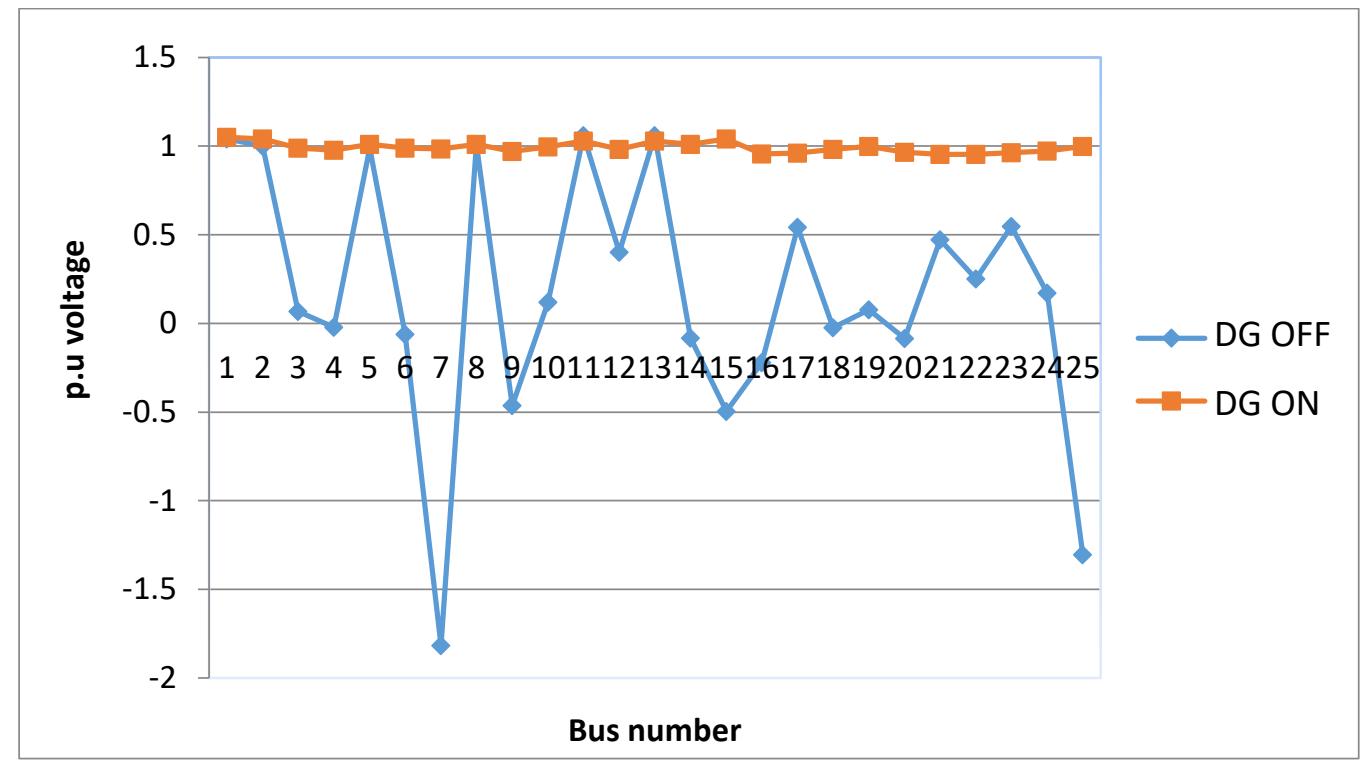

Figure 5.14: p.u. voltage at all buses when $D G$ is $O N$ and DG is off

\section{Scenario 6}

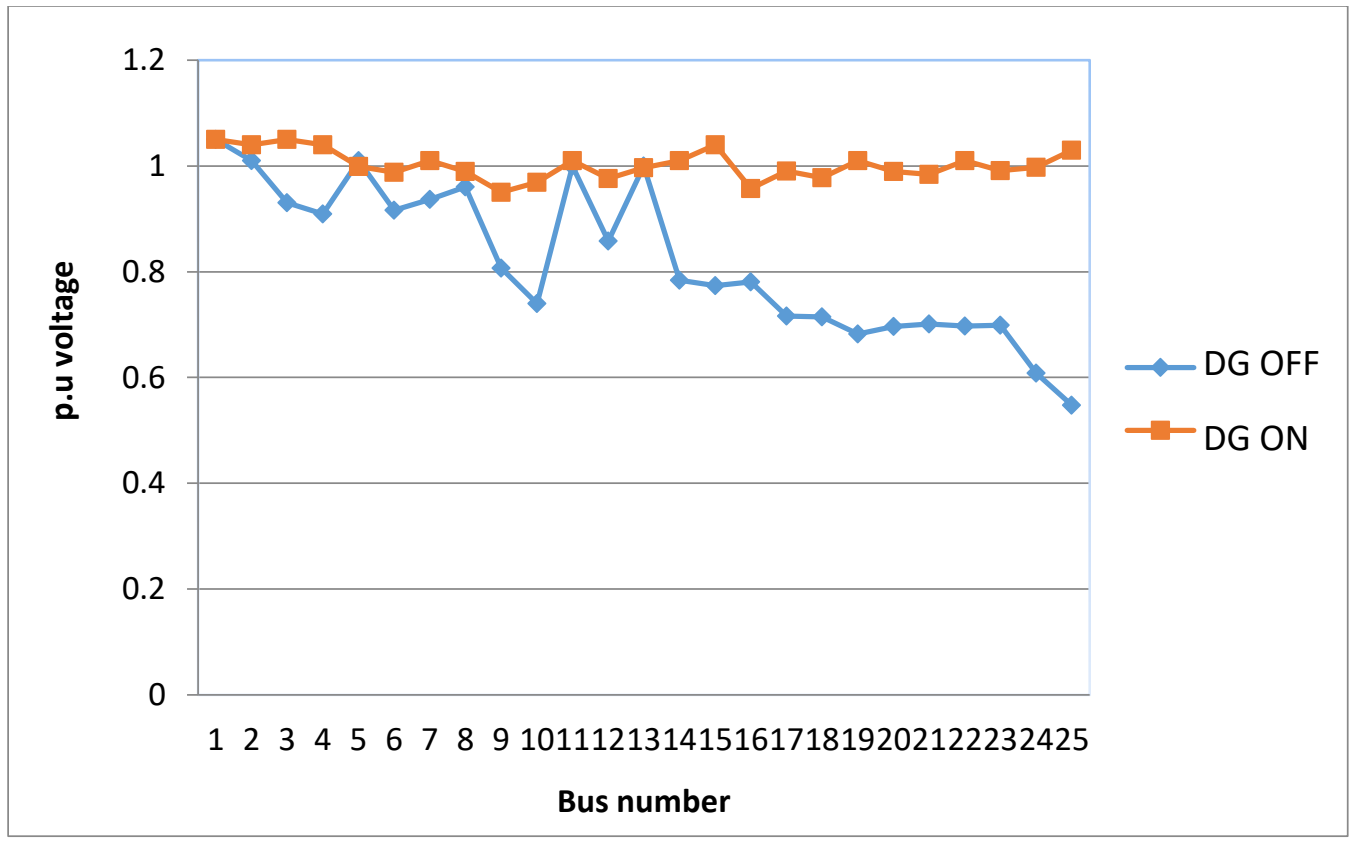

Figure 5.15: p.u. voltage at all buses when DG is ON and DG is off 


\section{Scenario 7}

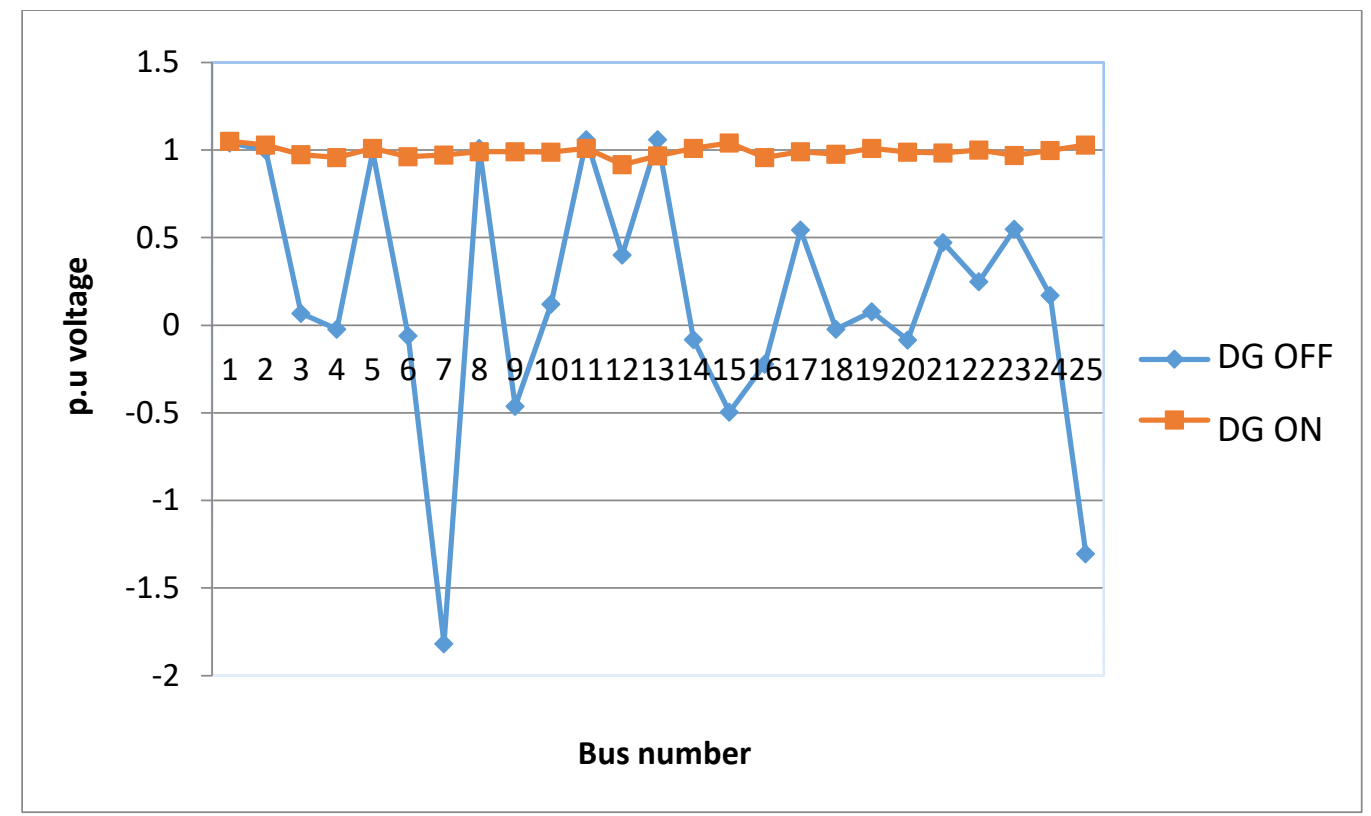

Figure 5.16: p.u. voltage at all buses when DG is $O N$ and DG is off

\section{Scenario 8}

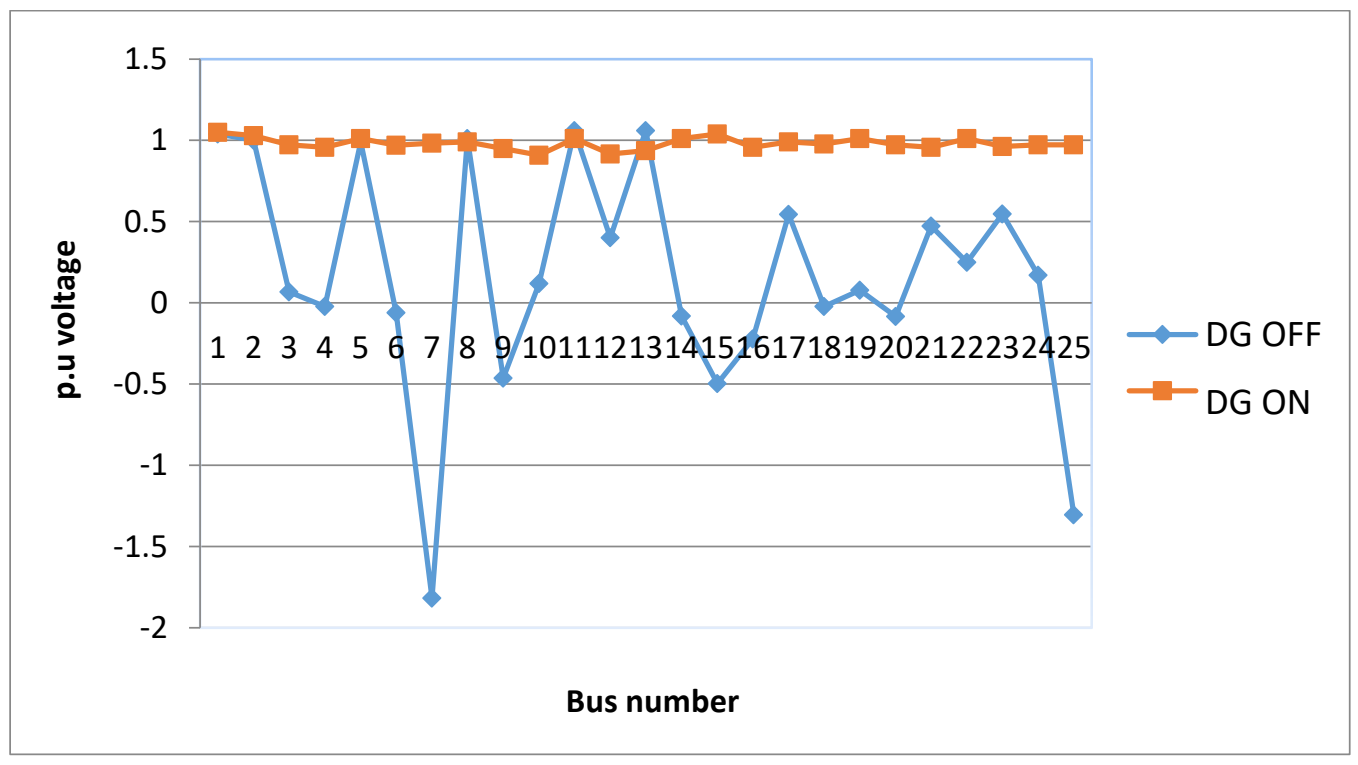

Figure 5.17: p.u. voltage at all buses when DG is ON and DG is off 


\section{Scenario 9}

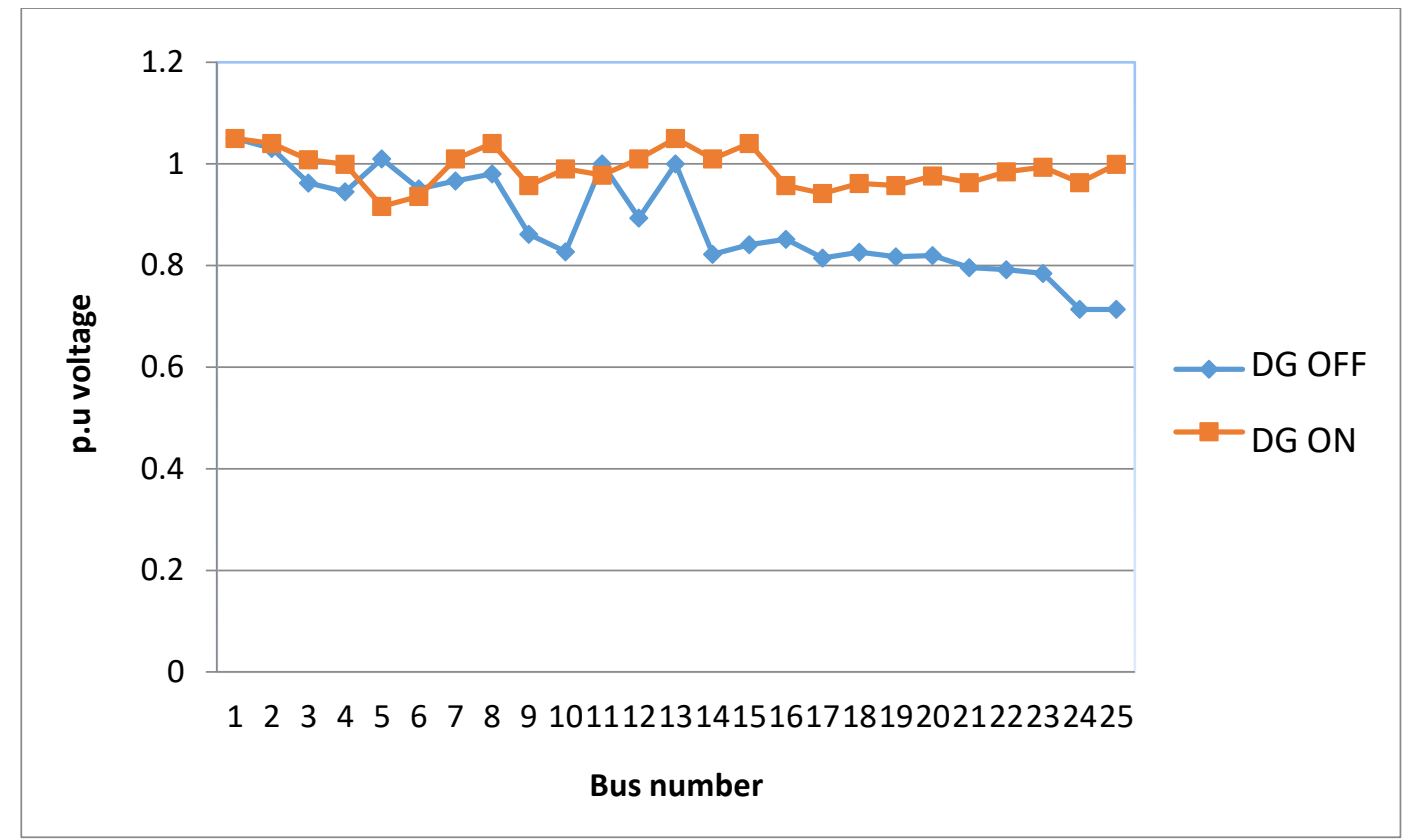

Figure 5.18: p.u. voltage at all buses when DG is $\mathrm{ON}$ and $\mathrm{DG}$ is off

\section{Scenario 10}

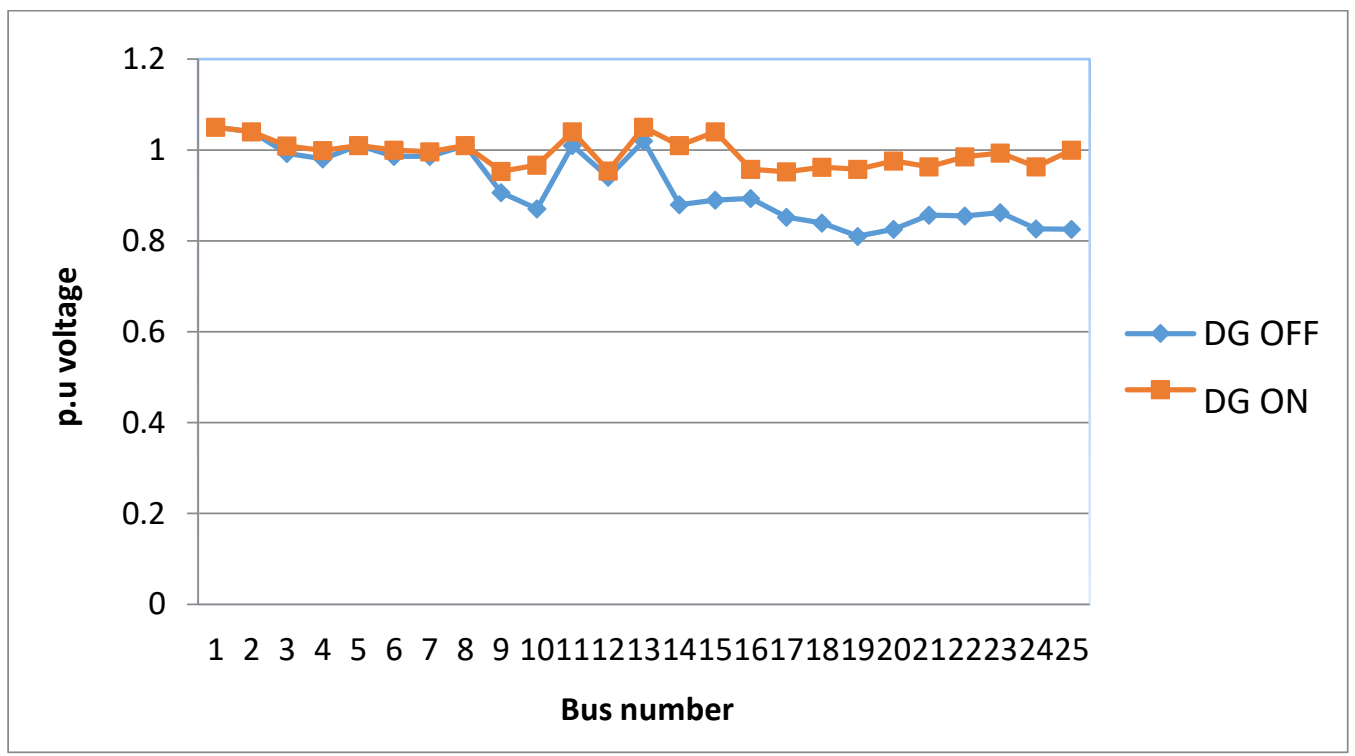

Figure 5.19: p.u. voltage at all buses when DG is ON and DG is off 


\section{CHAPTER VI}

\section{CONCLUDING REMARKS AND FUTURE WORK}

\subsection{Summary}

Al-Zawea refinery power system needs to modernize from traditional configuration to a decentralized smart system to mitigate the serious power supply issues facing it. Simulation results have highlighted the advantages of integrating distributed generation with the existing distribution power system at the refinery. Implementing wind based DG in the existing power system at AlZawea refinery would benefit the refinery in many ways - reliability, availability, efficiency, and environmental benefit for overall refinery operations. In this study DG system is implemented with renewable energy sources represented by wind turbines with limit capacity of $3 \mathrm{MW}$ to ensure a cleaner environment by reducing $\mathrm{CO}_{2}$ emission. The results are presented four basic parts:

- Investigation of power fluctuations (unbalanced load) and voltage collapse.

- Wind speed modeling and analysis.

- Upgraded system with DG integration and the resulting voltage stability.

- Contributions of this study and suggestions for future work.

The system has experienced power fluctuation, blackouts and imbalanced loads. Analysis of load data indicated that the fluctuations always occur during peak times due to load imbalance, leading to voltage collapse and gas turbine trips two to three times a year. 
In this study, wind and load modelling are discussed. A probabilistic method of wind based DG allocation under load uncertainty conditions is proposed. This study also considered optimal placement and sizing of distributed generation to maintain system imbalance. The main aims of DG integration at Al-Zawea refinery power system are to keep the load in balance, improve voltage profile and overall system operation, and enhance system reliability and power quality. Random behaviour of the wind speed was modelled using Ralyeigh distribution. Analysis of wind speed data indicated that wind energy conversation systems can have a good capacity factor for use as DG.

Integration of DG will improve the overall system in terms operation, efficiency and reliability. DG integration results in a good voltage profile to maintain load balance and system stability. .

\subsubsection{Contributions of this Work}

- Analysis of the site's wind speed data indicated that wind-based DG can provide sufficient power to the Al-Zawea refinery and also to the city in Libya.

- The proposed system guarantees no voltage collapse under any load conditions. It was found that, the voltage profile of all buses in the system during extreme scenario stays within acceptable limits.

- The proposed approach guarantees optimum allocation of the DG units under all possible operating conditions.

\subsection{Future Work}

The approach developed to assets the benefits of DG unit wind-electric system can be expanded to include photovoltaic and other forms of DG. Advantage gained by exploring both wind and solar system together could be studied in detailed. 
Economic aspects of employing DG should be studied in depth. This should include a cost benefit analysis under different scenarios over the lifetimes of DG units with credit given to environmental benefits of using renewable energy resources.

In addition to voltage profile improvement and avoidance of blackouts, several other benefits would result in a smart-grid scenario. This would include economic dispatch, Var support, power quality improvement and others. 


\section{REFERENCES}

[1] Turan Gonen, Electric Power Distribution System Engineering, 2008, pp.1.

[2] U.S Department of Energy. "An Introduction to Smart Grid", 2009.

[3] Global Environment fund, "Electric Power Grid", 2005..

[4] Asko Vuorinen world electricity in the year 2050, 2008.

[5] J. Jardim, C. Neto, and M. G. dos Santos, "Brazilian system operator online security assessment system," in Power Systems Conference and Exposition, 2006, pp. 7-12.

[6] Rohit Nair, R. Ramakumar, "A PROPOSED SYSTEM FOR A SMART GRID IMPLEMETATION AT OKLAHOMA STATE UNIVERSITY” 2009, MSc., Thesis, ECE dept. ,Oklahoma State University, 2009.

[7] Lars T Berger and Krzysztof Iniewski "Smart Grid Application, Communications, and Security“ 2012 PP 3,4.

[8] Zhang W.L., Liu Z.Z., Wang M.J., and Yang X.S., Research status and development trend of smart grid. Power system technology, vol. 33, no. 13, pp. 1-11, 2009.

[9] Massoud Amin, John Stringer, The electric Power Grid: Today and Tomorrow, Volume 33 Harnessing Materials for Energy, 2008

[10] V. C. Gungor, B. Lu, and G. P. Hancke, "Opportunities and challenges of wireless sensor networks in smart grid," IEEE Trans. Ind. Electron., vol. 57, no. 10, pp. 3557-3564, Oct. 2010.

[11] U.S. Department of Energy, 2011. [Online]. Available: http://www.oe.energy.gov.

[12] U.S Department of Energy. "An Introduction to Smart Grid", 2009,http://www.gegridsolutions.com/smartgrid_generation.htm.

[13] A. Gawedar, R.Ramakumar, "Opportunities for Smart Grid Implementation for the AlZawea Refinery In Libya" 46th Annual Frontiers of Power Conference October, 2013 Conoco/Phillips OSU Alumni Center.

[14] Zhang W.L., Liu Z.Z., Wang M.J., and Yang X.S., Research status and development trend of smart grid. Power system technology, vol. 33, no. 13, pp. 1-11, 2009 IEEE. 
[15] Text of the "Energy Independence and Security Act of 2007 (EISA)"- H.R. 6-Decemper $19,2007$.

[16] A. Gawedar, R. Ramakumar "Prospects for Upgrading the Power Supply to the Al-Zawea Refinery in Libya" 47th Annual Frontiers of Power Conference, October 27-28, 2014 Conoco/Phillips OSU Alumni Center.

[17] Wolfs, P.; Isalm, S.; , "Potential barriers to smart grid technology in Australia,"Power Engineering Conference, 2009. AUPEC 2009. Australasian Universities , vol.,no., pp.1-6, 27-30 Sept. 2009

[18] Chouhan, Nishant S; Ferdowsi, Mehdi; , "Review of energy storage systems," North American Power Symposium (NAPS), 2009, vol, no, pp.1-5, 4-6 Oct.2009 doi:101109/NAPS.2009.5484062.

[19] P.J. Binduhewa, A.C. Renfrew, and M. Barnes,'Ultracapacitor Energy Storage for MicroGrid MicroGrid micro-generation,'IET Power Electronics, Machines and Drivers, Conf 2008,pp.270-274.

[20] J.D. Boyes, and N.H.Clark," Technologies for energy storage, flywheels and super conducting magnetic energy storage, "Power Engineering Society Summer Meeting,IEEE,2000.

[21] Robin Roche ; Elias Kyriakides ; Sid Suryanarayanan ; Benjamin Blunier ; Kerry D. McBee ; Phuong H. Nguyen ; Paulo F. Ribeiro ; Abdellatif Miraoui, “A Comparison of Smart Grid Technologies and Progresses in Europe and the U.S" IEEE Transactions on Industry Applications, July 2012.

[22] Lovins, A., Datta, K. and T. Feiler, A. Lehmann, K. Rabago, J. Swisher, K. Wicker, 2002. Small is Profitable: The Hidden Economic Benefits of Making Electrical Resources the Right Size. Rocky Mountain Institute, Snowmass, Colorado.

[23] L.P.Allfather,"impedance measuring," U.S. Patent 5818245,issued on October 6,1998.

[24] B. Bachmann, D.G. Hart, Y. Hu, D. Novosel, and M.M. Saha,'Impedence measurement system for power system transmission lines,” U.S. Patent 6397156, issued on may 28,2002.

[25] Zhenhua Jiang, Fangxing Li, “A vision of smart transmission grids” 2009 IEEE Power \& Energy Society General Meeting.

[26] Lars T. Berger, Krzysztof,” Smart Grid Application, Communications and Security” 2012

[27] Roy Hoffman, “ Applying Smart Grid Technology for Reducing Electric Energy Consumption”, SNC-Lavalin Energy Control System, Montreal, Canada.

[28] Araree Jirapornanan, "Study of Smart Grid for Thailand and Identification of the required research and development", IEEE,2010. 
[29] A.Atputharajah and T. K. Saha, "Power system blackouts-literature review," Proceeding of Industrial and Information System (ICIIS), 2009, pp.460-465.

[30] Nouri Daw, R.Ramakumar “ A STUDY OF THE PENETRATION OF WIND GENERATED ELECTRICAL ENERGY INTO THE LIBYAN POWER SYSTEM" Ph.D., dissertation, ECE dept. ,Oklahoma State University, 2011.

[31] Energy Information Administration (EIA) (2009b) Libya energy profile. Energy Data Series US, Energy Information Administration, viewed September 2010, online (www.eia.doe.gov).

[32] National Company, information department, operation engineering, summer 2013, Libya.

[33] Energy Information Administration (EIA) (2009a) Libya energy data, statistics and analysis- oil, gas, electricity, coal. Country Analysis Briefs. U.S, Energy Information Administration, viewed September 2010, online (www.eia.doe.gov).

[34] I. M. Saleh ibrahim, the forth Arab international Solar Energy Confrence, Amman, Jordan 1993.

[35] M. Saleh Ibrahim, Photovoltaic in Libya Applications, and Evaluation, General Electrical Company of Libya, 2011.

[36] H. Lee Willis, Power Distribution Planning references Book, Marcel Dekker Inc. Publication, 2004 pp. 32

[37] https://en.wikipedia.org/wiki/Electric_power_distribution, 12:21 PM 08/24/2012.

[38] Alexandra Von Meier, Electric Power Systems - A conceptual Model, John Wiley \& Sons Inc., Publication, 2006, pp. 201.

[39] Global Environment fund, "Electric Power Grid", 2005.

[40] Rowen, W.I. Simplified mathematical representations of heavy-duty gas turbines. J. Eng. Gas Turbines Power 1983, 105, 865-869.

[41] H. Lee Willis, Walter G. Scott, Distributed Power Generation - Planning and Evaluation, Marcel Dekker Inc. Publication, 2000, pp. 1

[42] Nick Jenkins, Janaka Ekanayake, G Strabac “Distributed generation”, 2010, pp.45

[43] P. Rajendra, Asheesh, "Planning of different types of distributed generation with seasonal mixed load models", International Journal of Engineering, Science and Technology Vol. 4, No. 1, 2012, pp. 112-124.

[44] Slootweg, J.G., and Kling, W.L., "Is the Answer Blowing in the Wind?," IEEE Power\&Energy Magazine, pp. 26-33,November/December 2003.

[45] Large-scale deployment of renewables for electricity generation. Oxford Review of Economic Policy, Vol.21, pp. 88-110. 
[46] W. Wu, B. Zhang, H. Sun, and Y. Zhang, "Development and application of on-line dynamic security early warning and preventive control system in China," in Power and Energy Society General Meeting, 2010 IEEE, 2010, pp. 1-7.

[47] I. M. Saleh Ibrahim, the forth Arab international Solar Energy Conference, Amman, Jordan 1993.

[48] M. Saleh Ibrahim, Photovoltaic in Libya Applications, and Evaluation, General Electrical Company of Libya 2011.

[49] (2016) 11:05 PM, 8/26/16. https://en.wikipedia.org/wiki/Zawiya,_Libya.

[50] Zulqarnain Maria, Xu David, Bo Yuwen, "Synchronous generator based wind conversion system (WECS) using multi-modular converters with autonomouse controller," IEEE, Electric Machines \& Drives Conference (IEMDC), pp.819-824,2011.

[51] Logan, J. \& Kaplan, S. M. (2008) Wind power in the United States: Technology, economic, and policy issues. CRS Report for Congress. Energy Policy Resources, Science, and Industry Division.

[52] http://www.cntimar.com/news/the-contrast-of-horizontal-axis-wind-turbine-and-verticalaxis-wind-turbine-eml-4790.html.

[53] Miller, A., Muljadi, E., Zinger, D., 1997. A variable speed wind turbine power control. IEEE Transactions on Energy Conversion 12 (2), 181-186.

[54] P. M. Anderson and A. Bose, "A probabilistic approach to power system stability analysis," IEEE Transactions on Power Apparatus and Systems, pp. 2430-2439, 1983.

[55] Ahmed, S., Cohen, J., 1994. Renewable energy sources: technology and economics. In: IEEE International Conference on Systems, Man. and Cybernetics, Humans, Information and Technology. pp. 2355-2360.

[56] Thomas Ackermann. 2005. Wind Power in Power Systems. John Wiley \& Sons Inc., 111 River Street, Hoboken, NJ 07030, USA.

[57] T. Guo and J. V. Milanovic, "Identification of power system dynamic signature using hierarchical clustering," in PES General Meeting| Conference \& Exposition, 2014 IEEE, 2014, pp. 1-5. 
[58] Isaac Y.F. Lun, Joseph C. Lam. A study of Weibull parameters using long-term wind observations. Renewable Energy 20 (2000) 145-153.

[59] Y Gilbert M. Masters 'Renewable and efficient electric power systems', 2nd edition, Wiley, Hoboken, NJ, USA. 2013, ISBN-13: 978-1118140628.

[60] Y Atwa, E F El-saadany 'Probabilistic approach for optimal allocation of wind based distributed generation in distribution systems' IET Renewable Power Generation Jornal, vol 5., pp 79-88,2011.

[61] A.Gawedar, R.Ramakumar 'Impact of Wind Energy System Integration on the Al-Zawiya Refinery Electric Grid in Libya' International Journal of Power and Energy Engineering (JPEE) Vol.4 No.9, September 2016,

[62] A Gawedar, R Ramakumar, "Upgrading the Al-Zawea Refinery Power System”, Seventh IEEE ISGT Conference, Minneapolis, MN. 2016,

[63] Lof, P.A., Andersson, G., Hill, D.J.: 'Voltage stability indices for stressed power systems', IEEE Trans. Power Syst., 1993, 8, pp. 326-335

[64] Overbye, T.J., DeMarco, C.L.: 'Improved techniques for power system voltage stability assessment using energy methods', IEEE Trans. Power Syst., 1991, 6, pp. 1446-1452

[65] Tarek Masuad, and Sen P.K, "Study of Implementation of STATCOM on DFIG-based wind farm connected to a power system, "IEEE PES Conference on Innovative Smart Grid Technologies (ISGT), Washington DC, USA. Jan 16-20.2012, pp.1-7.

[66] Geethika Nannapaneni, and Tarek Masuad, "Optimal Allocation of SCIG and DFIG Based Distributed Generation Considering Load Uncertainty and Line Outage: A comparative Study, "IEEE PES Conference on Innovative Smart Grid Technologies (ISGT2016), Minneapolis, MN, USA. Spt 06-09.2016. 


\section{APPENDIX A}

\section{Load Records}

\begin{tabular}{|c|c|c|c|c|}
\hline \multicolumn{5}{|c|}{ Load Records } \\
\hline Load Name & Status & MW & Mvar & MVA \\
\hline Bus 4 & Closed & 0.5 & 0.1 & 0.5 \\
\hline Bus 7 & Closed & 0.27 & 0.05 & 0.27 \\
\hline Bus 9 & Closed & 0.15 & 0.03 & 0.15 \\
\hline Bus 12 & Closed & 0.7 & 0.14 & 0.71 \\
\hline Bus 14 & Closed & 0.6 & 0.121 & 0.61 \\
\hline Bus 17 & Closed & 0.3 & 0.06 & 0.3 \\
\hline Bus 19 & Closed & 0.13 & 0.02 & 0.13 \\
\hline Bus 21 & Closed & 0.45 & 0.09 & 0.46 \\
\hline Bus 24 & Closed & 0.36 & 0.07 & 0.37 \\
\hline Bus 25 & Closed & 0.45 & 0.08 & 0.46 \\
\hline
\end{tabular}




\section{APPENDIX B}

\section{CURRENT DISTRIBUTION SYSTEM}

\begin{tabular}{|c|c|c|c|c|c|c|c|}
\hline Bus No & $\begin{array}{l}\text { Norm } \\
(\mathrm{kV})\end{array}$ & PU Volt & $\begin{array}{l}\text { Norm } \\
(\mathrm{kV})\end{array}$ & $\begin{array}{l}\text { Angle } \\
\text { (Deg) }\end{array}$ & $\begin{array}{l}\text { Load } \\
\text { MW }\end{array}$ & $\begin{array}{l}\text { GEN } \\
\text { MW }\end{array}$ & $\begin{array}{l}\text { Gen } \\
\text { Mvar }\end{array}$ \\
\hline 1 & 0.38 & 1.00000 & 0.380 & 0.00 & 0.00 & 3.67 & 0.02 \\
\hline 2 & 6.60 & 0.99997 & 6.600 & -0.19 & 0.00 & 0.00 & 0.00 \\
\hline 3 & 6.60 & 0.99997 & 6.600 & -0.23 & 0.00 & 0.00 & 0.00 \\
\hline 4 & 6.60 & 0.99997 & 6.600 & -0.24 & 0.45 & 0.00 & 0.00 \\
\hline 5 & 6.60 & 0.99998 & 6.600 & -0.26 & 0.00 & 0.00 & 0.00 \\
\hline 6 & 6.60 & 0.99997 & 6.600 & -0.28 & 0.00 & 0.00 & 0.00 \\
\hline 7 & 0.38 & 0.99998 & 0.380 & -0.38 & 0.30 & 0.00 & 0.00 \\
\hline 8 & 6.60 & 0.99997 & 6.600 & -0.39 & 0.00 & 0.00 & 0.00 \\
\hline 9 & 6.60 & 0.99998 & 6.600 & -0.41 & 0.30 & 0.00 & 0.00 \\
\hline 10 & 0.38 & 0.99997 & 0.380 & -0.42 & 0.00 & 0.00 & 0.00 \\
\hline 11 & 0.38 & 0.99998 & 0.380 & -0.42 & 0.00 & 0.00 & 0.00 \\
\hline 12 & 6.60 & 0.99998 & 6.600 & -0.42 & 0.27 & 0.00 & 0.00 \\
\hline 13 & 6.60 & 0.99997 & 6.600 & -0.45 & 0.00 & 0.00 & 0.00 \\
\hline 14 & 0.38 & 0.99997 & 0.380 & -0.45 & 0.45 & 0.00 & 0.00 \\
\hline 15 & 6.60 & 0.99997 & 6.600 & -0.47 & 0.00 & 0.00 & 0.00 \\
\hline 16 & 0.38 & 1.00001 & 0.380 & -0.48 & 0.00 & 0.00 & 0.00 \\
\hline 17 & 6.60 & 0.99997 & 6.600 & -0.48 & 0.45 & 0.00 & 0.00 \\
\hline 18 & 6.60 & 0.99997 & 6.600 & -0.50 & 0.00 & 0.00 & 0.00 \\
\hline 19 & 6.60 & 1.00000 & 6.600 & -0.52 & 0.35 & 0.00 & 0.00 \\
\hline 20 & 6.60 & 0.99998 & 6.600 & -0.52 & 0.00 & 0.00 & 0.00 \\
\hline 21 & 0.38 & 0.99997 & 0.380 & -0.53 & 0.15 & 0.00 & 0.00 \\
\hline 22 & 0.38 & 0.99998 & 0.380 & -0.53 & 0.00 & 0.00 & 0.00 \\
\hline 23 & 6.60 & 0.99998 & 6.600 & -0.56 & 0.00 & 0.00 & 0.00 \\
\hline 24 & 6.60 & 0.99998 & 6.600 & -0.57 & 0.15 & 0.00 & 0.00 \\
\hline 25 & 0.38 & 0.99998 & 0.380 & -0.58 & 0.80 & 0.00 & 0.00 \\
\hline
\end{tabular}




\section{APPENDIX C}

Scenario 1

\begin{tabular}{|c|c|c|c|c|c|}
\hline $\begin{array}{c}\text { Bus } \\
\text { No }\end{array}$ & $\begin{array}{c}\text { Norm } \\
(\mathrm{kV})\end{array}$ & PU Volt DG OFF & PU Volt DG ON & $\begin{array}{c}\text { P Load } \\
\text { MVar }\end{array}$ & $\begin{array}{c}\text { P Load } \\
\text { MW }\end{array}$ \\
\hline 1 & 0.38 & 1.04000 & 1.04000 & 0 & 0 \\
\hline 2 & 6.60 & 1.01000 & 1.04000 & 0 & 0 \\
\hline 3 & 6.60 & 0.93458 & 0.99293 & 0 & 0 \\
\hline 4 & 6.60 & 0.91524 & 0.98257 & 0.10 & 0.50 \\
\hline 5 & 6.60 & 1.01000 & 1.01000 & 0 & 0 \\
\hline 6 & 6.60 & 0.93449 & 0.99494 & 0 & 0 \\
\hline 7 & 0.38 & 0.95251 & 0.98938 & 0.14 & 0.27 \\
\hline 8 & 6.60 & 0.97000 & 1.01000 & 0 & 0 \\
\hline 9 & 6.60 & 0.85949 & 0.95223 & 0.03 & 0.15 \\
\hline 10 & 0.38 & 0.81182 & 0.92571 & 0 & 0 \\
\hline 11 & 0.38 & 1 & 1.05000 & 0 & 0 \\
\hline 12 & 6.60 & 0.84885 & 0.95518 & 0.14 & 0.70 \\
\hline 13 & 6.60 & 1 & 1.01000 & 0 & 0 \\
\hline 14 & 0.38 & 0.72847 & 0.971814 & 0.121 & 0.60 \\
\hline 15 & 6.60 & 0.79298 & 0.966349 & 0 & 0 \\
\hline 16 & 0.38 & 0.82531 & 0.998568 & 0 & 0 \\
\hline 17 & 6.60 & 0.80265 & 0.971950 & 0.06 & 0.30 \\
\hline 18 & 6.60 & 0.79463 & 0.969112 & 0 & 0 \\
\hline 19 & 6.60 & 0.79618 & 0.951098 & 0.02 & 0.03 \\
\hline 20 & 6.60 & 0.80020 & 0.984896 & 0 & 0 \\
\hline 21 & 0.38 & 0.76836 & 0.988900 & 0.09 & 0.45 \\
\hline 22 & 0.38 & 0.76427 & 0.951598 & 0 & 0 \\
\hline 23 & 6.60 & 0.73851 & 0.991625 & 0 & 0 \\
\hline 24 & 6.60 & 0.66790 & 0.9531 & 0.07 & 0.36 \\
\hline 25 & 0.38 & 0.57095 & 0.9616 & 0.04 & 0.20 \\
\hline & & & & & \\
\hline
\end{tabular}




\section{APPENDIX D}

Scenario 2

\begin{tabular}{|c|c|c|c|c|c|}
\hline $\begin{array}{c}\text { Bus } \\
\text { No }\end{array}$ & PU Volt DG OFF & PU Volt DG ON & $\begin{array}{c}\text { Norm } \\
(\mathrm{kV})\end{array}$ & $\begin{array}{c}\text { Q L } \\
\text { MVar }\end{array}$ & $\begin{array}{c}\mathrm{PL} \\
\mathrm{MW}\end{array}$ \\
\hline 1 & 1.05000 & 1.05000 & 0.380 & 0 & 0 \\
\hline 2 & 1.03000 & 1.04000 & 6.600 & 0 & 0 \\
\hline 3 & 0.97152 & 1.01143 & 6.600 & 0 & 0 \\
\hline 4 & 0.95635 & 1.00227 & 6.600 & 0.05 & 0.27 \\
\hline 5 & 1.01000 & 1.01000 & 6.600 & 0 & 0 \\
\hline 6 & 0.96351 & 1.00337 & 6.600 & 0 & 0 \\
\hline 7 & 0.96237 & 0.98703 & 0.380 & 0.14 & 0.70 \\
\hline 8 & 0.99000 & 1.01000 & 6.600 & 0 & 0 \\
\hline 9 & 0.88738 & 0.96030 & 6.600 & 0.08 & 0.45 \\
\hline 10 & 0.85143 & 0.94139 & 0.380 & 0 & 0 \\
\hline 11 & 1 & 1.05000 & 0.380 & 0 & 0 \\
\hline 12 & 0.90048 & 0.97345 & 6.600 & 0.07 & 0.36 \\
\hline 13 & 1 & 1.05000 & 6.600 & 0 & 0 \\
\hline 14 & 0.81232 & 0.90333 & 0.380 & 0.09 & 0.45 \\
\hline 15 & 0.84170 & 0.94551 & 6.600 & 0 & 0 \\
\hline 16 & 0.87674 & 0.95744 & 0.380 & 0 & 0 \\
\hline 17 & 0.85418 & 0.94189 & 6.600 & 0.02 & 0.13 \\
\hline 18 & 0.81972 & 0.92173 & 6.600 & 0 & 0 \\
\hline 19 & 0.80677 & 0.90768 & 6.600 & 0.06 & 0.30 \\
\hline 20 & 0.81786 & 0.91616 & 6.600 & 0 & 0 \\
\hline 21 & 0.82001 & 0.93349 & 0.380 & 0.12 & 0.06 \\
\hline 22 & 0.81429 & 0.93484 & 0.380 & 0 & 0 \\
\hline 23 & 0.78681 & 0.94325 & 6.600 & 0 & 0 \\
\hline 24 & 0.71642 & 0.94325 & 6.600 & 0.10 & 0.5 \\
\hline 25 & 0.65506 & 0.99959 & 0.380 & 0.03 & 0.15 \\
\hline
\end{tabular}




\section{APPENDIX E}

Scenario 3

\begin{tabular}{|c|c|c|c|c|c|}
\hline $\begin{array}{l}\text { Bus } \\
\text { No }\end{array}$ & PU Volt DG OFF & PU Volt DG ON & $\begin{array}{c}\text { Norm } \\
(\mathrm{kV})\end{array}$ & $\begin{array}{c}\text { Q L } \\
\text { MVar }\end{array}$ & $\begin{array}{c}\mathrm{PL} \\
\mathrm{MW}\end{array}$ \\
\hline 1 & 1.05000 & 1.050000 & 0.380 & 0 & 0 \\
\hline 2 & 1.03000 & 1.04000 & 6.600 & 0 & 0 \\
\hline 3 & 0.96237 & 1.00861 & 6.600 & 0 & 0 \\
\hline 4 & 0.94544 & 0.99895 & 6.600 & 0.1 & 0.5 \\
\hline 5 & 1.01000 & 1.01000 & 6.600 & 0 & 0 \\
\hline 6 & 0.95071 & 0.99949 & 6.600 & 0 & 0 \\
\hline 7 & 0.96679 & 0.99651 & 0.380 & 0.03 & 0.15 \\
\hline 8 & 0.98000 & 1.01000 & 6.600 & 0 & 0 \\
\hline 9 & 0.86175 & 0.95335 & 6.600 & 0.05 & 0.27 \\
\hline 10 & 0.82661 & 0.99682 & 0.380 & 0 & 0 \\
\hline 11 & 1 & 1.04000 & 0.380 & 0 & 0 \\
\hline 12 & 0.89372 & 0.97375 & 6.600 & 0.14 & 0.7 \\
\hline 13 & 1 & 1.05000 & 6.600 & 0 & 0 \\
\hline 14 & 0.82238 & 1.01000 & 0.380 & 0.08 & 0.45 \\
\hline 15 & 0.84093 & 1.04000 & 6.600 & 0 & 0 \\
\hline 16 & 0.85186 & 0.95744 & 0.380 & 0 & 0 \\
\hline 17 & 0.81431 & 0.97189 & 6.600 & 0.07 & 0.36 \\
\hline 18 & 0.82604 & 0.96173 & 6.600 & 0 & 0 \\
\hline 19 & 0.81725 & 0.95768 & 6.600 & 0.09 & 0.45 \\
\hline 20 & 0.81972 & 0.99616 & 6.600 & 0 & 0 \\
\hline 21 & 0.79553 & 0.97349 & 0.380 & 0.02 & 0.13 \\
\hline 22 & 0.79182 & 0.95484 & 0.380 & 0 & 0 \\
\hline 23 & 0.78416 & 0.96325 & 6.600 & 0 & 0 \\
\hline 24 & 0.71344 & 0.95325 & 6.600 & 0.06 & 0.3 \\
\hline 25 & 0.71344 & 0.99959 & 0.380 & 0.12 & 0.60 \\
\hline
\end{tabular}




\section{APPENDIX F}

Scenario 4

\begin{tabular}{|c|c|c|c|c|c|}
\hline Bus No & PU Volt DG OFF & PU Volt DG ON & $\begin{array}{c}\text { Norm } \\
(\mathrm{kV})\end{array}$ & $\begin{array}{c}\text { QL } \\
\text { MVar }\end{array}$ & $\begin{array}{c}\mathrm{PL} \\
\mathrm{MW}\end{array}$ \\
\hline 1 & \multirow{25}{*}{ 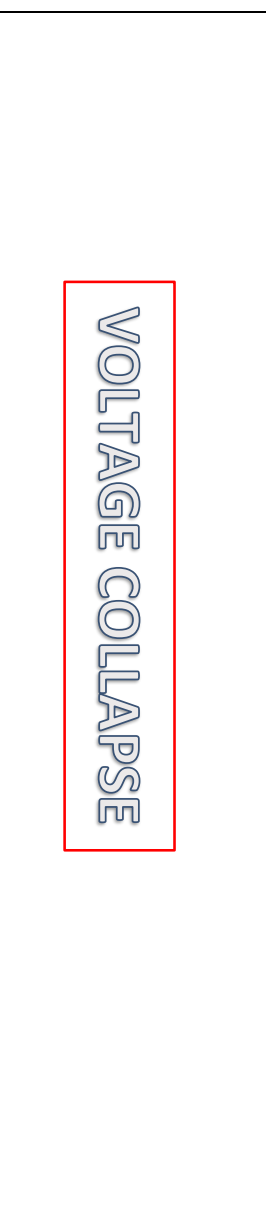 } & 1.050000 & 0.380 & 0 & 0 \\
\hline 2 & & 1.04000 & 6.600 & 0 & 0 \\
\hline 3 & & 1.00861 & 6.600 & 0 & 0 \\
\hline 4 & & 0.99895 & 6.600 & 0.03 & 0.15 \\
\hline 5 & & 1.01000 & 6.600 & 0 & 0 \\
\hline 6 & & 0.99949 & 6.600 & 0 & 0 \\
\hline 7 & & 0.99651 & 0.380 & 0.05 & 0.27 \\
\hline 8 & & 1.01000 & 6.600 & 0 & 0 \\
\hline 9 & & 0.95335 & 6.600 & 0.05 & 0.70 \\
\hline 10 & & 0.95682 & 0.380 & 0 & 0 \\
\hline 11 & & 1.04000 & 0.380 & 0 & 0 \\
\hline 12 & & 0.97375 & 6.600 & 0.14 & 0.45 \\
\hline 13 & & 1.05000 & 6.600 & 0 & 0 \\
\hline 14 & & 1.01000 & 0.380 & 0.08 & 0.36 \\
\hline 15 & & 1.04000 & 6.600 & 0 & 0 \\
\hline 16 & & 0.95744 & 0.380 & 0 & 0 \\
\hline 17 & & 0.98189 & 6.600 & 0.07 & 0.45 \\
\hline 18 & & 0.99173 & 6.600 & 0 & 0 \\
\hline 19 & & 0.99768 & 6.600 & 0.09 & 0.13 \\
\hline 20 & & 0.97616 & 6.600 & 0 & 0 \\
\hline 21 & & 0.96349 & 0.380 & 0.02 & 0.30 \\
\hline 22 & & 0.95484 & 0.380 & 0 & 0 \\
\hline 23 & & 0.97325 & 6.600 & 0 & 0 \\
\hline 24 & & 0.96325 & 6.600 & 0.12 & 0.60 \\
\hline 25 & & 0.99959 & 0.380 & 0.1 & 0.5 \\
\hline
\end{tabular}




\section{APPENDIX G}

Scenario 5

\begin{tabular}{|c|c|c|c|c|c|}
\hline $\begin{array}{l}\text { Bus } \\
\text { No }\end{array}$ & PU Volt DG OFF & PU Volt DG ON & $\begin{array}{c}\text { Norm } \\
(\mathrm{kV})\end{array}$ & $\begin{array}{c}\text { QL } \\
\text { MVar }\end{array}$ & $\begin{array}{c}\mathrm{PL} \\
\mathrm{MW} \\
\end{array}$ \\
\hline 1 & \multirow{25}{*}{ 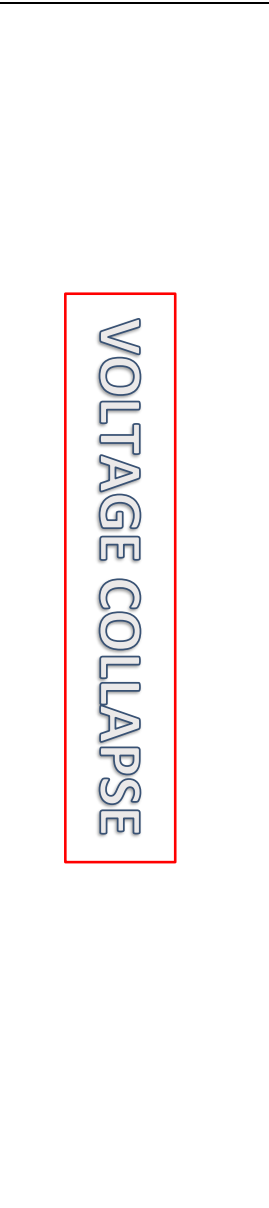 } & 1.05000 & 0.380 & 0 & 0 \\
\hline 2 & & 1.04000 & 6.600 & 0 & 0 \\
\hline 3 & & 0.99019 & 6.600 & 0 & 0 \\
\hline 4 & & 0.97786 & 6.600 & 0.12 & 0.60 \\
\hline 5 & & 1.01000 & 6.600 & 0 & 0 \\
\hline 6 & & 0.98940 & 6.600 & 0 & 0 \\
\hline 7 & & 0.98382 & 0.380 & 0.10 & 0.50 \\
\hline 8 & & 1.01000 & 6.600 & 0 & 0 \\
\hline 9 & & 0.97075 & 6.600 & 0.03 & 0.15 \\
\hline 10 & & 0.99703 & 0.380 & 0 & 0 \\
\hline 11 & & 1.03000 & 0.380 & 0 & 0 \\
\hline 12 & & 0.98308 & 6.600 & 0.05 & 0.27 \\
\hline 13 & & 1.03000 & 6.600 & 0 & 0 \\
\hline 14 & & 1.01000 & 0.380 & 0.14 & 0.70 \\
\hline 15 & & 1.04000 & 6.600 & 0 & 0 \\
\hline 16 & & 0.95744 & 0.380 & 0 & 0 \\
\hline 17 & & 0.96189 & 6.600 & 0.08 & 0.45 \\
\hline 18 & & 0.98173 & 6.600 & 0 & 0 \\
\hline 19 & & 0.99768 & 6.600 & 0.07 & 0.36 \\
\hline 20 & & 0.96616 & 6.600 & 0 & 0 \\
\hline 21 & & 0.95349 & 0.380 & 0.09 & 0.45 \\
\hline 22 & & 0.95484 & 0.380 & 0 & 0 \\
\hline 23 & & 0.96325 & 6.600 & 0 & 0 \\
\hline 24 & & 0.97325 & 6.600 & 0.02 & 0.13 \\
\hline 25 & & 0.99959 & 0.380 & 0.06 & 0.30 \\
\hline
\end{tabular}




\section{APPENDIX H}

Scenario 6

\begin{tabular}{|c|c|c|c|c|c|}
\hline $\begin{array}{c}\text { Bus } \\
\text { No }\end{array}$ & PU Volt DG OFF & PU Volt DG ON & $\begin{array}{c}\text { Norm } \\
(\mathrm{kV})\end{array}$ & $\begin{array}{c}\text { QL } \\
\text { MVar }\end{array}$ & $\begin{array}{c}\mathrm{PL} \\
\mathrm{MW}\end{array}$ \\
\hline 1 & 1.05000 & 1.05000 & 0.380 & 0 & 0 \\
\hline 2 & 1.01000 & 1.04000 & 6.600 & 0 & 0 \\
\hline 3 & 0.93034 & 1.05000 & 6.600 & 0 & 0 \\
\hline 4 & 0.90905 & 1.04000 & 6.600 & 0.06 & 0.30 \\
\hline 5 & 1.01000 & 0.99893 & 6.600 & 0 & 0 \\
\hline 6 & 0.91644 & 0.98815 & 6.600 & 0 & 0 \\
\hline 7 & 0.93645 & 1.01000 & 0.380 & 0.12 & 0.60 \\
\hline 8 & 0.96000 & 0.98970 & 6.600 & 0 & 0 \\
\hline 9 & 0.80695 & 0.95034 & 6.600 & 0.10 & 0.50 \\
\hline 10 & 0.73992 & 0.96905 & 0.380 & 0 & 0 \\
\hline 11 & 1 & 1.01000 & 0.380 & 0 & 0 \\
\hline 12 & 0.85825 & 0.97644 & 6.600 & 0.03 & 0.15 \\
\hline 13 & 1 & 0.99645 & 6.600 & 0 & 0 \\
\hline 14 & 0.78427 & 1.01000 & 0.380 & 0.05 & 0.27 \\
\hline 15 & 0.77353 & 1.04000 & 6.600 & 0 & 0 \\
\hline 16 & 0.78115 & 0.95744 & 0.380 & 0 & 0 \\
\hline 17 & 0.71594 & 0.99019 & 6.600 & 0.14 & 0.70 \\
\hline 18 & 0.71473 & 0.97786 & 6.600 & 0 & 0 \\
\hline 19 & 0.68243 & 1.01000 & 6.600 & 0.08 & 0.45 \\
\hline 20 & 0.69655 & 0.98940 & 6.600 & 0 & 0 \\
\hline 21 & 0.70118 & 0.98382 & 0.380 & 0.07 & 0.36 \\
\hline 22 & 0.69729 & 1.01000 & 0.380 & 0 & 0 \\
\hline 23 & 0.69874 & 0.99075 & 6.600 & 0 & 0 \\
\hline 24 & 0.60866 & 0.99703 & 6.600 & 0.09 & 0.45 \\
\hline 25 & 0.54771 & 1.03000 & 0.380 & 0.02 & 0.13 \\
\hline & & & & & \\
\hline
\end{tabular}




\section{APPENDIX I}

\section{Scenario7}

\begin{tabular}{|c|c|c|c|c|c|}
\hline $\begin{array}{l}\text { Bus } \\
\text { No }\end{array}$ & PU Volt DG OFF & PU Volt DG ON & $\begin{array}{c}\text { Norm } \\
(\mathrm{kV})\end{array}$ & $\begin{array}{c}\text { Q L } \\
\text { MVar }\end{array}$ & $\begin{array}{c}\mathrm{PL} \\
\mathrm{MW}\end{array}$ \\
\hline 1 & \multirow{25}{*}{ 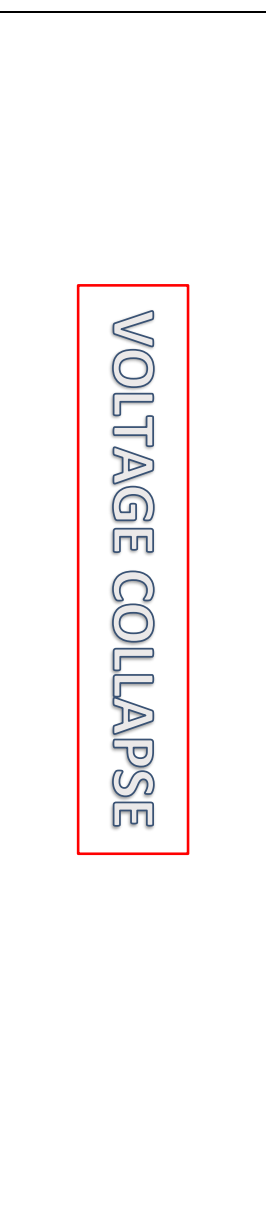 } & 1.05000 & 0.380 & 0 & 0 \\
\hline 2 & & 1.03000 & 6.600 & 0 & 0 \\
\hline 3 & & 0.97375 & 6.600 & 0 & 0 \\
\hline 4 & & 0.95807 & 6.600 & 0.02 & 0.13 \\
\hline 5 & & 1.01000 & 6.600 & 0 & 0 \\
\hline 6 & & 0.96202 & 6.600 & 0 & 0 \\
\hline 7 & & 0.97284 & 0.380 & 0.06 & 0.30 \\
\hline 8 & & 0.99000 & 6.600 & 0 & 0 \\
\hline 9 & & 0.99034 & 6.600 & 0.12 & 0.60 \\
\hline 10 & & 0.98905 & 0.380 & 0 & 0 \\
\hline 11 & & 1.01000 & 0.380 & 0 & 0 \\
\hline 12 & & 0.91644 & 6.600 & 0.10 & 0.50 \\
\hline 13 & & 0.96645 & 6.600 & 0 & 0 \\
\hline 14 & & 1.01000 & 0.380 & 0.03 & 0.15 \\
\hline 15 & & 1.04000 & 6.600 & 0 & 0 \\
\hline 16 & & 0.95744 & 0.380 & 0 & 0 \\
\hline 17 & & 0.99019 & 6.600 & 0.05 & 0.27 \\
\hline 18 & & 0.97786 & 6.600 & 0 & 0 \\
\hline 19 & & 1.01000 & 6.600 & 0.14 & 0.70 \\
\hline 20 & & 0.98940 & 6.600 & 0 & 0 \\
\hline 21 & & 0.98382 & 0.380 & 0.08 & 0.45 \\
\hline 22 & & 1.0000 & 0.380 & 0 & 0 \\
\hline 23 & & 0.97075 & 6.600 & 0 & 0 \\
\hline 24 & & 0.99703 & 6.600 & 0.07 & 0.36 \\
\hline 25 & & 1.03000 & 0.380 & 0.09 & 0.45 \\
\hline
\end{tabular}




\section{APPENDIX J}

\section{Scenario 8}

\begin{tabular}{|c|c|c|c|c|c|}
\hline $\begin{array}{l}\text { Bus } \\
\text { No }\end{array}$ & PU Volt DG OFF & PU Volt DG ON & $\begin{array}{c}\text { Norm } \\
(\mathrm{kV})\end{array}$ & $\begin{array}{c}\text { Q L } \\
\text { MVar }\end{array}$ & $\begin{array}{c}\mathrm{PL} \\
\mathrm{MW}\end{array}$ \\
\hline 1 & \multirow{25}{*}{ 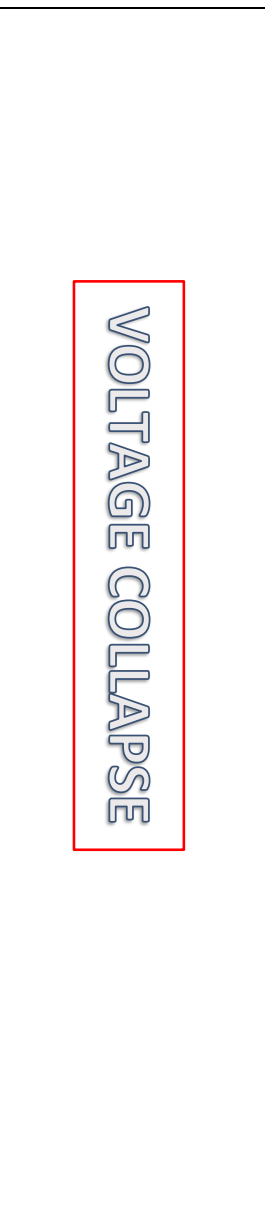 } & 1.05000 & 0.380 & 0 & 0 \\
\hline 2 & & 1.03000 & 6.600 & 0 & 0 \\
\hline 3 & & 0.97322 & 6.600 & 0 & 0 \\
\hline 4 & & 0.95760 & 6.600 & 0.09 & 0.45 \\
\hline 5 & & 1.01000 & 6.600 & 0 & 0 \\
\hline 6 & & 0.97072 & 6.600 & 0 & 0 \\
\hline 7 & & 0.98284 & 0.380 & 0.02 & 0.13 \\
\hline 8 & & 0.99000 & 6.600 & 0 & 0 \\
\hline 9 & & 0.95034 & 6.600 & 0.06 & 0.30 \\
\hline 10 & & 0.90905 & 0.380 & 0 & 0 \\
\hline 11 & & 1.01000 & 0.380 & 0 & 0 \\
\hline 12 & & 0.91644 & 6.600 & 0.12 & 0.60 \\
\hline 13 & & 0.93645 & 6.600 & 0 & 0 \\
\hline 14 & & 1.01000 & 0.380 & 0.10 & 0.50 \\
\hline 15 & & 1.04000 & 6.600 & 0 & 0 \\
\hline 16 & & 0.95744 & 0.380 & 0 & 0 \\
\hline 17 & & 0.99019 & 6.600 & 0.03 & 0.15 \\
\hline 18 & & 0.97786 & 6.600 & 0 & 0 \\
\hline 19 & & 1.01000 & 6.600 & 0.05 & 0.27 \\
\hline 20 & & 0.97375 & 6.600 & 0 & 0 \\
\hline 21 & & 0.95807 & 0.380 & 0.14 & 0.70 \\
\hline 22 & & 1.01000 & 0.380 & 0 & 0 \\
\hline 23 & & 0.96202 & 6.600 & 0 & 0 \\
\hline 24 & & 0.97284 & 6.600 & 0.08 & 0.45 \\
\hline 25 & & 0.97375 & 0.380 & 0.07 & 0.36 \\
\hline
\end{tabular}




\section{APPENDIX K}

\section{Scenario 9}

\begin{tabular}{|c|c|c|c|c|c|}
\hline $\begin{array}{c}\text { Bus } \\
\text { No }\end{array}$ & PU Volt DG OFF & PU Volt DG ON & Norm (kV) & $\begin{array}{c}\text { QL } \\
\text { MVar }\end{array}$ & $\begin{array}{c}\text { P L } \\
\text { MW }\end{array}$ \\
\hline 1 & 1.05000 & 1.050000 & 0.380 & 0 & 0 \\
\hline 2 & 1.03000 & 1.04000 & 6.600 & 0 & 0 \\
\hline 3 & 0.96237 & 1.00861 & 6.600 & 0 & 0 \\
\hline 4 & 0.94544 & 0.99895 & 6.600 & 0.07 & 0.36 \\
\hline 5 & 1.01000 & 0.91644 & 6.600 & 0 & 0 \\
\hline 6 & 0.95071 & 0.93645 & 6.600 & 0 & 0 \\
\hline 7 & 0.96679 & 1.01000 & 0.380 & 0.09 & 0.45 \\
\hline 8 & 0.98000 & 1.04000 & 6.600 & 0 & 0 \\
\hline 9 & 0.86175 & 0.95744 & 6.600 & 0.02 & 0.13 \\
\hline 10 & 0.82661 & 0.99019 & 0.380 & 0 & 0 \\
\hline 11 & 1 & 0.97786 & 0.380 & 0 & 0 \\
\hline 12 & 0.89372 & 1.01000 & 6.600 & 0.06 & 0.30 \\
\hline 13 & 1 & 1.05000 & 6.600 & 0 & 0 \\
\hline 14 & 0.82238 & 1.01000 & 0.380 & 0.12 & 0.60 \\
\hline 15 & 0.84093 & 1.04000 & 6.600 & 0 & 0 \\
\hline 16 & 0.85186 & 0.95744 & 0.380 & 0 & 0 \\
\hline 17 & 0.81431 & 0.94189 & 6.600 & 0.10 & 0.50 \\
\hline 18 & 0.82604 & 0.96173 & 6.600 & 0 & 0 \\
\hline 19 & 0.81725 & 0.95768 & 6.600 & 0.03 & 0.15 \\
\hline 20 & 0.81972 & 0.97616 & 6.600 & 0 & 0 \\
\hline 21 & 0.79553 & 0.96349 & 0.380 & 0.05 & 0.27 \\
\hline 22 & 0.79182 & 0.98484 & 0.380 & 0 & 0 \\
\hline 23 & 0.78416 & 0.99325 & 6.600 & 0 & 0 \\
\hline 24 & 0.71344 & 0.96325 & 6.600 & 0.14 & 0.70 \\
\hline 25 & 0.71344 & 0.99959 & 0.380 & 0.08 & 0.45 \\
\hline & & & & & \\
\hline
\end{tabular}




\section{APPENDIX L}

Scenario 10

\begin{tabular}{|c|c|c|c|c|c|}
\hline $\begin{array}{c}\text { Bus } \\
\text { No }\end{array}$ & PU Volt DG OFF & PU Volt DG ON & Norm (kV) & $\begin{array}{c}\text { Q L } \\
\text { MVar }\end{array}$ & $\begin{array}{c}\text { P L } \\
\text { MW }\end{array}$ \\
\hline 1 & 1.05000 & 1.050000 & 0.380 & 0 & 0 \\
\hline 2 & 1.04000 & 1.04000 & 6.600 & 0 & 0 \\
\hline 3 & 0.99263 & 1.00861 & 6.600 & 0 & 0 \\
\hline 4 & 0.98068 & 0.99895 & 6.600 & 0.08 & 0.45 \\
\hline 5 & 1.01000 & 1.01000 & 6.600 & 0 & 0 \\
\hline 6 & 0.98633 & 0.99949 & 6.600 & 0 & 0 \\
\hline 7 & 0.985852 & 0.99651 & 0.380 & 0.07 & 0.36 \\
\hline 8 & 1.01000 & 1.01000 & 6.600 & 0 & 0 \\
\hline 9 & 0.90585 & 0.95335 & 6.600 & 0.09 & 0.45 \\
\hline 10 & 0.87039 & 0.96682 & 0.380 & 0 & 0 \\
\hline 11 & 1.01000 & 1.04000 & 0.380 & 0 & 0 \\
\hline 12 & 0.94004 & 0.95375 & 6.600 & 0.02 & 0.13 \\
\hline 13 & 1.02000 & 1.05000 & 6.600 & 0 & 0 \\
\hline 14 & 0.87965 & 1.01000 & 0.380 & 0.06 & 0.30 \\
\hline 15 & 0.88941 & 1.04000 & 6.600 & 0 & 0 \\
\hline 16 & 0.89348 & 0.95744 & 0.380 & 0 & 0 \\
\hline 17 & 0.85187 & 0.95189 & 6.600 & 0.12 & 0.60 \\
\hline 18 & 0.83889 & 0.96173 & 6.600 & 0 & 0 \\
\hline 19 & 0.81037 & 0.95768 & 6.600 & 0.10 & 0.50 \\
\hline 20 & 0.82522 & 0.97616 & 6.600 & 0 & 0 \\
\hline 21 & 0.85681 & 0.96349 & 0.380 & 0.03 & 0.15 \\
\hline 22 & 0.85532 & 0.98484 & 0.380 & 0 & 0 \\
\hline 23 & 0.86240 & 0.99325 & 6.600 & 0 & 0 \\
\hline 24 & 0.82649 & 0.96325 & 6.600 & 0.05 & 0.27 \\
\hline 25 & 0.82513 & 0.99959 & 0.380 & 0.14 & 0.7 \\
\hline
\end{tabular}


VITA

\author{
Akram Taher Ibrahim Gawedar \\ Candidate for the Degree of \\ Doctor of Philosophy
}

\title{
Thesis: A STUDY OF THE AL-ZAWEA OIL REFINERY POWER SYSTEM IN LIBYA
}

\author{
Major Field: Electrical Engineering
}

Biographical:

Education:

Completed the requirements for the Doctor of Philosophy in Electrical Engineering at Oklahoma State University, Stillwater, Oklahoma in December, 2016.

Completed the requirements for the Master of Science in Control Engineering at Coventry University, Coventry, United Kingdom in 2007.

Completed the requirements for the Bachelor of Engineering in Computer Engineering at University of $7^{\text {th }}$ of April, Al-Zawea, Libya 2004.

Experience:

Research Assistant at Engineering Energy Laboratory, School of Electrical and Computer Engineering, Oklahoma State University from January 2012 to December, 2015.

Assistant Lecturer at School of Electrical and Computer Engineering, Sabratha, $7^{\text {th }}$ of April University, Al-Zawea from Fall 2008 to Spring 2011 